\title{
Recent Developments in the Field of Explosive Trace Detection
}

\author{
Ka Chuen To, ${ }^{*, \dagger}$ Sultan Ben-Jaber, ${ }^{\ddagger}$ and Ivan P. Parkin ${ }^{*}, \dagger$ \\ $\dagger$ Department of Chemistry, University College London, 20 Gordon Street, Bloomsbury, \\ London, WC1H OAJ, U.K. \\ $\ddagger$ King Fahad Security College, Department of Science and Forensics, Riyadh, 13232, Saudi \\ Arabia \\ E-mail: k.to.17@ucl.ac.uk; i.p.parkin@ucl.ac.uk
}

\begin{abstract}
Explosive trace detection (ETD) technologies play a vital role in maintaining national security. ETD remains an active research area with many analytical techniques in operational use. This review details the latest advances in animal olfactory, ion mobility spectrometry (IMS), Raman and colorimetric detection methods. Developments in optical, biological, electrochemical, mass and thermal sensors are also covered in addition to the use of nanomaterials technology. Commercially available systems are presented as examples of current detection capabilities and as benchmarks for improvement. Attention is also drawn to recent collaborative projects involving government, academia and industry, to highlight the emergence of multimodal screening approaches and applications. The objective of the review is to provide a comprehensive overview of ETD by; highlighting challenges in ETD and providing an understanding of the principles, advantages and limitations of each technology and relating this to current systems.
\end{abstract}

\section{Keywords}

explosives detection, Raman spectroscopy, SERS, sensors, nanomaterials, quantum dots, IMS, artificial intelligence

The detection of trace quantities of explosives is important in many fields, including; forensics, environmental monitoring as well as during the manufacture and storage of explosives. Explosives remain a threat to homeland security and recent events ${ }^{1-3}$ emphasize the importance of explosive trace detection (ETD) technologies. A particular concern is the increasing use of home-made explosives (HMEs); their destructive power, ease in procurement along with the availability of online tutorials for manufacture and deployment makes HMEs an easy weapon of choice in many terrorist attacks. As such, there is a continuing need to improve existing ETD technologies as well as maintain efforts to identify new approaches.

The aim of this review is to report on the latest developments in key ETD technologies. Animal olfaction has been included as it remains the benchmark which emerging technologies are compared with. Other traditional approaches used in ETD include; ion mobility spectrometry (IMS), colorimetry and Raman spectroscopy. For each technology, general principles are described as well as advances in these areas along with examples of in-field devices. Developing technologies are discussed and include sensor platforms used in artificial olfaction systems and nanomaterials technology. The review will conclude with a discussion of the advantages and limitations of each technology with respect to the feasibility of operational deployment and future perspectives in ETD. 


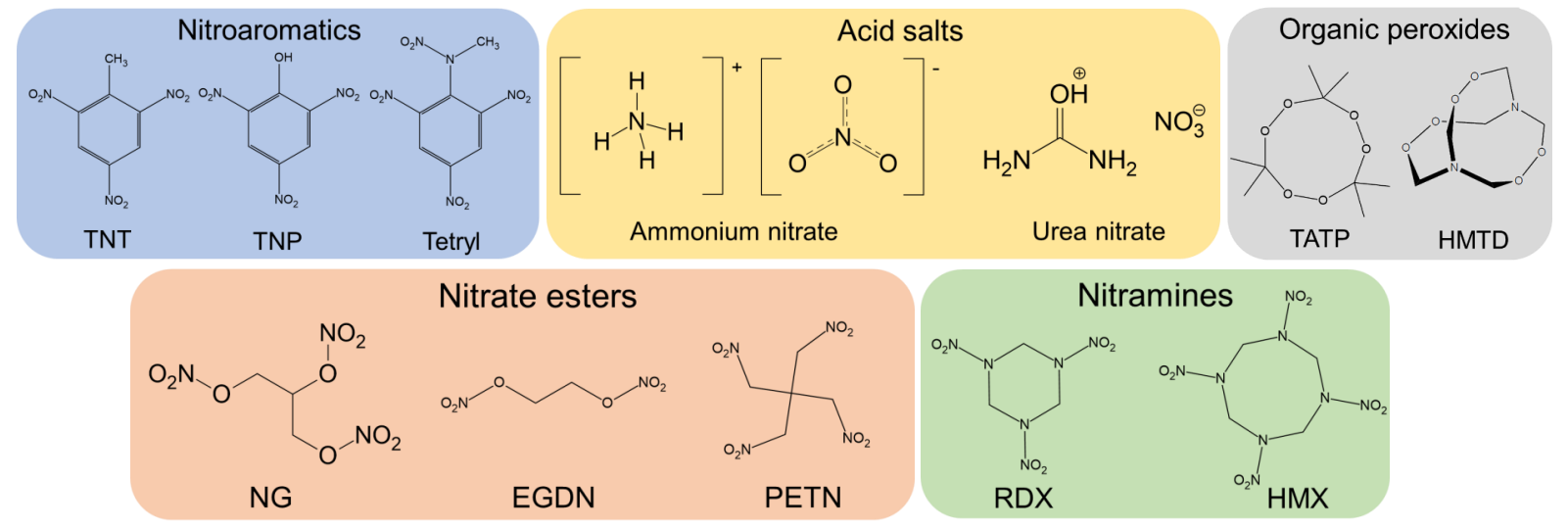

Figure 1: Classification of explosives by chemical groups. 2,4,6-trinitrotoluene (TNT), 2,4,6trinitrophenol (TNP), 2,4,6-trinitrophenylmethylnitramine (tetryl), triacetone triperoxide (TATP), hexamethylene triperoxide diamine (HMTD), ethylene glycol dinitrate (EGDN), nitroglycerine $(\mathrm{NG})$, pentaerythritol tetranitrate (PETN), 1,3,5-trinitroperhydro-1,3,5-triazine (RDX) and Octahydro-1,3,5,7-tetranitro-1,3,5,7-tetrazocine (HMX).

\section{Explosive trace detection (ETD) challenges}

A wide range of explosives exist and they can be categorised according to their composition (Figure 1). Nitroaromatic explosives such as TNT and TNP are used in munitions and are an environmental concern as they can contaminate soil and groundwater. ${ }^{4}$ Dinitrotoluenes have high vapour pressures and are present in compositions of blasting gelatine as well as impurities in TNT manufacture. ${ }^{5}$ Many nitrate esters are liquids and military applications include; propellants, detonators and plastic explosives. ${ }^{6}$ In addition, brisant explosives such as RDX and HMX are also components of plastic explosives. Heat, shock and friction sensitive organic peroxides are commonly used in HMEs. Ammonium nitrate/fuel oil (ANFO) is used as a blasting explosive but is also commonly used as a fertiliser. Along with urea nitrate (UN), both have also been used in improvised explosive devices (IEDs). Due to the different chemical and physical properties of explosives, many types of ETD technologies exist with sampling accomplished through particulates, vapours and liquids.

Explosive trace detection is a challenging task. The majority of particulate sampling is achieved through use of sampling wands so direction, pressure and technique are important factors for successful collection of material. Sampling also requires intuition from the security agent to select areas most likely to contain explosive trace. Vapour sampling is even more challenging since many explosives have very low vapour pressures. ${ }^{7}$ Sampling liquids raises practical issues and through-barrier screening is limited to a small number of technologies. Many explosives are also considered "sticky" and will adhere to a range of surfaces. ${ }^{8,9}$ For materials with high surface energies, this could result in accumulation of explosive particles, thus limiting the number of analyte molecules per volume of sample.

The operational environment also presents challenges. Passenger screening requires technologies with fast analysis times, low false alarm rates and minimal disruption. Cargo is usually wrapped in protective materials which may restrict efficient sampling. Screening baggage poses logistical issues. In all cases, there will be interference from benign materials which could cause false positive alarms, so technologies need to be selective. As such, deployment of new detection technologies requires careful 
consideration of the regulatory (threats, sensitivity, selectivity), operational, civilian and financial requirements.

\section{Reviews by other authors}

There are a number of technologies used in the detection of explosives, for bulk and trace quantities. ETD remains a dynamic research area and it is pertinent to mention several recent articles in the area. For an overview of bulk and trace detection technologies including principles, Caygill ${ }^{10}$ and Brown ${ }^{11,12}$ provide comprehensive reports. Mokalled ${ }^{13}$ and Buryakov ${ }^{14}$ reviewed the use of sensors in ETD and Giannoukos provides an overview of 'electronic noses' and in-field devices. ${ }^{15}$

\section{Types of detection methods}

As the name suggests, 'trace' refers to quantities of materials difficult to see with the naked eye. In ETD, this quantity can be considered to be $<1 \mathrm{mg}$. ETD technologies differ from bulk detection methods, which screen for anomalies in composition. Examples include; X-ray detection, where materials are identified by their density and effective nuclear charge $\left(Z_{\text {eff }}\right)^{16}$ and nuclear-based techniques which compares nitrogen content. ${ }^{17}$ Many spectroscopic techniques are used in ETD to identify explosives from their unique molecular signatures (Figure 2). The various properties of explosives has led to different approaches to enhance detection capability. For example, the taggant 2,3-dimethyl2,3-dinitrobutane (DMNB) is added to plastic explosives ${ }^{5}$ due to its high vapour pressure, permeability through clothing and limited commercial use. The vapour pressures of explosives vary widely across the different classes, from high vapour pressure materials in the parts-perbillion to parts-per-million (ppb-ppm) range such as DNT, EGDN and TATP, to low vapour pressure materials in the parts-per-trillion (ppt) region, such as HMX and nitroguanidine. TNT and TNP, which have been extensively studied as target molecules in gas sensors, have equilibrium vapour concentrations in air at ppb quantities. $^{7}$ A comparison of the different vapour pressures for various explosives at room temperature can be found in a papers by Östmark and Ewing. ${ }^{7,18}$ Heating can increase the vapour pressure of non-volatile explosives and improve detection. Pre-concentration by whole-air collection and sorbent enrichment are additional techniques which can be used. ${ }^{19,20}$ To achieve selectivity, many techniques incorporate the use of chemical modification to facilitate binding of specific explosives/explosive groups. For example, to exploit the electron deficient nature of many nitro-explosives, chemically modified silanes containing electron donating groups are frequently used. ${ }^{21,22}$ Charge-transfer complexes are formed and exploited as transducing elements in sensors. Example functional moieties include; amines, thiols and pyrroles. ${ }^{23-26} \mathrm{Com}$ putational and experimental studies have found a number of ions to form strong complexes with TATP, including $\mathrm{Co}^{2+}, \mathrm{Zn}^{2+}, \mathrm{In}^{3+27-29}$ and these properties have been utilised into a range of sensors. ${ }^{30-32}$ Standoff technologies involve non-contact detection at distance and generally involve optical methods and imaging linked to identification software. These technologies have recently been covered by other authors. ${ }^{33,34}$

\section{European projects concerning ex- plosives detection}

In addition to screening at critical locations such as borders and transport hubs, there is a need to pre-empt threats through advance warning systems. EMPHASIS (Explosive Material Production (Hidden) Agile Search and Intelligence System), BONAS (BOmb factory detection by Networks of Advanced Sensors) and LOTUS (Localisation of Threat Substances in Urban Society) are complimentary EU-funded projects involving partnerships between government, academia and industry, with the aim of developing systems for identifying bombmaking facilities. With focus on using standoff detection technologies to identify peroxide explosive precursors, ${ }^{35}$ the approach involves developing sensors (LOTUS) which can be wirelessly networked (BONAS) and embedded within urban infrastructure to carry out 

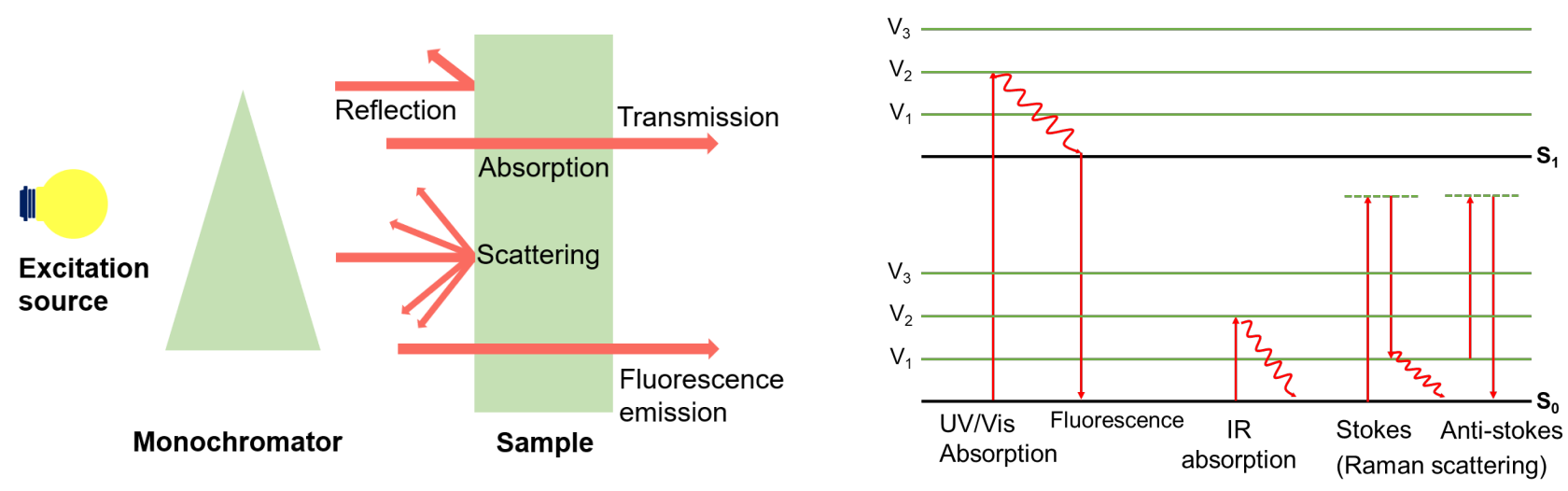

Figure 2: Examples of spectroscopic phenomena used for explosives trace detection. Diagram representing phenomena shown in addition to Jablonski diagram comparing energy transitions.

real-time monitoring (EMPHASIS). ${ }^{36-38}$ The multi-sensor system consists of several optical techniques including surface-enhanced Raman spectroscopy (SERS), quartz-enhanced photoacoustic spectroscopy (QEPAS), electrochemical (EC) sensing, a light detection and ranging (LIDAR)/differential absorption LIDAR detection system (DIAL) sensor. ${ }^{39}$ The COSMIC project, due to be completed in 2021, aims to develop new screening technologies for the detection of Chemical, Biological, Radiological, Nuclear and Explosive (CBRNE) materials concealed in shipping containers. ${ }^{40}$ The NATOfunded STANDEX (STANdoff Detection of EXplosives) program is another example of an integrated early-warning system, for deployment in mass transit infrastructure locations. Of particular relevance, is the RAman Detection of EXplosives (RADEX) system, which uses an eye-safe laser and has standoff detection capability. ${ }^{41}$

\section{Animal olfactory systems}

The detection capabilities of animals far exceeds many of the current technologies in use today and as such, there is a continuing need for animals in explosives detection. One of the key advantages of biological systems is concurrent detection of multiple analytes of interest in real-time which is a challenging task and difficult to achieve even with integrated sensing technologies. Examples of animal systems used in explosives detection include; dogs, rats, honeybees and pigs. For a comprehensive review of biological detection systems, including genetically-modified plants, microbial and immunological-based techniques, please refer to papers by Habib ${ }^{42}$ and Brown. ${ }^{11}$

Sniffer dogs are the most common animals which are trained for contraband detection and are widely used for their ability to achieve fast, real-time and directional screening. Many breeds of dogs are used and a thorough review of ideal traits for detection dogs is provided by Jamieson et al. ${ }^{43}$ The environmental, training and physiological factors affecting detection dog performance is provided by Hayes et. al. ${ }^{44}$

A limitation of sniffer dogs is the amount of training required before deployment. Training takes several months, which is time-consuming and costly. The dog-handler interface also affects performance, ${ }^{45}$ as can screening conditions, with indications that increased panting, as result of overheating, can reduce the ability of dogs to detect explosives. ${ }^{46}$ Despite these limitations, efforts have been made to re-produce aspects of canine olfactory systems. Staymates et. al connected a 3D-printed structure of a dog's nose with a pump to produce a system which mimics the "sniffing" action of canines. ${ }^{47}$ The bio-inspired system showed better detection compared with a commercial ETD device, suggesting active sniffing to be a crucial part of the sample delivery process.

Rats have also been trained to detect explosives and have the benefit of being lightweight, which makes them ideal for landmine detec- 
tion. ${ }^{48}$ In addition, rats have lower training, maintenance and transportation costs compared with sniffer dogs. Honey bees have been trained to detect TNT, C4 and TATP explosives at parts-per-trillion levels. Similar to rats, training costs are low and can be completed within days. Their abundant populations and ability to cover large areas quickly and the ability to sample solid, liquid and gaseous samples make them ideal detection tools. However, honey bees can be affected by the weather, cannot sample at night and are highly unlikely to be deployed in screening environments where humans are present. The development of a transportable sensor using honey bees can be exemplified by the Inscentinel Vasor (Volatile Analysis by Specific Odour Recognition) 136. Initially developed in the UK, the device exploits the Proboscis Extension Reflex (PER), ${ }^{49}$ whereby honey bees extend their tongues when their anntenae touch a sugar/honey solution. With pavolovian conditioning, honey bees were trained to respond to TNT, Semtex, PE-4 and C-4 down to detection limits of 78 ppt $^{50}$ (Figure 3). The device consists of 36 bees held in a self-contained unit, integrated with an imaging system to detect PER. The EU-funded 'Biological Method (Bees) for Explosive Detection' project utilises trained bee colonies to identify landmines. ${ }^{51}$ This is realised through active and passive methods, with the former integrating artificial intelligence and drone technology to track bee colonies hovering over landmines. The passive approach involves using a commercially available semiconducting polymer as a pre-concentrator, installed at the entrance of beehives. Sensing is achieved through desorption of analytes and luminescence quenching of a conjugated polymer, Super Yellow. ${ }^{52,53}$ 

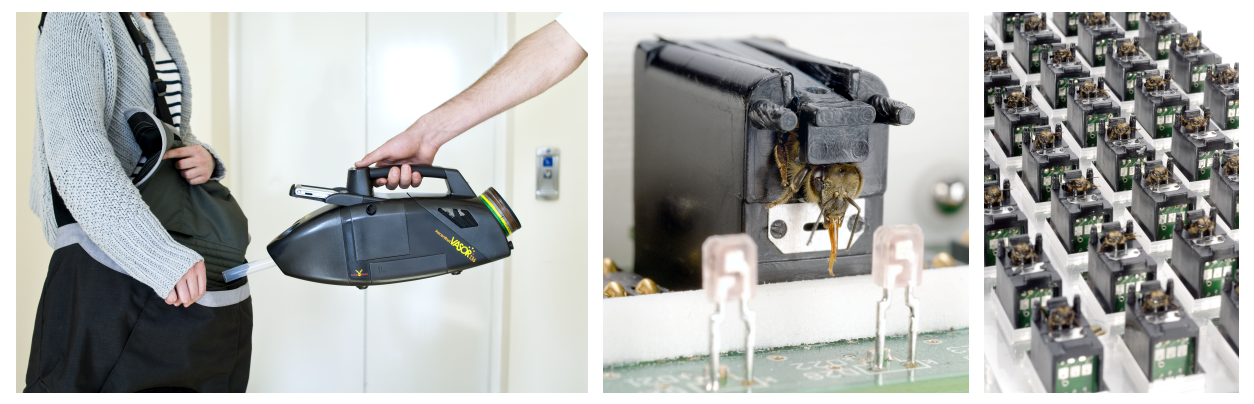

Figure 3: Inscentinel Vasor 136 system. Rothamsted Research Ltd.

\section{Sensors}

Efforts to mimic mammalian olfactory systems has led to the development of electronic noses (E-noses). First proposed in 1982, Enoses broadly describe systems consisting of a sensor combined with pattern matching software to achieve vapour detection. ${ }^{54}$ Single sensors, for individual analyte detection or sensor arrays, for simultaneous detection of multiple targets can be used. Many sensor technologies have since been used to develop Enoses and examples include; field effect transistors (FET), chemoresistors, quartz crystal microbalance (QCM) and electrochemical sensors. ${ }^{55}$ However, even the most advanced systems have yet to reach the capability of their mammalian counterparts. The following subsections will describe some of the sensing technologies used in E-noses.

\section{Colorimetric sensor arrays}

Colorimetric sensor arrays contain different reagent dyes which can change colour on interaction with solid, liquid and vapour analytes. Chromophores and fluorophores are common reagents and the colour change is measured as a result of the change in absorbance or fluorescence. Advances in image capture technologies have led to the development of sensor arrays which carry out analysis by perturbing the red, green and blue (RGB) intensities of digital images. ${ }^{56} \mathrm{RGB}$ analysis has already been demonstrated on conventional colorimetric kits using iphone cameras. ${ }^{57-59}$ The combination of a sensor array with digital image analysis provides a much greater discriminatory power. As such, a range of molecular interactions can be identified through use of combinations of reagents which produce patterns of colour, thus allowing 'optical fingerprinting' to be achieved. ${ }^{60}$ Examples of such colorimetric agents exploited for sensing include; $\mathrm{pH}$ and redox indicators ${ }^{61,62}$ and derivatives of xanthene dyes, the latter of which is used in the DETECHIP ${ }^{\circledR}$ sensor. ${ }^{63}$ 

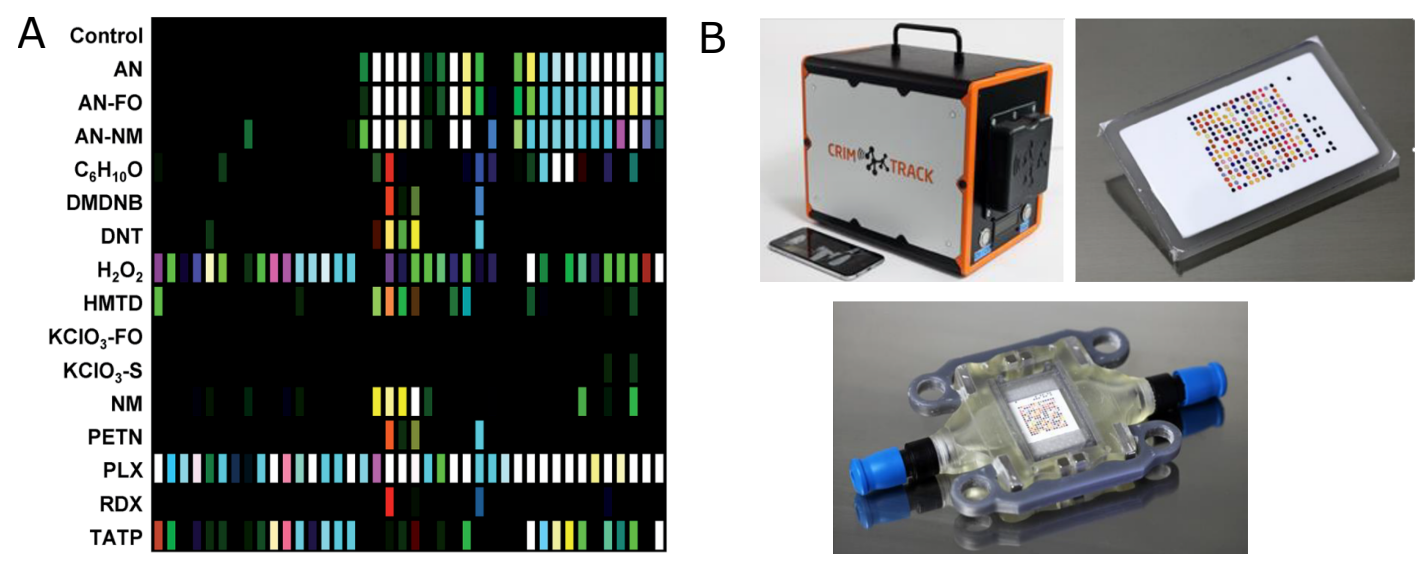

Figure 4: Examples of colorimetric arrays. A) 40-reagent colorimetric sensor array as described in. ${ }^{64}$ B) CRIM-TRACK colorimetric sensor for explosive vapours. A) Reproduced from ref. ${ }^{64}$ Copyright 2016 RSC. B) Reproduced with permission from ref. ${ }^{65}$

Salles et al. report detection of peroxide and nitroaromatic explosives using a 3-reagent sensor consisting of potassium iodide, creatine, and aniline. Colour discrimination was achieved through software evaluation of RGB values acquired from images on an iPhone. Detection limits between $0.2 \mu \mathrm{g}-0.1 \mathrm{mg}$ were achieved for TATP, HMTD, picric acid and nitrobenzene (NB), within 15 minutes. ${ }^{66}$ Simultaneous detection of 16 explosive vapours was achieved using a colorimetric sensor array made up of 40 components. ${ }^{64}$ Detection limits were in the mg-scale, which falls within the levels considered for trace detection but lacks the sensitivity achievable in IMS systems (Figure 4). Another study by the same research group, report the detection TATP and HMTD vapours ${ }^{67}$ with a limit of detection (LOD) at $\mu \mathrm{g}$ quantities. The CRIM-TRACK system uses 26 chemoselective dyes spotted onto a chip to form a colorimetric sensor array (Figure 4). Detection of HMTD, TATP and drug molecules are reported, with initial testing in mixed air conditions showing detection limits in the ppt range. ${ }^{65,68}$ In addition, machine learning was successfully used to detect target analytes in contaminated samples. A fluorescence quenching sensor prepared using aerosol-jet printing was reported by Bolse et. al. Detection of nitrobenzene, 1,3-dinitrobenzene and DNT was achieved at ppb levels with high classification rates, using an array of six fluorescent spiro and homopolymers. ${ }^{69,70}$

\section{Immunosensors}

Immunosensors function through specific antibody-antigen conjugations to detect analytes of interest. For explosives detection, competitive assays are the most common type of immunosensor reported. Here, an antibody is affixed onto a platform and an unlabelled substrate in a sample competes with a labelled analogue to bind to the antibody. The amount of labelled, unbound substrate is measured. If the labelled substrate contains a fluorophore, then detection can be achieved through measuring an increase or quenching of the fluorescence signal. The latter technique provides greater sensitivity since benign materials which fluoresce can lead to false signals. Detection can also be achieved by changes in colour, absorbance or electrochemical signal. ${ }^{71}$ Monoclonal antibodies for high explosives TNT, RDX and PETN are commercially available through BBI Detection. ${ }^{72}$ The BioSENS ${ }^{\circledR}$ 300 device combines an immunoassay with surface acoustic wave (SAW) technology (Figure 5). The system was tested as part of an EU project ${ }^{73,74}$ and detection occurs through monitoring the change in mass on a surface which contains antibody-antigen immunocomplexes immobilised onto SAW sensors. In the presence of analyte antigens, antibodies are displaced from the immunocomplex, generating a measurable signal. Nanogram detection is possible for a range of nitro-based explosives 
in addition to PETN and NG, within 30 seconds. ${ }^{75,76}$ Surface-plasmon resonance (SPR), frequently used in lab-on-a-chip sensors, has also been reported for the detection of TNT, EGDN and RDX. ${ }^{77-79}$
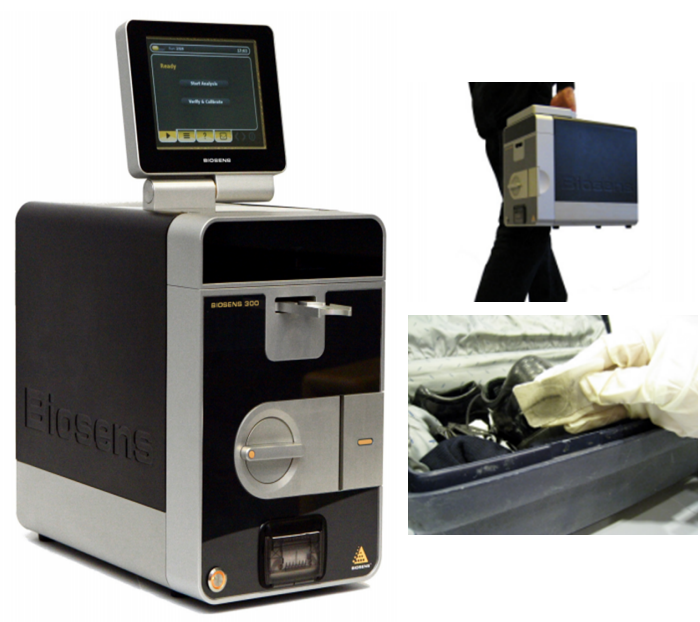

Figure 5: $\quad$ BIOSENS ${ }^{\circledR} 300$ from Biosensor Applications ${ }^{\circledR}$ AB utilising antibody immunosensors with SAW detection technology. Biosensor Applications International AB.

The U.S. Naval Research Laboratory has developed several microfluidic immunosensors for the detection of TNT. In one study, a device for detection in seawater was developed. Monoclonal antibodies with high affinity for TNT were immobilised onto a device consisting of poly(methylmethacrylate) (PMMA). Detection was achieved by measuring the increase in fluorescence upon binding of TNT, with the LOD reported as 1 ppb. ${ }^{80}$ Similarly, a fluorescence-based displacement immunoassay using neutravidin-coated biotinylated antiTNT achieved detection limits of $10 \mathrm{ppt} .{ }^{81} \mathrm{An}-$ other device, by the same group, using recombinant proteins, achieved detection limits of 0.5 ppb. ${ }^{82}$

Wang et al. used peptide-functionalised SPR for the detection of TNT with an LOD of 1.35 ppm. ${ }^{83}$ In contrast to protein antigens, peptide antigens are synthetically produced from carefully-selected amino acid sequences of a native target protein, thus offering greater specificity. Gubanova et al. report the development of an enzymatic biosensor microfluidic system which uses an ion sensitive field effect transistor
(ISFET) for signal transduction. ${ }^{84}$ The LOD for TNT was $5 \mathrm{ppb}$.

\section{Nanomaterials}

Nanotechnology is a rapidly expanding area and the tunable nature of nanomaterials makes them desirable for use as sensor arrays. Nanostructured materials provide high surface areas for detection and selectivity can be achieved by utilising their unique electrical, optical, catalytic, magnetic and mechanical properties. Nanomaterials can be classified in many different ways and Table 1 lists some examples according to chemical composition. The rest of this section will focus on semiconductor materials used as sensors for ETD. 
Table 1: Different classes of nanomaterial sensors used for the detection of explosives

\begin{tabular}{|c|c|c|c|c|}
\hline Type & Detection method & $\begin{array}{l}\text { Materials } \\
\text { detected }\end{array}$ & LOD & Reference \\
\hline \multirow{4}{*}{ Plasmonic } & $\mathrm{Au}$ nanoparticles functionalised with 4- & PETN & $0.15 \mathrm{mg} \mathrm{L}^{-1}$ & 85 \\
\hline & $\begin{array}{l}\text { Aminothiophenol and N-(1-Naphthyl)- } \\
\text { ethylenediamine dichloride (NED) }\end{array}$ & & & \\
\hline & $\begin{array}{l}\text { Electrochemical sensor consisting of } \mathrm{Ag} \\
\text { nanoparticles on carbon fibre electrodes }\end{array}$ & $\begin{array}{l}\text { TATP, } \\
\text { HMTD }\end{array}$ & $200 \mathrm{ppb}$ (TATP), $250 \mathrm{ppb}$ (HMTD) & 86 \\
\hline & $\begin{array}{l}\text { Cu nanoparticle-incorporated polyfurfural film } \\
\text { electrochemical sensor }\end{array}$ & TNT & $41.6 \mathrm{ppb}$ & 87 \\
\hline \multirow{4}{*}{ Semiconductors } & $\begin{array}{l}\mathrm{TiO}_{2} \text { sensor contained within a quartz crystal } \\
\text { microbalance }\end{array}$ & $\mathrm{NG}$ & $1-10 \mathrm{ppm}$ & 88 \\
\hline & $\begin{array}{l}\text { Optoelectronic sensor using polyoxometalate- } \\
\text { doped } \mathrm{TiO}_{2}\end{array}$ & TATP & $50 \mathrm{ppb}$ & 89 \\
\hline & $\mathrm{In}_{2} \mathrm{O}_{3}$ amperometric sensor & TATP & $2.9 \mathrm{ppb}-2.8 \mathrm{ppm}$ & 90 \\
\hline & $\mathrm{WO}_{3}$ and chromium titanium oxide gas sensor & $\begin{array}{l}\text { Ammonia, } \\
\text { ni- } \\
\text { tromethane, } \\
\mathrm{NO}_{2}\end{array}$ & Ppm & 91 \\
\hline \multirow{4}{*}{$\begin{array}{l}\text { Quantum } \\
\text { dots }\end{array}$} & Fluorescent silicon nanodots & TNP & $0.92 \mathrm{nM}$ & 92 \\
\hline & Fluorescent graphene oxide dots & TNP & $92 \mathrm{nM}$ & 93 \\
\hline & L-cysteine-coated CdS quantum dots & TNP & $39 \mathrm{ng} \mathrm{mL}^{-1}$ & 94 \\
\hline & $\begin{array}{l}\text { Electrochemiluminescence (ECL) resonance } \\
\text { energy transfer (ERET) sensor using CdTe } \\
\text { quantum dots }\end{array}$ & TNT & $0.65 \mathrm{ppm}$ & 95 \\
\hline \multirow{3}{*}{$\begin{array}{l}\text { Carbon- } \\
\text { based }\end{array}$} & $\begin{array}{l}\text { Electrochemical sensor using MIP cast on } \\
\text { multi-walled carbon nanotube (MWCNT) }\end{array}$ & RDX & $20 \mathrm{pmol} \mathrm{L}^{-1}$ & 96 \\
\hline & SWCNT & TNT & $772 \mathrm{ppb}$ & 97 \\
\hline & $\begin{array}{l}\text { Electrochemical sensor using boron-doped di- } \\
\text { amond/graphene nanowall electrodes }\end{array}$ & $\begin{array}{l}\text { TNT } \\
\text { and 2,4,6- } \\
\text { trinitroanisol } \\
\text { (TNA) }\end{array}$ & $73 \mathrm{ppb}(\mathrm{TNT}), 270 \mathrm{ppb}(\mathrm{TNA})$ & 98 \\
\hline \multirow[t]{3}{*}{ Composite } & $\begin{array}{l}\text { Chemically modified polypyrrole-bromophenol } \\
\text { blue QCM sensor }\end{array}$ & $\begin{array}{l}\text { TNT, } \\
\text { PETN, } \\
\text { RDX and } \\
\text { HMX }\end{array}$ & $\begin{array}{l}500 \text { ppt (TNT), } 800 \text { ppt (PETN), } 1 \\
\text { ppb (RDX) and } 2 \mathrm{ppb}(\mathrm{HMX})\end{array}$ & 26 \\
\hline & $\begin{array}{l}\text { Functionalised SU- } 8 \text { polymer nano-composite } \\
\text { microcantilevers }\end{array}$ & $\begin{array}{l}\text { TNT, RDX } \\
\text { and PETN }\end{array}$ & $\begin{array}{l}1.30 \mathrm{pg}(\mathrm{TNT}), 0.07 \mathrm{fg}(\mathrm{RDX}), 0.23 \mathrm{fg} \\
(\mathrm{PETN})\end{array}$ & 99 \\
\hline & $\mathrm{MoS}_{2} /$ reduced graphene oxide composite & $\begin{array}{l}\text { TATP } \\
\text { (precur- } \\
\text { sors) }\end{array}$ & $0.65 \mathrm{ppm}$ & 100 \\
\hline
\end{tabular}

\section{Inorganic semiconductors}

Metal oxide $\left(\mathrm{MO}_{\mathrm{x}}\right)$ semiconductors are promising materials for sensing applications due to their low production costs, ease of use, high thermal, chemical and electrical stability. ${ }^{101}$ These properties have led to a range of applications, including; monitoring of volatile organic compounds, environmental and toxic gases. ${ }^{102,103} \mathrm{MO}_{\mathrm{x}}$ semiconductors have characteristic wide band gaps $(>2 \mathrm{eV})$ and electron transition energies in the $\mathrm{UV} /$ visible wavelengths of light. Not only is this favourable for optoelectronic and electronic sensors, but a wide tunable spectral range can also be exploited to improve sensitivity and selectivity. Resistive gas sensors are the most common and the sensing mechanism is based on measuring the change in conductance on adsorption of a target molecule. ${ }^{104}$ In ambient conditions, ad- sorption of $\mathrm{O}_{2}$ onto the surface of the $\mathrm{MO}_{\mathrm{x}}$ leads to the formation of oxygen ions. The conductivity of the $\mathrm{MO}_{\mathrm{x}}$ sensor is determined by both 1) the nature of the charge carrier, either electrons or holes in $n$ and $p$-type semiconductors, respectively and 2) the oxidative/reductive nature of the target gas (Figure 6).

Many $n$ - and $p$-type semiconductor materials have been used for explosives detection and examples include; $\mathrm{TiO}_{2},{ }^{28,105} \mathrm{ZnO},{ }^{32,106}$ $\mathrm{Sn}_{2} \mathrm{O}^{107,108}$ and $\mathrm{Cu}_{2} \mathrm{O} .{ }^{109}$ Tang et.al synthesised $\mathrm{TiO}_{2}$ nanostructures onto indium tin oxide (ITO) and fluorine-doped tin oxide (FTO) conducting glasses. The photoresponse towards TATP was highest for $\mathrm{TiO}_{2}$-FTO homojunction structures with detection possible at ppb levels. The authors found positioning of the conducting glass during synthesis of $\mathrm{TiO}_{2}$ was important for the types of nanostructures formed. ${ }^{110}$ 


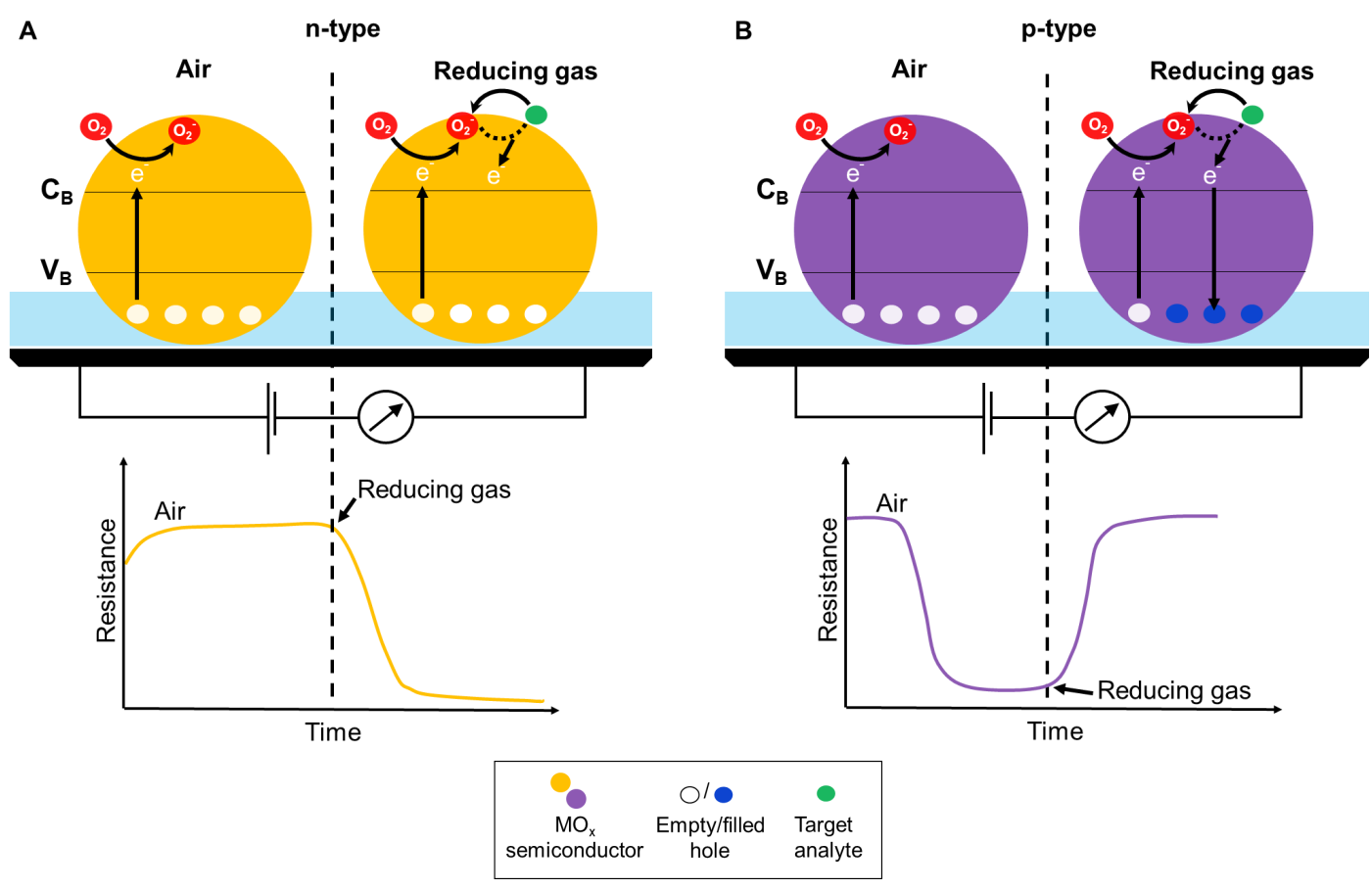

Figure 6: Mechanisms of metal oxide $\left(\mathrm{MO}_{\mathrm{x}}\right)$ semiconductor gas sensors for a reducing gas target analyte. When the sensor is exposed to air, adsorption of $\mathrm{O}_{2}$ onto the surface leads to uptake of electrons from the conduction band $\left(\mathrm{C}_{\mathrm{B}}\right)$, creating oxygen ions $\left(\mathrm{O}_{2}{ }^{-}\right)$. A) In $n$-type semiconductors, a redox reaction occurs between the $\mathrm{O}_{2}{ }^{-}$and target analyte, leading to injection of electrons into the $\mathrm{C}_{\mathrm{B}}$. As a result, conductance increases and resistance decreases. B) In $p$-type semiconductors, holes are the dominant charge carriers. However, since the concentration of hole carriers has increased, there is an increase in conductivity. In the presence of a reducing target analyte, reaction between the $\mathrm{O}_{2}{ }^{-}$and analyte will lead to injection of electrons into the $\mathrm{MO}_{\mathrm{x}}$ and the filling of holes. This results in decrease in the concentration of hole charge carriers, a decrease in conductivity and increase in resistance.

Bastatas et. al fabricated a chemiresistive sensor using $\mathrm{ZnO}$-coated silica nanosprings for the detection of ammonium nitrate (AN). UV-A irradiation was used to improve the activation of charge carriers as well as facilitate analyte desorption and reuse of the sensor. ${ }^{111} \mathrm{Qu}$ et.al developed a chemiresistive sensor array for the detection of TNT, DNT, TNP, RDX and AN. The authors doped $\mathrm{ZnO}$ with $\mathrm{Co}$, Ni and Fe to produce $p$-type semiconductor films to improve the adsorption of explosives onto the $\mathrm{MO}_{\mathrm{x}}$ surface and sensor response. Detection was achieved at ppb-ppt levels with response times within 12 seconds. The authors attribute the rapid response of the doped sensors to reduction in the charge transfer distance between the charge reservoir layer and surface defect centres of the $\mathrm{MO}_{\mathrm{x}}$ nanoparticles ${ }^{112}$ (Figure 7). The ability of some $\mathrm{MO}_{\mathrm{x}}$ sensors to function (as shown by Bastatas and $\mathrm{Qu}$ ) at low temperatures is a promising development, not only in terms of reduced energy consumption but also in reduction of potential hazards for use in an operational environment.

Efforts to improve the selectivity of $\mathrm{MO}_{\mathrm{x}}$ semiconductors towards specific explosives include; changing the operating temperature, using sensor arrays and composite materials. Temperature modulation affects the charge and rate of oxygen adsorbed onto the $\mathrm{MO}_{\mathrm{x}}$ surface. As such, sensor response can be used to profile specific gases. Further selectivity can be achieved by combing information from a several sensors with different operating temperatures. ${ }^{101,113}$ Composite $\mathrm{MO}_{\mathrm{x}}$ structures can be designed whereby each material is chosen with selectivity to a specific gas analyte. ${ }^{114}$ Warmer et. al used $\mathrm{SnO}_{2}$ and $\mathrm{WO}_{3}$ 

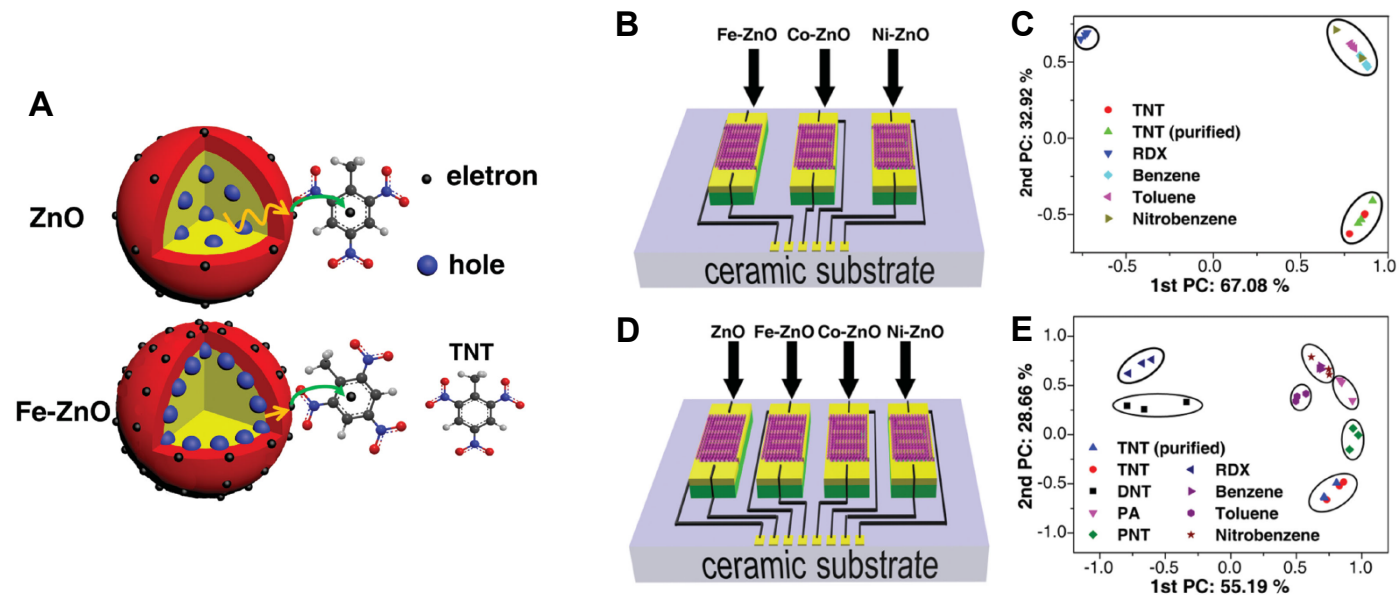

Figure 7: Fe-doped ZnO chemiresistive sensor A) Models showing the charge transfer mechanism of undoped and doped $\mathrm{ZnO}$. In Fe-doped $\mathrm{ZnO}$, a charge reservoir layer exists from which charge carriers migrate, to the surface of Fe-doped $\mathrm{ZnO}$ nanoparticles B) Schematic showing the gas sensor array composed of three doped sensors; Fe-ZnO, Co-ZnO, and $\mathrm{Ni}-\mathrm{ZnO}$, (C) PCA analysis of analytes detected using the sensor array in B), D) Schematic showing the gas sensor array composed of four sensors; ZnO, Fe-ZnO, Co-ZnO, and $\mathrm{Ni}-\mathrm{ZnO}$, E) PCA analysis of analytes detected using the sensor array in D). ${ }^{112}$ Reproduced from ref. ${ }^{112}$ Copyright 2016 Small.

to detect TATP and DADP. The authors note the oxidising and reducing properties of organic peroxides is temperature dependent and utilise this feature for selectivity towards TATP by temperature cycling of $\mathrm{WO}_{3}$ films. An LOD in the ppb range is reported. ${ }^{115} \mathrm{An} \mathrm{E}$ nose using silicon nanowire-field effect transistors (SiNW-FETs) has been developed by Tracense Systems. Chemically modified silicon nanowire arrays provide selective binding of nitro-containing and peroxide-based explosives, with detection achieved through measuring the change in conductance on adsorption of explosives. Parts-per-quadrillion (ppq)ppt detection was achieved for TNT and peroxides explosives TATP and HMTD, respectively. ${ }^{116,117}$ A Schottky optoelectronic sensor array consisting of SiNW's incorporated with $\mathrm{TiO}_{2}$ and reduced graphene oxide was developed by Yang et. al. Detection limits were reported between $0.05 \mathrm{ppq}-74 \mathrm{ppb}$ for a range of nitro-based explosives. ${ }^{118}$ Further adaptation by the same group, which involved replacing $\mathrm{TiO}_{2}$ with $\mathrm{ZnO}$, showed discrimination between urea, black powder, nitrate- and nitro- explosives. ${ }^{119}$

Selectivity can also be achieved by using the catalytic activities of some metal oxides, in the form of thermodynamic sensors. Here, a typical setup involves scanning two microheaters, one of which is coated in the catalytic material. By comparing the electrical power required to maintain both heaters at a constant temperature, thermodynamic data can be collected attributed to the catalytic activity specific to the analyte. ${ }^{120} \mathrm{SnO}_{2-\mathrm{x}}$ and $\mathrm{ZnO}$ were used in this way by Amani et. al for detection of TATP at ppm levels. ${ }^{31} \mathrm{~A}$ similar system developed by Rossi et. al, using sensors with lower thermal mass improved detection to ppb levels. Furthermore, the trend in the sensitivity of metal oxide catalysts towards TATP was observed to be $\mathrm{SnO}>\mathrm{ZnO}>\mathrm{CuO}$. The authors report the mechanism of TATP detection as due to the oxidation/reduction of the catalyst from decomposition of TATP. ${ }^{32}$ Further improvements to this system involved the addition of a conductometric platform to collect the electrical resistance of the catalytic $\mathrm{MO}_{\mathrm{x}}$ sensor in addition to the thermodyamic response. ${ }^{121}$

\section{Organic semiconductors}

Conjugated polymers generally have alternating single and double bonds in the polymer chain which provides a $\pi$-conjugated structure 
A

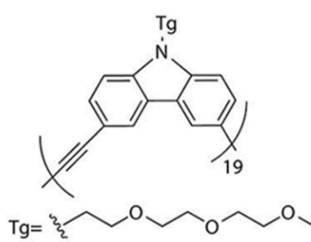

$\mathrm{Tg}=\mathrm{s}_{\mathrm{O}} \mathrm{NO}_{\mathrm{O}}$

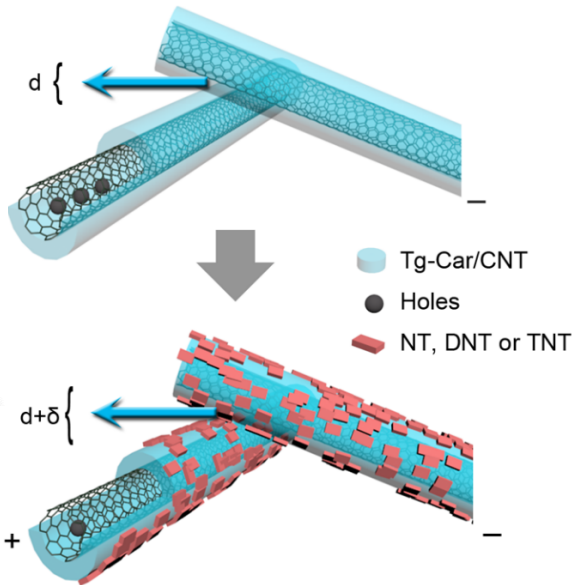

B

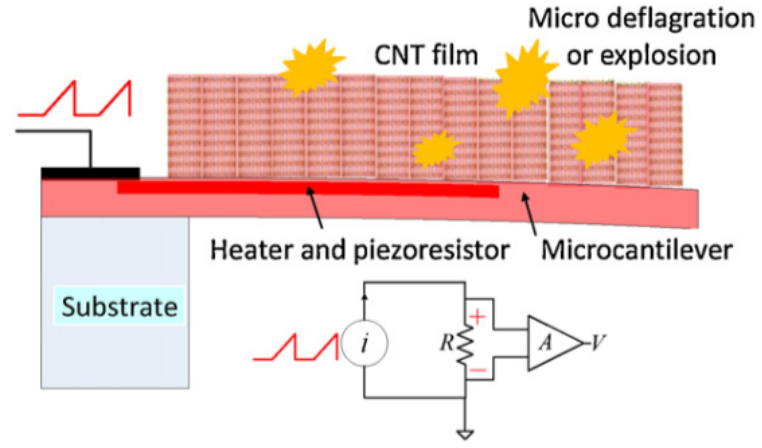

Figure 8: Sensing of nitroaromatic explosives using carbon nanotubes A) Sensor using single-walled carbon nanotubes (CNTs) modified with Tg-Car oligomer (structure inset). The schematic shows charge carriers moving in the Tg-Car/CNTs before and after exposure to nitroaromatic explosives (NT, DNT and TNT) ${ }^{122}$ B) Piezoresistive microcantilever sensor coated in CNT film. Explosive vapours adsorbed onto the sensors are heated to induce micro deflagration, leading to bending of the microcantilever and detection by the piezoresistors. ${ }^{123}$ Reproduced from ref. ${ }^{123}$ Copyright 2013 Elsevier.

resulting in a continuous delocalized electron system. These features give rise to unique photoconductive, photoluminescent and mechanical properties. For explosives detection, research surrounding conjugated polymers has primarily focused on their fluorescent properties and tuning these to improve sensitivity and selectivity. Examples of such materials are discussed later in the paper. This section will cover work on conducting polymers, a sub-category of conjugated polymers and also part of the organic semiconductors class of materials. ${ }^{124,125}$

An attractive feature of semiconducting polymers is having both tunable electronic properties and mechanical plasticity. In addition, a range of facile deposition methods exist, making them ideal for composite sensors in E-noses. ${ }^{126,127}$ Surya et. al developed an organic field effect transistor (OFET) sensor using diketopyrrolopyrrole and metal organic framework as the sensing element. In this system, the Cd(II) MOF acted as the receptor and pre-concentrator and the thienylenevinylene- thienylene (PDPP-TVT) semiconducting polymer was used as the channel material. The system detected TNT and RDX at ppb and ppt levels, respectively. ${ }^{128}$ Semiconducting poly(dendrimer)s modified with fluo- rene and carbazole as fluorophore moieties were developed by Loch et. al for the detection of DNT and the explosive taggant DMNB. ${ }^{129}$ Blue et. al developed polymer-based microsensors for vapour detection of nitro and peroxidebased explosive precursors. The authors synthesised copolymers using a Bromine derivative of the conductive polymer PRODOT (3,4Propylenedioxythiophene), Br-ProDOT, as the starting material. The resultant copolymers were electrochemically deposited onto interdigitated electrodes (IDEs) with sensing achieved through measuring the change in capacitance on adsorption of target vapours. Detection limits of $200 \mathrm{ppb}$ were achieved for nitrobenzene and 2-nitrotoluene and for peroxide vapours, ppm levels were achieved. ${ }^{130}$

\section{Graphene and carbon nanotubes}

Carbon-based semiconductors such as graphene and carbon nanotubes (CNTs) have been extensively researched as sensing materials due to their favourable electrical, mechanical and chemical properties over inorganic equivalents. These materials are amenable to chemical functionalisation and many can be printed using low-cost methods. ${ }^{131}$ The 2D structure of 
graphene provides a high surface area to volume ratio and the sp2 network facilitates $\pi-\pi$ interactions, which is favourable for the detection of electron deficient nitroaromatic explosives. ${ }^{132,133}$ Introducing oxygen functional moieties, either chemically as graphene oxide ${ }^{134}$ or through the fabrication process ${ }^{135}$ can further improve sensitivity through van der waals interactions with the $\mathrm{NO}_{2}$ groups. Efforts to improve the selectivity of graphene materials for ETD include; peptide modifications, ${ }^{136}$ nanoparticles, ${ }^{137}$ doping ${ }^{98,138}$ and organic polymers. ${ }^{139,140}$

The high conductivity of single walled (SW), multi-walled (MW) carbon nanotubes, have also been investigated for explosives detection with the majority of studies focused on nitroaromatic materials. Studies by Woods and Star show the interactions between CNTs and nitroaromatic explosives involve a combination of $\pi-\pi$ stacking and charge-transfer effects. ${ }^{141,142}$ Kumar et.al developed a SWCNT sensor on a flexible polycarbonate membrane. Detection of DNT was possible at ppb levels and the sensor could be recovered through UV irradiation. ${ }^{143}$ Stefano et. al compared the response of an electrochemical sensor for TNT using pure and acid-treated CNT-coated electrodes. The study found that residual metallic impurities in pure CNTs can improve the electrochemical response for TNT due to catalytic effects and increased surface roughness of the electrodes. ${ }^{144}$ Ruan et. al fabricated a piezoelectrical microcantilever sensor coated with CNTs for the detection of TNT ${ }^{123}$ (Figure 8). As with graphene-based sensors, selectivity of pure CNT materials is limited and chemical modifications are often required. Zhang et. al coated SWCNTs with carbazolylethynylene oligomers for the detection of 4-nitrotoluene (NT), TNT and DNT. Differential sensing was achieved by using both coated and uncoated SWCNTs on the same sensor. The resultant $n$-type and $p$-type semiconductor properties showed different trends in conductance which could then used to differentiate each analyte ${ }^{122}$ (Figure 8).

Other nanoforms of carbon used in ETD include carbon dots which have promising appli- cations for sensors, due to their fluorescence properties and chemical inertness. Ran et. al used nitrogen-doped carbon dots modified with the macrocyclic structure pillar[6]arene, for selective detection of TNT. The electrochemical sensor achieved a detection limit of 0.95 nM. ${ }^{145}$ A magnetic carbon dot-based MIP composite was developed by Wang et al. for the detection of TNP with a LOD of 0.5 nM. ${ }^{146} \mathrm{Ju}$ et. al synthesised carbon dots using a simple solvothermal approach involving o-phenylenediamine and chloroform. The colorimetric sensor showed a LOD of $2 \mu \mathrm{M}$. Practicality of this method was demonstrated by immobilising the carbon dots on standard filter paper. ${ }^{147}$

\section{Quantum dots}

Quantum dots (QDs) are nanocrystalline semiconductor materials with excellent fluorescent properties due to their quantum confinement effects. QDs also have high quantum yield, broad excitation spectra, narrow emission spectra and high stability, making them favourable for use as colorimetric probes. The small size of QDs, typically 2-10 nm, gives rise to their unique optical properties. At these dimensions, semiconductor crystals are similar in size to the Bohr radius and hence distance between an electronhole pair. At these distances, the conduction band of the semiconductor material separates into sub-bands of discrete energy states and the bandgap changes with respect to the size of the crystal $^{148,149}$ (Figure 9). This greatly increases the tunability of QDs with emission wavelengths achievable from UV to near-IR. ${ }^{150}$

QDs can be grouped by their semiconductor components, with the majority of developments seen in groups II-IV ${ }^{151,152}$ and IV. ${ }^{153,154}$ QDs can also include carbon nanostructures with sizes $<10 \mathrm{~nm}$, which includes graphene QDs and carbon QDs, ${ }^{155}$ examples of which have been described previously. Semiconductor QDs can also be grouped according to their composition, such as core-type, core-shell and alloyed. The electron-rich nature of QDs are suitable for the detection of nitroaromatic explosives as the electron-withdrawing nitro groups can act 
A

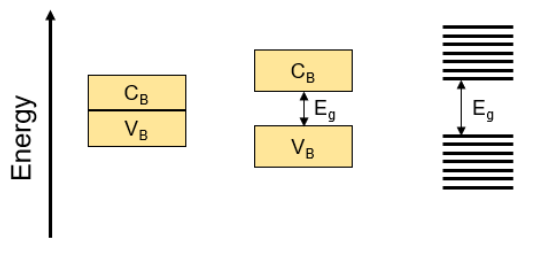

Metal Semiconductor Quantum dot

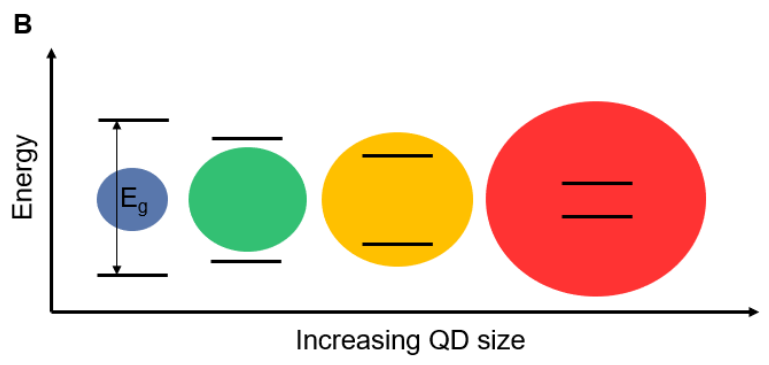

Figure 9: Properties of semiconductor quantum dots A) Comparison of the band gap en$\operatorname{ergy}\left(E_{g}\right)$ between metals, bulk semiconductors and semiconductor quantum dots, B) Relationship between the size of semiconductor quantum dots and $\mathrm{E}_{\mathrm{g}}$, resulting in different emission energies.

as fluorescence quenchers. Two mechanisms widely used to achieve such sensing are fluorescence resonance energy transfer (FRET) and photo-induced electron transfer (PET) (Figure 10). ${ }^{156,157}$ A FRET-based sensor consisting of $\mathrm{N}$ and S co-doped carbon QDs was used by Khan et. al for the detection of TNP. The nascent donor QDs showed maximum fluorescence emission at $300 \mathrm{~nm}$ which was quenched in the presence of TNP. ${ }^{158}$ Ganiga et. al used CdS QDs and diphenylamine for the detection of RDX and PETN. In this system, the fluorescent CdS QDs acted as the acceptor and is quenched by the diphenylamine. Electrostatic interactions between explosives and diphenylamine result in the formation of a complex and restoration of fluorescence, with maximum emission at 355 nm. ${ }^{159}$ Gong et. al synthesised QDs consisting of core-shell CdSe/silica functionalised with $\mathrm{NH}_{3}$ for the detection of TNP. ${ }^{160}$

A fluorescent sensor array consisting of modified core-shell CdSe/ZnS QDs was developed by Peveler et. al containing calixarene, cyclodextrin -OH and -OMe surface modifications. Interactions between explosive targets and surface receptors occur through a combina- tion of host-guest binding, electrostatics, and $\pi$ $\pi$ stacking, resulting in fluorescence quenching of the QDs (Figure 11). The system was able to differentiate between DNT, TNT, tetryl, RDX and PETN at ppb levels. Application of machine learning also showed good classification results. ${ }^{161,162}$ Komikawa et. al report a chemical sensor for TNT using TNT binding peptides conjugated to $\mathrm{CdTe} / \mathrm{CdS}$ quantum dots. Detection is observed through fluorescence quenching in the presence of TNT. ${ }^{163}$ Qian et. al developed a two-component composite sensor using 3-mercaptopropionic acid-capped $\mathrm{SiO}_{2}$ spheres and L-cysteine capped CdTe quantum dots (QDs). Detection of TNT was achieved through the formation of Meisenheimer complexes between TNT and the amine moiety of cysteine. A relationship between TNT concentration and fluorescence emission was established by comparing the ratio between the fluorescence intensities of the two probes. A limit of detection of $3.3 \mathrm{nM}$ was reported. ${ }^{164}$ Other approaches to improve the selectivity of QDs towards explosives include using molecular-imprinted polymers (MIPs) ${ }^{146,165}$ and doping. ${ }^{166,167}$

\section{Micro-electromechanical systems}

The miniaturisation of E-noses towards portable, easy to use and cost effective devices for use in the field is a challenging task. One approach is to use micro-electromechanical systems (MEMS). MEMS is a process technology which describes the fabrication of microscopic devices consisting of a microprocessor and a mechanical component, contained in an integrated system, typically a silicon chip. ${ }^{168}$ The products of MEMS, or micro-machined devices, are used in a variety of industries and the versatility of MEMS devices lies in the variety of miniaturised mechanical components available such as micro-structures, sensors, actuators and electronics. These provide a means to sense, control or perform work at the microscale. As such, many sensor technologies already discussed above can be incorporated into MEMS, provided there is a means of miniaturisation.

Microcantilevers are versatile sensing plat- 

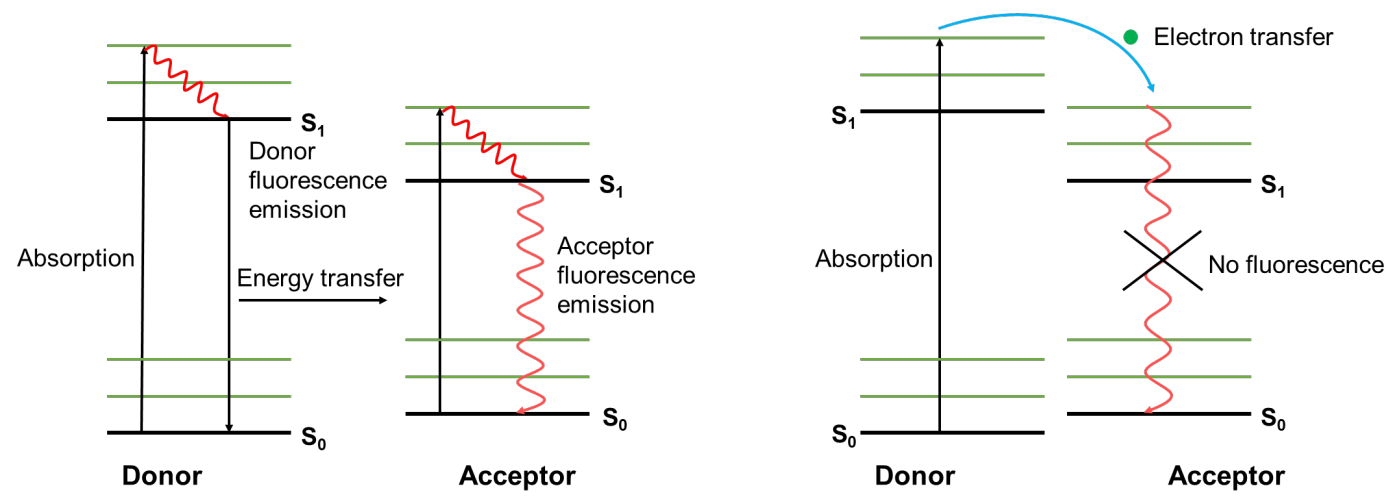

Figure 10: Energy level diagrams showing generalised FRET and PET processes. A) FRET involves transfer of non-radiative energy from an excited donor moiety to an acceptor. The interaction between donor and acceptor is distance dependent. B) PET involves electron transfer between a donor and acceptor moiety. Fluorescence is quenched in the PET-ON system (i.e. the system is in an 'off' state). Fluorescence emission is observed on disruption of the donor-acceptor system, whereby the system is in an 'on' state (not shown in diagram).

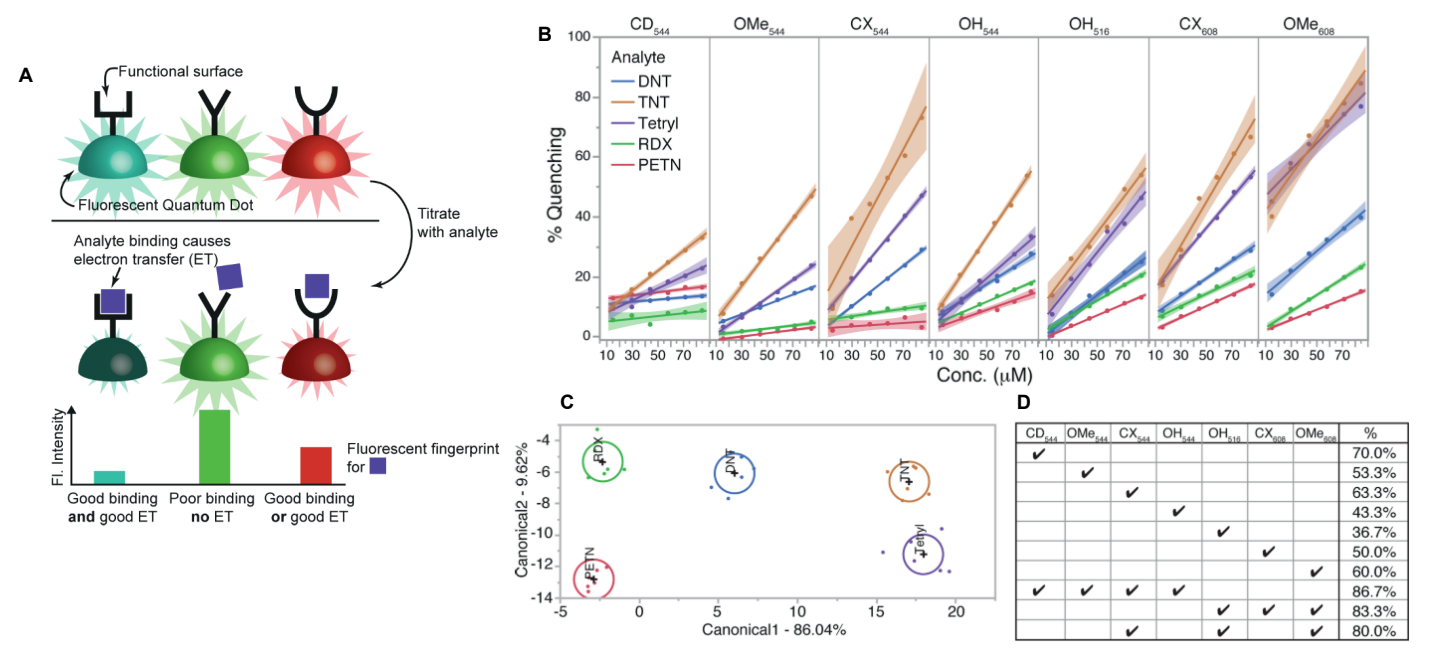

Figure 11: Fluorescent assay consisting of modified $\mathrm{CdO} / \mathrm{ZnS}$ quantum dots (QDs) A) Schematic showing sensing mechanism using the QD system B) Plots showing \%Quenching for each QD for a range of analyte concentrations. Machine learning classification of sensor data with C) showing Canonical plot (LDA) for \%Qdata set and D) showing the classification percentage for several subsets of the array. ${ }^{161}$

forms suitable for MEMS due to their high sensitivity, small size and low cost of manufacture. Different coatings can be applied to microcantilevers to achieve chemical, physical and biochemical characterisation data. ${ }^{169}$ Recently, polyethyleneglycol diacrylate (PEGDA) was used to fabricate microcantilevers for the detection of PETN, TNT and RDX. Detection was achieved using photothermal cantilever resonance spectroscopy (PCRS), through exploit- ing the resonance shifts in PEG-DA on absorption of IR radiation. IR-active analytes present on the microcantilever causes a reduction in the natural resonance frequency of the microcantilever, thus providing a molecular 'fingerprint'. Detection limits of $600 \mathrm{ng} / \mathrm{cm}^{2}$ and 40 $\mathrm{ng} / \mathrm{cm}^{2}$ were achieved, for RDX and PETN, respectively. ${ }^{170}$ Selectivity in microcantileverMEMS can be achieved by incorporating transducing elements with selective binding for ana- 
lytes of interest. Palaparthy et.al reports an Enose with piezo-resistive micro-cantilever sensors coated with mercaptobenzoic acid, methyl benzene thiol and amino thiol phenol for selective detection of TNT, RDX, and PETN at ppb levels. ${ }^{171}$ Holthoff et. al demonstrated selective detection of 2,4-dinitrotoluene (DNT) down to 500 parts-per-trillion (ppt) using microcantilevers functionalized with molecular imprinted polymers (MIPs). ${ }^{172}$ Udara et. al showed coating a silicon substrate microcantilever with polyvinylpyrrlidone led to enhanced detection of ammonium nitrate. ${ }^{173}$ An electrochemical MIP sensor for TATP was developed by Kassahun et. al, reporting detection limits of $26.9 \mu \mathrm{g} / \mathrm{L} .{ }^{174}$ Strle et. al reports a multichannel E-nose which uses $\mathrm{SiO}_{2}$ MEMS capacitors for multiple analyte detection. The comb-shaped capacitors (Figure 12) were functionalised with different silane molecules and selective adsorption of target analytes which resulted in a change in capacitance. Detection of TNT was possible at $3.5 \mathrm{ppt}$, within 1 second at room temperature. ${ }^{175}$ Chemical selectivity was further improved using machine learning. ${ }^{176}$

Zandieh et. al report the detection of RDX and PETN using a multi-modal sensor. The system consists of a microcantilever, microheater/micro-thermometer device with an IR laser. Identification of RDX, PETN and binary mixtures of each material was achieved, with LOD for RDX and PETN reported as $31 \mathrm{pg}$ and $49 \mathrm{pg}$, respectively. ${ }^{177}$ Analyte interrogation through use of opto-calorimetric IR spectra and micro-differential thermal analysis enabled selectivity and sensitivity of the system. Similarly, detection of TNT, RDX and DNT ${ }^{178,179}$ has been achieved using heat absorption monitoring (HAM) sensors, with selectivity achieved through monitoring temperature variation during the melting process. Quantities of TNT and RDX at 1 ppm and DNT at $20 \mathrm{ppb}$ were detected. A graphene-oxide HAM device was also developed with chemical selectivity for DNT and an LOD of 4.6 ppb. ${ }^{134}$

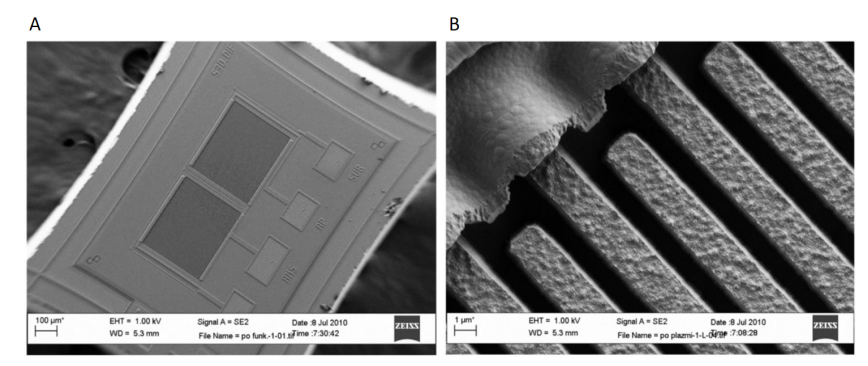

Figure 12: Scanning electron micrographs of the micro-capacitor sensor. (A) a pair of capacitors forming the differential sensor. (B) closeup detail of the comb-structure. ${ }^{175}$ Reproduced from ref. ${ }^{175}$ Copyright 2017 MDPI.

\section{Ion mobility spectrometry}

IMS remains one of the most popular techniques used in security and is the preferred analytical method for explosives detection worldwide. ${ }^{180}$ IMS is also used in the detection of illicit drugs ${ }^{181}$ and chemical warfare agents ${ }^{182}$ and in many areas outside of the security sector. Systems can exist as hand-held or desktop variants and can sample both particulates and vapours. In-field devices are portable, have low detection limits and are easy to use. Another major advantage of IMS when compared with other techniques is the ability to screen samples in seconds. This is particularly beneficial in operational environments such as airports, where fast screening methodologies are needed to process large passenger numbers and minimise delays.

The setup of most commercial IMS systems consists of four main components: a sample collection and introduction methodology, an ionisation chamber, a drift tube and detector (Figure 13). IMS functions by analysing ions from vaporised samples. Sample collection can be achieved using swabs or directly sampling vapour. Collected samples are thermally desorbed into a chamber and ionised. ${ }^{3} \mathrm{H},{ }^{241} \mathrm{Am}$ and ${ }^{63} \mathrm{Ni}$ can be used as ionisation sources ${ }^{183}$ but the latter is more commonly found in commercial devices. Due to safety concerns and stringent rules for transporting radioactive materials, there is now an increasing move towards the use of non-radioactive ionisation sources. Examples include; photoionisation, ${ }^{184}$ corona 
discharge ${ }^{185,186}$ and helium plasma ionisation (HEPI). ${ }^{187}$ Table 2 outlines some of the commercial systems currently in use and Table 3 shows recent advances in IMS for ETD.

\section{Recent developments}

Traditional methods for mimicking human wipe-sampling involved the use of a TLslip/peel tester or similar devices where pressure, speed and direction are controlled parameters. Such devices offered limited automation capability and suffered from human error associated with manual loading unloading of samples. A robotic variant of the TL-slip/peel tester was developed by Robinson et al., with the main advantage the ability to investigate multidirectional swiping with constant pressure and speed, as well as minimising human errors. ${ }^{198}$ Choi et al. report the use of different hydrophilic surfaces as smear matrices, in conjunction with a stainless steel roller to manually collect particulate trace explosives for detection with IMS. Detection of RDX and TNT were reported to be at several hundred nanograms. ${ }^{199}$ Although these values are much higher than what is currently achieved in field instruments, the study provides important fundamental data useful for characterising explosives on surfaces which may lead to the development of better swabs or collection methodologies. The effect of swab re-use on the collection efficiency was studied by DeGreeff who characterised wear using GC-MS and silhouette microscopy. Comparing two widely used materials, Nomex and teflon-coated fibreglass, collection efficiency was found to increase with re-use due to increased surface roughness. ${ }^{200}$

Various methods of chemical modification have been reported to improve IMS detection of exlosives. Chouyyok et al. modified swabs using phenyl-functionalised fibreglass to improve the collection efficiency of explosives. The enhanced swabs showed better performance compared to muslin, a commercially available swab material. ${ }^{201}$ Kelley et al. showed the addition of sulphuric acid to chlorate and perchlorate salts improved the availability of product ions in both thermal desorption MS and IMS-MS systems. ${ }^{202}$ The research is promising for detection of materials with low vapour pressures and also for the development of new swab materials, as realised in the form of a patented Naiform swab. ${ }^{203}$ Laster et. al compared the collection efficiency of modified polypyrrole films and commercial swabs for TNT. Polypyrrole and polypyrrole-poly[pyrrole-N-propionic acid] films were found to show greater interaction with TNT (Figure 14). ${ }^{204}$ Dopants can be used to generate reactant ions to improve the selectivity of product ions. Recently, Jiang et. al. reported detection of HMTD and TATP using dopant assisted positive ionisation IMS (DAPPI-IMS) in the presence of complex matrices. ${ }^{205}$ Acetone was used to improve the resolution of product ion peaks and detection limits for TATP and HMTD were reported to be $23.3 \mathrm{ng}$ and $0.2 \mathrm{ng}$, respectively. An improved thermal desorber capable of activation within 0.8 seconds of sample input is also reported which would benefit the short lifetimes of peroxide explosives. The technology could also be used for drug detection which favour electropositive ionisation. Tsai et al. also report the use of chemical modifiers to improve the detection of AN and UN. Detection was achieved using crown ethers and sugars to form adducts with the cationic and anionic constituents, respectively, for each explosive. Modified ions generated were identified using electrospray ionisation mass spectrometry (ESI-MS) and ESI high performance IMS mass spectrometry (ESIHPIMS-MS). ${ }^{206}$

Fundamental errors and experimental drift associated with determining reference $K_{0}$ values can lead to wide threshold windows in detection equipment and impair the accuracy of detection equipment. For operational equipment, these values are rarely disclosed, however $1-2 \%$ is reported by some manufacturers, ${ }^{207} .{ }^{208}$ Hauck et al. report an IMS design with a hermetically sealed drift tube to improve the accuracy of calculated $K_{0}$ values and overcome the effect of pressure on $K_{0}$ drift. An accuracy of $0.1 \%$ was achieved for a device using a ${ }^{63} \mathrm{Ni}$ ionisation source. ${ }^{209}$

The sensitivity of IMS can be enhanced through incorporating separation technologies 


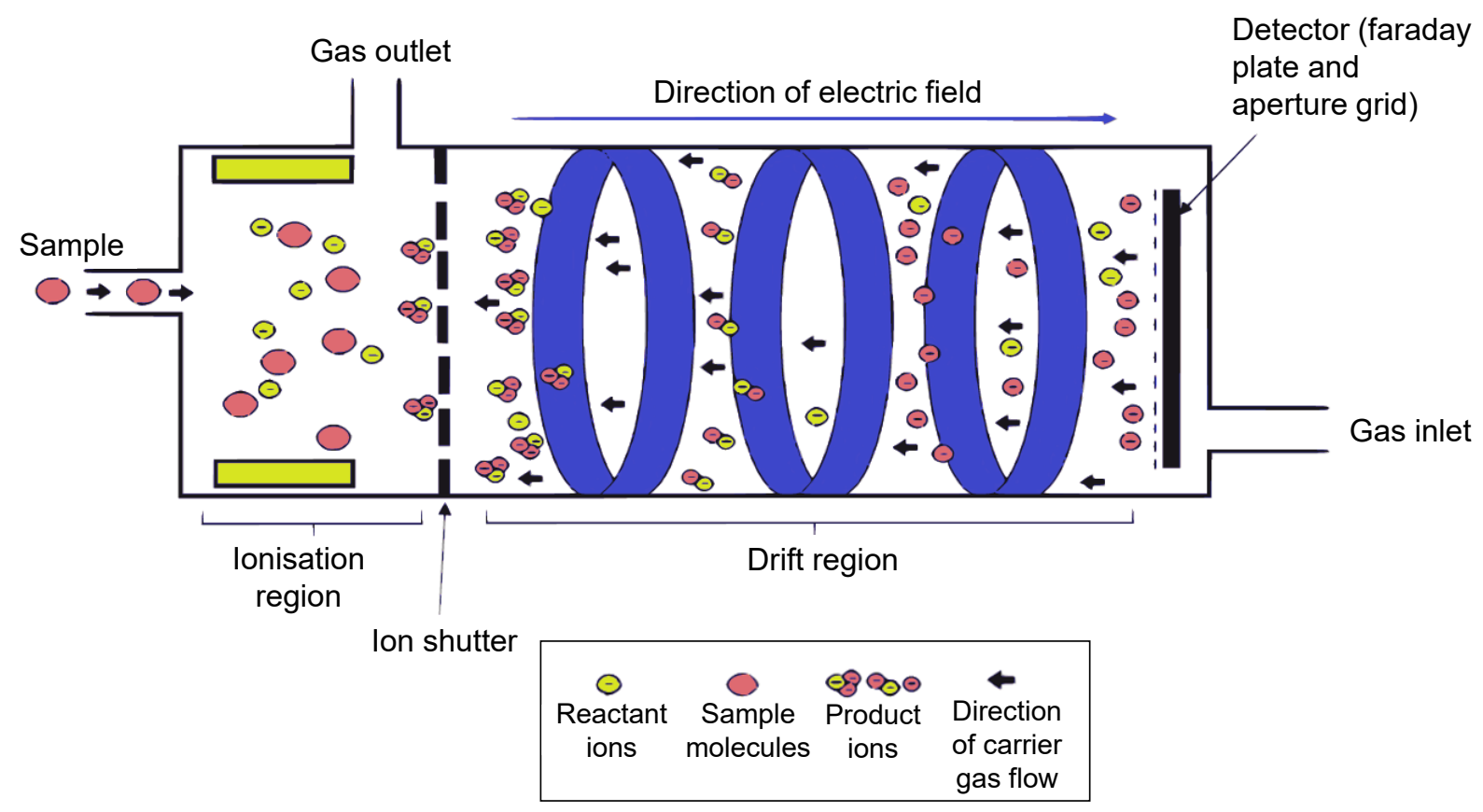

Figure 13: Typical set-up of an ion mobility spectrometer.

Table 2: Examples of IMS ETD devices currently in use

\begin{tabular}{|c|c|c|c|c|c|}
\hline Manufacturer & Model & Sample Type & Swab Type & Ionisation Method & Reference \\
\hline Bruker Daltonik GmbH & DE-tector & Particulate & Teflon ${ }^{\circledR}$-coated (PTFE) fiberglass & HEPI & 188 \\
\hline Bruker Daltonik GmbH & RoadRunner & $\begin{array}{l}\text { Particulate, } \\
\text { vapour }\end{array}$ & Teflon ${ }^{\circledR}$-coated (PTFE) fiberglass & HEPI & 189 \\
\hline L3 Technologies & QS-B220 & Particulate & Teflon ${ }^{\circledR}$-coated (PTFE) fiberglass & Photo ionisation & 190 \\
\hline Rapiscan Systems & ITEMISER 4DX & Particulate & $\begin{array}{l}\text { Teflon }{ }^{\circledR} \text { d-coated (PTFE) fiber- } \\
\text { glass }\end{array}$ & Corona discharge & 191 \\
\hline Rapiscan Systems & ITEMISER DX & Particulate & Teflon ${ }^{\circledR}$-coated (PTFE) fiberglass & ${ }^{63} \mathrm{Ni}$ & 192 \\
\hline Nuctech & TR2000DB-A & Particulate & Swab & ${ }^{63} \mathrm{Ni}$ & 193 \\
\hline Smiths Detection & IONSCAN 500DT & Particulate & Cotton, Nomex ${ }^{\circledR}$ & ${ }^{63} \mathrm{Ni}$ & 194 \\
\hline Smiths Detection & IONSCAN 600 & Particulate & Nomex ${ }^{\circledR}$ & Corona discharge & 195 \\
\hline Smiths Detection & $\begin{array}{l}\text { Multi-Mode } \\
\text { Threat Detec- } \\
\text { tor (MMTD) }\end{array}$ & $\begin{array}{l}\text { Particulate, } \\
\text { vapour, liquids }\end{array}$ & Cotton & ${ }^{63} \mathrm{Ni}$ & 196 \\
\hline Thermo Fisher Scientific & EGIS Defender & $\begin{array}{l}\text { Particulate, } \\
\text { vapour }\end{array}$ & Teflon ${ }^{\circledR}$-coated (PTFE) fiberglass & ${ }^{63} \mathrm{Ni}$ & 197 \\
\hline
\end{tabular}

such as High-Field Asymmetric Waveform Ion Mobility Spectrometry (FAIMS), mass spectrometry (MS) and tandem mass spectrometry (MS/MS). IMS-MS and IMS-MS/MS for explosives detection is well reported in literature and can detect both military and home-made explosives. ${ }^{210-214}$ ESI can be integrated with an IMS system to provide high resolution data and analysis of liquid phase samples. The Excellims GA2100 and GA2200 are examples of commercial ESI-IMS systems with the ability to detect 10 explosives, including thermally labile TATP and PETN. ${ }^{215,216}$ Recently, IMS was coupled to an orbitrap MS to produce a high resolution accurate mass (HRAM) device. Analyte peaks obtained for PETN and erythritol tetranitrate (ETN) using IMS-MS corresponded with peaks seen in a commercial IMS system. Studies conducted using ETN synthesised under different methods showed discrimination of analyte and impurity peaks, indicating the possibility of the technique being used to forensically identify sources of HMEs. ${ }^{217}$ Another modification of traditional IMS instruments is the use of lasers to achieve concurrent desorption and ionisation. Akmalov et. al compared the detection ability of this approach using pulsed and continuous wave lasers. Several nitro explosives were successfully detected, with analyte dissociation neglible in affecting detection. ${ }^{218}$ Sub- 
sequent studies by the same group report the detection threshold of TNT to be $10^{-14} \mathrm{~g} / \mathrm{cm}^{3}$, for a laser IMS system ${ }^{219}$ and improved sensitivity for the detection of TNT using dopants, for a laser FAIMS system. ${ }^{220}$ 


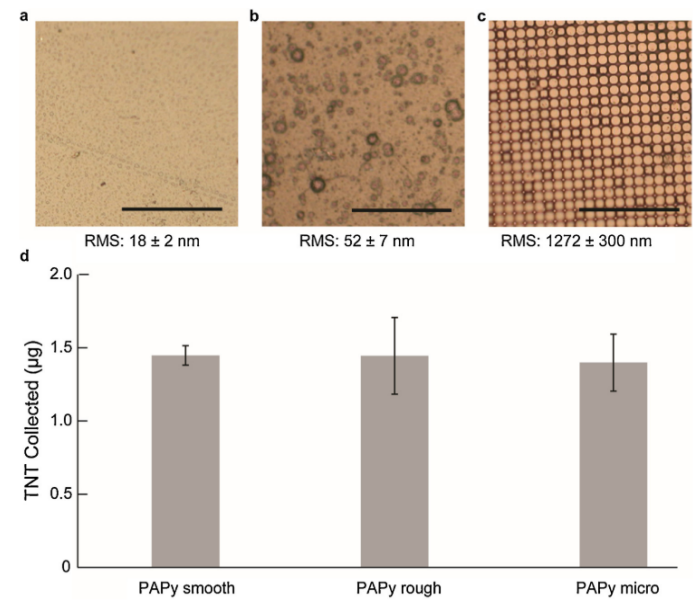

Figure 14: Study by Laster et. al into the effect of surface morphology on adhesion of TNT molecules. a-c) Microscopy images of PAPy films, d) Average collection of TNT by PAPy films with different surface roughness. ${ }^{204}$ Reproduced from ref. ${ }^{204}$ Copyright 2018 Elsevier.

Table 3: Recent developments involving IMS detection of explosives

\begin{tabular}{|c|c|c|c|c|c|}
\hline Ionisation source & Carrier gas & Dopant & Materials detected & LOD & Reference \\
\hline $266 \mathrm{~nm} \mathrm{Nd}^{3+}:$ YAG laser & Air & None & TNT, RDX & $\begin{array}{l}2 \mathrm{ppt}(\mathrm{TNT}), 5 \mathrm{ppt} \\
(\mathrm{RDX})\end{array}$ & 219 \\
\hline $\begin{array}{l}\text { Secondary } \\
\text { (SESI) }\end{array}$ & $\mathrm{N}_{2}$ & $\mathrm{KCl}$ & TNT & $1 \mu \mathrm{g} \mathrm{L}^{-1}$ & 221 \\
\hline Thermal ionisation & Air & $\mathrm{CCl}_{4}$ & TNT, RDX , PETN & $\begin{array}{l}0.15 \mathrm{ng} \quad(\mathrm{TNT} \text { re- } \\
\text { ported })\end{array}$ & 222 \\
\hline $\mathrm{Ni}^{63}$ & Air & $\mathrm{CCl}_{4}$ & $\begin{array}{l}\text { NG, } \\
\text { PETN }\end{array}$ & Not reported & 223 \\
\hline X-ray with Rhodium target & Air & - & Ammonia & $30-7500 \mathrm{ppt}$ & 224 \\
\hline SESI & $\mathrm{N}_{2}$ & - & $\begin{array}{l}\text { RDX, PETN, NG, } \\
\text { EGDN, TNT }\end{array}$ & Ppq & 225 \\
\hline
\end{tabular}

\section{Colorimetric kits}

Colorimetry describes techniques which use colour change to determine the presence of analytes in solution, usually through indicating the presence of specific functional groups. A wide range of applications exists for colorimetric kits ${ }^{226-228}$ and examples of commercially available kits for ETD are listed in Table 4 . Such kits are easy to use, exists in different forms i.e. sprays, swabs and pens and provides results in seconds. Thus, colorimetric kits are very useful as a diagnostic tool. As with colorimetric arrays discussed previously, technological advances have seen the integration of colorimetric kits with digital sensors for better colour discrimination. Many commercial systems exist as electronic portable devices which benefit from data storage, automated detection and ruggedness capability. Recent reviews covering luminescent approaches, design and de- ployment of colorimetric kits for security, are provided by Kangas $^{60}$ and Meaney. ${ }^{229}$

\section{Recent developments}

Colorimetric kits exploit luminescence, absorbance and fluorescence phenomena to elicit colour changes. Fluorescence quenching methods remain the most popular technique and an in-depth review can be found by Sun et. al. ${ }^{235}$ Such methods can be achieved through a variety of materials including; small molecules, metal organic frameworks (MOFs), polymers and functionalised nanoparticles. The basis of many nitroaromatic detection mechanisms exploit the electron withdrawing property of the $-\mathrm{NO}_{2}$ group, which deactivates the aromatic ring. As such, this makes nitroaromatic compounds good electron acceptors and charge transfer interactions between nucleophiles generally leads to the formation 
Table 4: Examples of commercially available colorimetric kits

\begin{tabular}{|c|c|c|c|c|c|}
\hline Manufacturer & Product name & Explosives detected & Test time & Detection mode & Reference \\
\hline Morphix $^{\circledR}{ }^{\circledR}$ & $\operatorname{TraceX}^{(\mathbb{R})}$ & $\begin{array}{l}\text { Nitroaromatics, nitramines/nitrate } \\
\text { esters, inorganic nitrates, chlo- } \\
\text { rates/bromates, peroxides, acids and } \\
\text { bases }\end{array}$ & $<3$ minutes & Naked eye & 230 \\
\hline ChemSee & $\begin{array}{l}\text { Portable explosive } \\
\text { test kit }\end{array}$ & $\begin{array}{l}\text { Nitroaromatics, nitramines, in- } \\
\text { organic nitrates, } \\
\text { rates/perchlorates }\end{array}$ & 20-60 seconds & Naked eye & 231 \\
\hline DetectaChem & SEEKERe & $\begin{array}{l}\text { Nitroaromatics, nitramines/nitrate } \\
\text { esters, inorganic nitrates, chlo- } \\
\text { rates/perchlorates, peroxides }\end{array}$ & Seconds & Digital & 232 \\
\hline BBI Detection & $\begin{array}{l}\text { Dry Explosive De- } \\
\text { tection Test Kit } \\
\text { (DETK) }\end{array}$ & $\begin{array}{l}\text { Nitroaromatics, nitroamines/nitrate } \\
\text { esters, nitrates, chlorates/bromates, } \\
\text { hydrogen peroxide }\end{array}$ & 3-6 minutes & Naked eye & 233 \\
\hline BBI Detection & $\begin{array}{l}\text { Liquid Explosive } \\
\text { Test Kit (LETK) }\end{array}$ & $\begin{array}{l}\text { Nitromethane, hydrazine, nitro- } \\
\text { glycerine, fuels, and precursor solvents, } \\
\text { peroxides, acids and bases }\end{array}$ & 1-2 minutes & Naked eye & 233 \\
\hline $\begin{array}{l}\text { Mistral Secu- } \\
\text { rity Inc. }\end{array}$ & DropEx & $\begin{array}{l}\text { TNT, Nitroaromatics, ni- } \\
\text { troamines/nitrate esters, inorganic } \\
\text { nitrates, perchlorates, peroxides, } \\
\text { inorganic oxidants, nitromethane }\end{array}$ & 5 seconds & Naked eye & 234 \\
\hline
\end{tabular}

of brightly coloured Meisenheimer complexes. Amines are commonly used and an example is shown in Figure 15 from the interaction of TNT and cysteine to produce a red Meisenheimer complex.

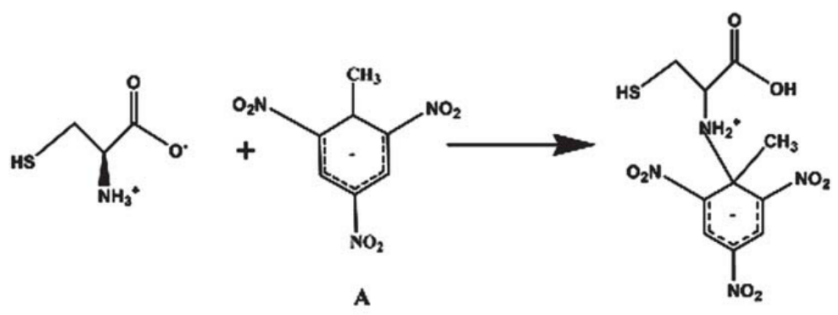

Figure 15: Example of a TNT-meisenheimer complex formed on interaction between TNT and cysteine. ${ }^{236}$ Reproduced from ref. ${ }^{236}$ Copyright 2013 RSC.

The Griess test is another traditional approach used to detect nitrate ester, nitramine and nitrate explosives such as AN and UN. Different mechanisms are used, including; alkali hydrolysis, $\alpha$-elimination, $\beta$-elimination and reduction of nitrates to produce nitrite ions. ${ }^{6}$ Zhang et al. report the development of a chemosensor for TNT and 2,4,6-trinitrophenol (TNP). The sensor probe features a Schiff base, naphthalene, which forms a red meisenheimer complex in the presence of TNT. TNP undergoes deprotonation and forms a yellow product. ${ }^{237}$ The reactions can also be observed using UV-VIS and fluorescence spec- troscopy, with the latter showing increasing fluorescence quenching with respect to TNT and TNP concentration. Choodum et. al developed several test kits for TNT by trapping different colorimetric reagents (tetramethylammonium hydroxide, ethylenediamine and potassium hydroxide) in polyvinyl alcohol or polyvinyl chloride hydrogels. ${ }^{57-59}$ Each test kit is portable, low cost and can be frozen for storage. Quantitative data from the resultant coloured meisenheimer complexes is provided through a conventional smartphone camera. The UN-1 kit exploits the acidic nature of UN to achieve selectivity against urea. The reaction proceeds under neutral conditions using p-dimethylaminocinnamaldehyde (p-DMAC), forming a red pigment within 60 seconds. The test can exist as a swab test with liquid reagent or as a spray, with detection limits of $100 \mu \mathrm{g} / \mathrm{cm}^{2} .{ }^{238}$ Zhao et. al developed a sensor array for the simultaneous detection of 10 explosives. The authors used time-resolved reduction of indigo carmine by dithiothreitol and discrimination was achieved by simultaneously monitoring 6 absorption peaks to produce a 'colorimetric fingerprint'. The limit of detection was $1.5 \mu \mathrm{M}$. This approach was also effective when tested against contaminated water samples. ${ }^{239}$

Peroxide-based explosives are generally detected through indirect means, after undergoing decomposition to hydrogen peroxide. Var- 

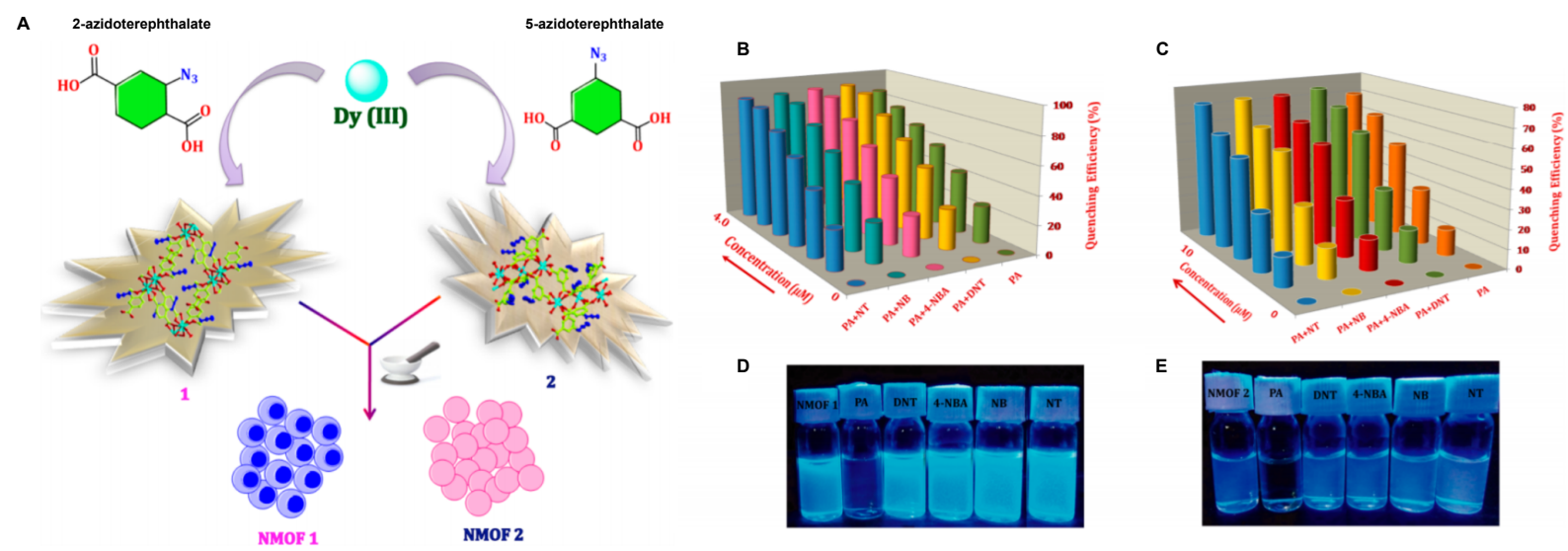

Figure 16: MOF-based fluorescent probes for detection of TNP using dysprosium centres A) Schematic showing formation of MOFs derived from two carboxylate ligands, 2-azidoterephthalate $\left(2 \mathrm{~N}_{3}\right.$-TPA) and 5-azidoterephthalate $\left(5 \mathrm{~N}_{3}\right.$-IPA), producing MOFs 1 and 2, respectively. Fluorescence quenching experiments in the presence of TNP and other nitro explosives to aqueous suspensions of B) MOF 1 and C) MOF 2. Optical images of aqueous dispersion of MOFs on addition of various nitro explosives under UV light for D) 1 and E) $2 .{ }^{240}$

ious approaches can be used, involving enzyme catalysed reactions. The 'Acro-P.E.T' is a 2-step field kit which involves liberation of hydrogen peroxide through acid hydrolysis of suspect materials, followed by oxidation of a chromogenic substrate, 2,2'-Azino-bis(3ethylbenzthiazoline-6-sulfonic acid) diammonium salt in the presence of horseradish peroxidase to produce a blue-green colour. ${ }^{241}$ Hydrogen peroxide present in detergents, cosmetics and cleaning products can lead to false positive results. Schulte-Ladbeck et al. overcame this by using catalase to remove trace hydrogen peroxide in samples prior to testing, followed by decomposition of explosive material through UV photolysis and detection of the resultant hydrogen peroxide using 2,2'-azino-bis(3ethylbenzothiazoline)-6-sulfonate (ABTS) and p-hydroxyphenylacetic acid (pHPAA) in the presence of horseradish peroxidase. ${ }^{242}$ Several thin film sensors were developed by Fan et. al using fluorenylboronate esters. Detection of TATP vapour was achieved through the generation of $\mathrm{H}_{2} \mathrm{O}_{2}$ using Amberlyst-15. A detection limit of $40 \mathrm{ppb}$ within 60 seconds was achieved, with the speed of detection enhanced through blending the boronate ester mixtures with tetra-n-butylammonium hydroxide. ${ }^{243}$

MOFs have received a lot of interest due to their many tunable properties such as; porosity, structure, topology and the variety of mechanisms with which to elicit responses. Several authors report the development of MOF materials capable of multi-target detection. Wang et. al incorporated a cationic dye, (E)-4-(4-(dimethylamino)styryl $)-1-$ methylpyridin-1-ium (DMASM), into a Zn-MOF, $\quad\left(\mathrm{Zn}_{8}(\mathrm{Ad})_{4}(\mathrm{BPDC})_{6} \mathrm{O} \cdot 2 \mathrm{Me}_{2} \mathrm{NH}_{2}\right.$, $\mathrm{Ad}=$ adeninate; $\mathrm{BPDC}=$ biphenyldicarboxylate) . The resultant probe enables two fluorescence quenching approaches, allowing differentiation between nitroaromatic, nitramide and nitrate esters explosives, including the taggant DMNB. ${ }^{245}$ In a similar study, Fu et. al incorporated an anionic dye, 8-hydroxy-1,3,6pyrenetrisulfonicacid (HPTS), into a Zn-MOF, $\left[\mathrm{Zn}(\mathrm{TIPA})\left(\mathrm{NO}_{3}{ }^{-}\right)_{2}\right] \cdot 5 \mathrm{H}_{2} \mathrm{O} \quad(\mathrm{TIPA}=(\operatorname{tri}(4-$ imidazolylphenyl)amine)). Using ratiometric fluorescence, the authors show detection of RDX is possible down to 39 ppm. ${ }^{246}$ Both MOF constructs are reusable. Jurcic et. al report the development of a MOF array for the differentiation between TNT, tetryl, RDX and PETN with limits of detection down to ppm. ${ }^{247}$ Various signal transduction approaches have been adopted to enhance the sensitivity of MOF materials. Recently, a $\mathrm{Cu}-\mathrm{MOF}$ was linked to an optical fibre Fabry-Pérot interferometer (FPI) to achieve real-time detection of nitrobenzene. ${ }^{248}$ Integration of a europium- 

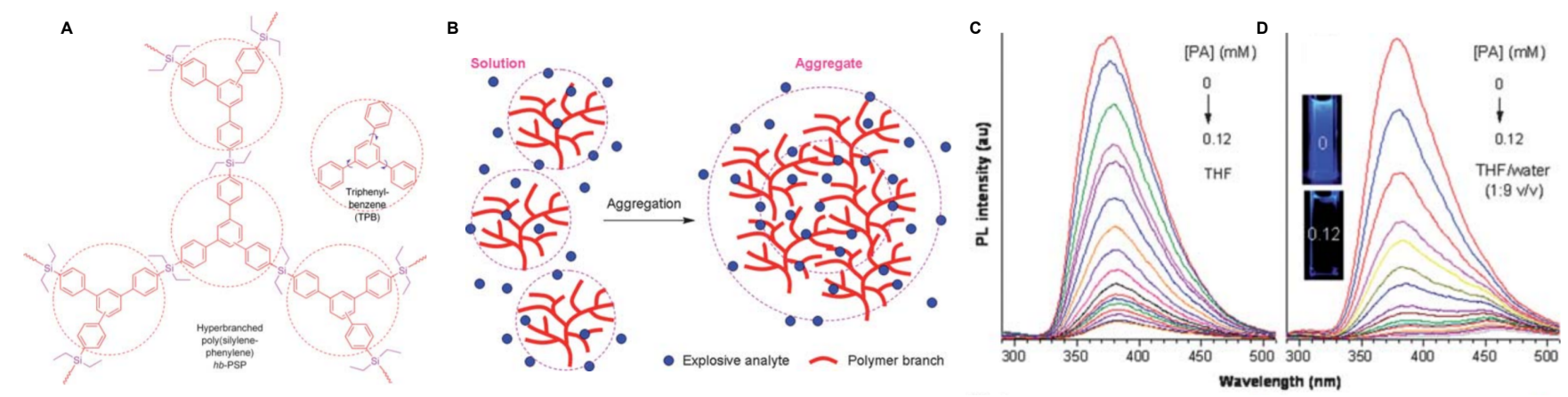

Figure 17: AIE hyperbranched poly(silylenephenylene) (hb-PSP) for the detection of trinitrophenol (picric acid, PA). A) Structure of hb-PSP with repeat units tri-phenylbenzene. B) In-solution and aggregate forms of hb-PSP in the presence of explosive. C) Detection of trinitrophenol using hbPSP in tetrahydrofuran (THF) and D) THF-water mixture. Inset image shows the active hb-PSP and fluorescence quenching of hb-PSP on addition of $0.12 \mathrm{mM}$ trinitrophenol. ${ }^{244}$ Reproduced from ref. ${ }^{244}$ Copyright 2010 RSC.

MOF with a hydrogel optical fibre was also shown to be an effective sensor for TNP. ${ }^{249}$ Mukherjee et. al synthesised MOFs using dysprosium incorporated into two carboxylate ligands for the detection of TNP, achieving limits of detection in the $\mu \mathrm{M}$ range (Figure 16). ${ }^{240}$ Additional metal centres which have been used in MOFs for explosives detection include; sodium, ${ }^{250}$ indium, ${ }^{251}$ cadmium,,${ }^{252}$ zinc $^{253}$ and lanthanide elements; europium ${ }^{254,255}$ and terbium. ${ }^{256,257}$

Conjugated polymers are effective candidates for the detection of nitroaromatic explosives because they are excellent electron donors. One mechanism exploited for ETD is the 'molecular wire' effect, which allows for the conductive quenching of connected polymer molecules on adsorption of a target analyte. ${ }^{258}$ Significant enhancement over molecule-based fluorophores can be achieved ${ }^{259}$ and this effect has been used to develop 'Amplifying fluorescent polymers (AFP)', as seen in the commercially available Fido explosives detectors which have detection limits down to ppt levels. ${ }^{260-262} \mathrm{Ma}$ et.al utilised the molecular wire effect through a hydrophillic polymer consisting of a carbazolebased backbone and diethanolamine-based side groups. The presence of hydroxyl groups on the polymer facilitated H-bonding with nitroaromatic explosives and signal amplification. The authors report selective detection of DNT and TNT with detection limits of $7.4 \times 10^{-7} \mathrm{M}$ and $1.1 \times 10^{-6} \mathrm{M}$, respectively. ${ }^{263}$ Recent developments in conjugated polymers has seen the use of aggregation-induced emission (AIE) materials, whereby polymer fluorophores exhibit low emission in a dissolved state but strong emission on aggregation. The effect is realised through free vibrational and rotational intramolecular motions which dissipate exciton energy of the polymer in solution. Aggregation of polymer molecules leads to conformational changes (i.e. $\pi-\pi$ stacking), which restricts these intramolecular motions, enabling radiative decay of exciton energy and emission. ${ }^{264}$ To date, a number of branched and linear AIE polymers have been reported for many nitroaromatic explosives. ${ }^{265}$ An example of a hyperbranched AIE polymer was reported by Liu et.al using poly(silylenephenylene) for the detection of TNP. ${ }^{244}$ The polymer's globular structure with numerous cavities results in high surface area for the binding of TNP molecules as well as improving exciton migration (Figure 17). Wu et. al used triphenylamine-based materials with dimethyl sulfoxide/water-mediated AIE to detect TNP. ${ }^{266}$

Carbazole-based nanostructures developed by the Zhao group have shown successful identification between classes of explosives, using different fluorescence quenching mechanisms. A two-member construct made up of nanofibres and nanoribbons was used by Zhu et. al. By proportioning the fluorescence quenching ratios 
between each sensor, nitroaromatic, nitramine, nitrate esters and ammonium nitrate explosives were identified at ng-levels. ${ }^{267}$ Using the same carbazole nanofibres by Zhu, along with a $\mathrm{Co}^{2+}$-coordinated analogue, Xiong et. al developed a binary polymer able to discriminate between six classes of explosives. Peroxide explosives were detected indirectly through active decomposition to produce $\mathrm{H}_{2} \mathrm{O}_{2}$, and reduction of $\mathrm{Co}^{+}$. Conversely, detection of nitroaromatic, nitramine, nitrate esters and black powder is achieved through electron transfer between the nanofibre network and explosive. The resultant fluorescence quenching by different parts of the same molecule enables selectivity and detection in the ng range. ${ }^{268}$ Self-assembling carbazole nanospheres were developed by $\mathrm{Ma}$ et al. for the detection of TNP in solution, with a detection limit of $120 \mathrm{nM}^{269}$

Due to their unique optical, catalytic and electronic properties, there is continuing interest in the use of nanoparticles to improve the speed, sensitivity and selectivity of colorimetric approaches. Au-Ag nanoparticles functionalised with $\beta$-cysteamine were developed by Arshad et. al and incorporated onto a paper sensor for the detection of TNT. ${ }^{270}$ The addition of cetyltrimethylammonium bromide surfactant (CTAB) enhanced the rate of reaction and selectivity was shown against TNP, DNT and NB explosives. Idros et. al used 3-aminopropyltriethoxysilane (APTES) to produce aminefunctionalised $\mathrm{SiO}_{2}$ nanoparticles for the detection of TNT. A red-green colour change on formation of $\mathrm{NH}_{3}$-TNT meisenheimer complexes is observed and discrimination between DNT was achieved by measuring the change in reflective properties of the self-assembling film. ${ }^{271}$ Tawfik et. al used polythiophene coated CdTe QDs to detect TNP. The amphiphilic sensors were coupled with a smartphone to facilitate on-site detection with LOD being $0.56 \times 10^{-9} \mathrm{M} .^{272}$

A fluorescence sensor using 4,5di(hetero)arylpyrimidine dyes has been developed, with ability to screen for a range of nitroaromatic explosives with detection limits between $10^{-4}-10^{-6} \mathrm{M}$. The sensor has been subsequently realised in the form a commercial device called 'Nitrosensor'. ${ }^{273} \mathrm{Hu}$ et. al report a DNA-based assay for the detection of TNT which uses a dual-identification approach. The DNA construct is capped at one end with an aptamer specific for TNT and with copper nanoparticles ( $\mathrm{CuNPs}$ ) at the other end. Exploiting the fluorescence properties of the CuNPs and with use of inductively coupled plasma mass spectrometry (ICPMS), identification was achieved with high selectivity and detection limits of $0.17 \mathrm{ng} / \mathrm{mL}$ and $0.32 \mathrm{pg} / \mathrm{mL}$ were achieved using fluorimetry and ICPMS, respectively. ${ }^{274}$ An electrochemical aptamer sensor specific for detection of TNT was also developed by Roushani et. al, consisting of gold nanoparticles deposited on fullerene (C60) and with a detection limit of $0.17 \mathrm{fM}{ }^{275}$ Table 5 shows recent developments in colorimetric approaches to ETD. 
Table 5: Colorimetric approaches to ETD - recent developments for MOF's, polymers, functionalised nanomaterials and fluorescent molecules. Physical parameters used for detection and LOD's are reported. ${ }^{1}$ MOF formula given.

\begin{tabular}{|c|c|c|c|c|c|c|c|}
\hline Type & Agent & $\begin{array}{l}\lambda_{\mathrm{Abs} \max } \\
(\mathrm{nm})\end{array}$ & $\begin{array}{l}\text { Emission } \lambda \\
(\mathrm{nm})\end{array}$ & $\begin{array}{l}\text { Excitation } \\
\lambda(\mathrm{nm})\end{array}$ & Analyte & LOD & $\overline{\text { Ref. }}$ \\
\hline & $\begin{array}{l}\mathrm{Cu} \text { nanoclusters capped } \\
\text { polyethylene imine }\end{array}$ & - & 480 & 330 & TNT & $0.05 \mathrm{nM}$ & 276 \\
\hline \multirow[t]{7}{*}{$\begin{array}{l}\text { Functionalised } \\
\text { nanoparticles }\end{array}$} & $\begin{array}{l}\text { Ag nanoparticles modified with } 4- \\
\text { amino-3-hydrazino-5-mercapto-- } \\
1,2,4 \text {-triazole }\end{array}$ & $\begin{array}{ll}\text { Not re- } \\
\text { ported }\end{array}$ & - & - & TNP & $0.13 \mathrm{nM}$ & 277 \\
\hline & $\begin{array}{l}\text { Mercaptoethylamine-capped Au } \\
\text { nanopaticles and mercaptopropi- } \\
\text { onic acid-capped CdSe quantum } \\
\text { dots }\end{array}$ & - & 540 & - & TNT & $21.9 \mathrm{nmol} \mathrm{L}^{-1}$ & 278 \\
\hline & $\begin{array}{l}\text { N,N-Dimethyl-p- } \\
\text { phenylenediamine with } \quad \mathrm{Fe}_{3} \mathrm{O}_{4} \\
\text { nanoparticles }\end{array}$ & 554 & - & - & TATP & $0.47 \mathrm{mg} \mathrm{L}^{-1}$ & 279 \\
\hline & $\mathrm{ZnCr}_{2} \mathrm{O}_{4}$ nanoparticles & 410 & - & - & TNP & $0.1 \mu \mathrm{M}$ & 280 \\
\hline & $\begin{array}{l}\mathrm{Ag} \text { nanoparticles and } 3,3^{\prime}, 5,5^{\prime}- \\
\text { tetramethylbenzidine (TMB) }\end{array}$ & 655 & - & - & TATP & $0.31 \mathrm{mg} \mathrm{L}^{-1}$ & 281 \\
\hline & {$\left[\mathrm{Zn}_{3}(\mathrm{~L})_{2}(\right.$ bipy $\left.)\left(\mu_{3}-\mathrm{OH}\right)_{2}\right] \cdot 3 \mathrm{H}_{2} \mathrm{O}$} & - & 363 & 281 & DNT, TNP & $400 \mu \mathrm{M}$ & 282 \\
\hline & $\mathrm{Ag} @ \mathrm{Zn}(\mathrm{TA}) \cdot\left(\mathrm{H}_{2} \mathrm{O}\right) \cdot(\mathrm{DMF})$ & 652 & - & - & TATP & $0.1 \mathrm{mg} \mathrm{L}^{-1}$ & 283 \\
\hline \multirow[t]{5}{*}{ MOF's ${ }^{1}$} & $\begin{array}{l}{\left[\left(\mathrm{CH}_{3}\right)_{2} \mathrm{NH}_{2}\right]\left[\mathrm{Eu}_{3}\left(\mu_{3}-\mathrm{OH}\right)(1,4-\right.} \\
\left.\mathrm{BDC})_{3}(\mathrm{HCOO})_{3}\right]\end{array}$ & 263 & 617 & 263 & $\begin{array}{l}\text { Tetryl, } \\
\text { TNP, TNT }\end{array}$ & $20-140 \mathrm{mg} / \mathrm{mL}$ & 284 \\
\hline & {$\left[\mathrm{Zn}_{4} \mathrm{~L}\left(\mathrm{H}_{2} \mathrm{O}\right)_{4} \cdot(\text { solvent })\right]_{\mathrm{n}}$} & - & 348 & 315 & $\begin{array}{l}\text { RDX, } \\
\text { PETN, } \\
\text { TNT, } \\
\text { DNT, } \\
\text { Tetryl }\end{array}$ & ppm & 247 \\
\hline & {$\left[\mathrm{Dy}\left(2 \mathrm{~N}_{3-}^{-}\right.\right.$} & - & 437,673 & 333 & TNP & $0.04 \mu \mathrm{M}$ & 240 \\
\hline & $\begin{array}{l}\left.\mathrm{TPA})_{2}\left(\mathrm{H}_{2} \mathrm{O}\right)\left(\mathrm{CH}_{3} \mathrm{OH}\right)\right]_{\infty} \\
{\left[\mathrm{Zn}(\mathrm{PBPCA})\left(\mathrm{H}_{2} \mathrm{O}\right)_{2}\right] \mathrm{Q}[6] \cdot 21 \mathrm{H}_{2} \mathrm{O}}\end{array}$ & - & 346 & 290 & TNP & $3.20 \times 10^{-7} \mathrm{M}$ & 285 \\
\hline & Pyrenyl-fluorene copolymers & - & 461 & - & $\begin{array}{l}\mathrm{H}_{2} \mathrm{O}_{2} \\
\text { TATP }\end{array}$ & $1.6 \mathrm{ppb}\left(\mathrm{H}_{2} \mathrm{O}_{2}\right)$ & 286 \\
\hline \multirow[t]{6}{*}{ Polymers } & $\begin{array}{l}\text { Fluorene substituted silica micro- } \\
\text { spheres }\end{array}$ & - & 525 & - & PETN & Not reported & 287 \\
\hline & Polyfluorene probe, PF6-Boc & - & - & 365 & RDX & $0.041 \mathrm{ppt}$ & 288 \\
\hline & $\begin{array}{l}\text { Carbazole and tetraphenylethylene } \\
\text { copolymer }\end{array}$ & - & 515 & - & TNT & $74 \mu \mathrm{M}$ & 289 \\
\hline & $\begin{array}{l}\text { Glutaraldehyde and chitosan } \\
\text { copolymer }\end{array}$ & - & 445 & 370 & TNP & $2.8 \mathrm{nM}$ & 290 \\
\hline & $\begin{array}{l}\text { Dimethyl-5-(pyren-1- } \\
\text { ylmethyleneamino)isophthalate }\end{array}$ & - & 469 & 365 & TNP & $10 \mathrm{nM}$ & 291 \\
\hline & $\begin{array}{l}2,4,6 \text {-triformyl phenol/amine sys- } \\
\text { tem }\end{array}$ & - & 590 & - & TATP & $0.2 \mathrm{ppb}$ & 292 \\
\hline \multirow[t]{6}{*}{$\begin{array}{l}\text { Fluorescent } \\
\text { molecules }\end{array}$} & $\begin{array}{l}\text { Azetidine derivative of naphthyldi- } \\
\text { imide }\end{array}$ & - & 650 & - & TATP & $0.5 \mu \mathrm{g} \mathrm{mL}-1$ & 293 \\
\hline & $\begin{array}{l}\text { 4-(dicyanomethylene)-2-methyl- } \\
6 \text {-(4-dimethylaminostyryl })-4 \mathrm{H}- \\
\text { pyran })\end{array}$ & - & 620 & - & $\begin{array}{l}\text { RDX, } \\
\text { HMX, } \\
\text { PETN }\end{array}$ & $\begin{array}{lr}1 \text { pmol } & \text { (RDX } \\
\text { and } & \text { HMX), } \\
1-10 & \text { pmol } \\
(\text { PETN }) & \end{array}$ & 294 \\
\hline & $\begin{array}{l}\text { Quinoline-benzimidazole conju- } \\
\text { gate }\end{array}$ & - & 442 & 369 & TNP & $4.86 \mathrm{ppb}$ & 295 \\
\hline & Curcumin conjugate & - & 516 & - & TNP & $11 \times 10^{-8} \mathrm{M}$ & 296 \\
\hline & Boronate ester quinoline & - & 520 & 365 & $\mathrm{H}_{2} \mathrm{O}_{2}$ & $150 \mathrm{ppt}$ & 297 \\
\hline & Polyaromatic imine conjugates & - & 410,492 & 308 & NB & $0.013 \mu \mathrm{M}$ & 298 \\
\hline
\end{tabular}




\section{Raman spectroscopy}

Raman spectroscopy involves the collection and analysis of scattered photons to provide information on molecular vibrations and hence sample identification and quantitation. The technique is widely used and advantages include; high selectivity, fast analysis times, minimal sample preparation and the ability to analyse solid, liquid and gaseous samples. In addition, analysis is carried out in a non-destructive manner and the technique offers stand-off detection capabilities. As such, these features are of great interest in the counter-terrorism community and such applications have been reviewed extensively for Raman ${ }^{299,300}$ and its most common variants; surface enhanced Raman spectroscopy (SERS) ${ }^{301-303}$ and spatially offset Raman spectroscopy (SORS). ${ }^{304,305}$ Examples of commercially available Raman systems are listed in Table 6. SERS overcomes the low sensitivity of conventional Raman through adsorption of analyte molecules onto a roughened metal surface, resulting in strong enhancement of the analyte's Raman signals. Significant enhancement factors and the capability for single-molecule detection using noble-metal nanostructures ${ }^{306,307}$ makes SERS a promising approach for explosives detection. SORS allows through-barrier analysis of opaque or semitransparent materials leaving samples intact. This makes the technology desirable for liquid screening and has been realised in the commercially available Agilent Insight and RESOLVE systems, widely used in UK airports.

\section{Recent developments}

SERS enhancement is attributed to both chemical and electromagnetic contributions. The latter process provides a much greater enhancement effect and is most significant when the surface plasmon frequency of the metal surface is in resonance with incident radiation. ${ }^{316}$ Surface plasmon resonance can be tuned by changing the size, morphology and spatial positioning and identity of nanostructures. ${ }^{317,318}$ As such, a range of nanostructures have been developed for explosives detection, including; rods, ${ }^{319}$ tubes, ${ }^{320}$ wires, ${ }^{321}$ prisms ${ }^{322,323}$ and octahedra. ${ }^{324}$ Additional examples of SERS substrates can be found in Table 7 . The chemical enhancement is generally considered to be due to charge transfer between analyte and metallic nanoparticles. ${ }^{325-327}$ Work towards exploiting this effect for explosives detection has led to the development of functionalised nanoparticles, with common linking agents being; APTES (3-aminopropyltriethoxysilane) ${ }^{328}$ DACH (trans-1,2-Diaminocyclohexane) ${ }^{329}$ and PATP (p-aminothiophenol (PATP). ${ }^{330}$ As with IMS devices, there is a need for convenient sample delivery and separation/pre-concentration of complex sample matrices for Raman-based techniques. Piorek et al. developed a microfluidic system with a SERS sensor and showed detection of 2,4-dinitrotoluene (DNT) down to $1 \mathrm{ppb}$ of gaseous phase. ${ }^{331}$ The system provides continuous, real-time sample analysis. A large surface-to-volume is achieved using shallow channels of $4-40 \mu \mathrm{m}$, enabling preconcentration of the sample and trace-level detection. 
Table 6: Examples of commercially available ETD Raman systems

\begin{tabular}{|c|c|c|c|c|c|}
\hline Manufacturer & Model & Laser & Excitation wavelength & Technology & Reference \\
\hline Smiths Detection Inc. & ACE-ID & Diode & $785 \mathrm{~nm}$ & Raman & 308 \\
\hline Nuctech & RT1003 series & Diode & $830 \mathrm{~nm}$ & Raman & 309 \\
\hline Thermo Fisher Scientific Inc. & FirstDefender RMX & Diode & $785 \mathrm{~nm}$ & SORS & 310 \\
\hline Thermo Fisher Scientific Inc. & Gemini Analyzer & Diode & $785 \mathrm{~nm}$ & IR and Raman & 311 \\
\hline $\begin{array}{l}\text { Agilent (formerly Cobalt Light Sys- } \\
\text { tems) }\end{array}$ & $\begin{array}{l}\text { Insight } 100 \mathrm{M} \text { and } \\
200 \mathrm{M}\end{array}$ & Diode & $830 \mathrm{~nm}$ & SORS & 312 \\
\hline $\begin{array}{l}\text { Agilent (formerly Cobalt Light Sys- } \\
\text { tems) }\end{array}$ & RESOLVE & Diode & $830 \mathrm{~nm}$ & SORS & 313 \\
\hline Real-Time Analyzers Inc. & $\begin{array}{l}\text { Portable SERS Ana- } \\
\text { lyzer }\end{array}$ & Diode & $785 \mathrm{~nm}$ & SERS & 314 \\
\hline Hamamatsu & $\begin{array}{l}\text { C13560 spectroscopic } \\
\text { module }\end{array}$ & Diode & 785 & SERS & 315 \\
\hline
\end{tabular}

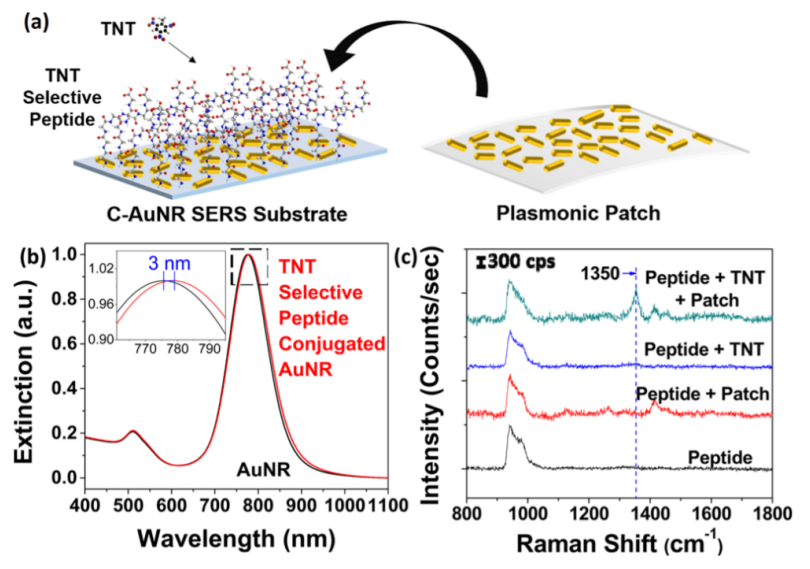

Figure 18: SERS 'plasmonic patch' for the collection and analysis of explosives as described in ref. ${ }^{332}$ A) Schematic representing vapour detection of TNT via peptide-conjugated gold nanorods. B) Characterisation of bare and peptide conjugated gold nanorods using UV-Vis spectroscopy. C) Raman data showing vaporphase detection of TNT.

Shi et al. report the development of a chemically modified SERS substrate for the detection of inorganic and organic explosives. Silver nanowires were manufactured with diethyldithiocarbamate (DDTC) ligands to produce a positively charged system. SERS detection was achieved using an excitation wavelength of $785 \mathrm{~nm}$. The detection of perchlorates $\left(\mathrm{ClO}_{4}^{-}\right)$, chlorates $\left(\mathrm{ClO}_{3}^{-}\right)$, nitrates $\left(\mathrm{NO}_{3}^{-}\right)$and 2,4-dinitrophenol were reported to be 2, 1.7, $0.1,45.8$, and $36.6 \mathrm{ng}$, respectively. ${ }^{333}$ The flexible substrate can be used as a swab and this is a promising advancement of SERS as a ETD technique for use in operational screening. Other flexible substrates have also been reported. Liyange et. al fabricated gold tri- angular nanoprisms onto an APTES functionalised glass coverslip followed by transfer onto a flexible adhesive tape. The resulting sensor showed detection of TNT down to 900 parts per quadrillion (ppq) and $56 \mathrm{ppq}$ for RDX and PETN, using a commercial off the shelf Raman system. ${ }^{323}$ The 'plasmonic patch' developed by Gupta et. al. is a transparent flexible PDMS film decorated with gold nanorods which can be added to different SERS substrates, leading to enhanced sensitivity ${ }^{332}$ (Figure 18). Liu et. al also report development of a flexible substrate, by immobilising silver nanoparticles onto a composite sponge surface consisting of polyurethane and polydopamine. Perchlorates, chlorates and nitrates were detected at subnanogram quantities. ${ }^{334}$

Non-plasmonic substrates including graphene and semiconductor materials generally have low enhancement capabilities, however, their strong charge transfer properties ${ }^{335,336}$ have been used effectively with noble nanoparticles for detection of many explosives. Examples include $\mathrm{ZnO},{ }^{337}$ graphene oxide ${ }^{338,339}$ and $\mathrm{TiO}_{2} \cdot{ }^{340}$ The introduction of oxygen vacancies can improve Raman enhancement of semiconductors and this can be achieved through surface and atomic defects. ${ }^{341}$ Ben-Jaber et al. report the use of photo-induced SERS (PIERS) for the detection of TNT, DNT, RDX and PETN at concentrations of $7 \mu \mathrm{g} / \mathrm{L}, 0.1 \mu \mathrm{g} / \mathrm{L}, 2.2 \mathrm{mg} / \mathrm{L}$ and 3.2 $\mathrm{mg} / \mathrm{L}$, respectively ${ }^{342}$ (Figure 19). PIERS signals showed enhancement compared with SERS for all explosives studied, with a 20-fold increase achieved for RDX. Substrate regeneration was achieved using UV-light. Additionally, Glass et. al studied the surface oxygen va- 
cancy states of different metal oxide substrates, including $\mathrm{TiO}_{2}, \mathrm{ZnO}$ and $\mathrm{WO}_{3} \cdot{ }^{343}$ Differences observed in vacancy formation and healing lifetimes of these materials could help guide development of PIERS substrates. Given the UV pre-irradiation step is sample-independent and the proven versatility of SERS in detecting a range of organic and inorganic explosives, ${ }^{344-346}$ development of a reusable multi-target sensor is a possibility and would greatly benefit routine screening in civilian and military environments. These studies indicate potential further applications of established metal oxide SERS materials as PIERS substrates. 

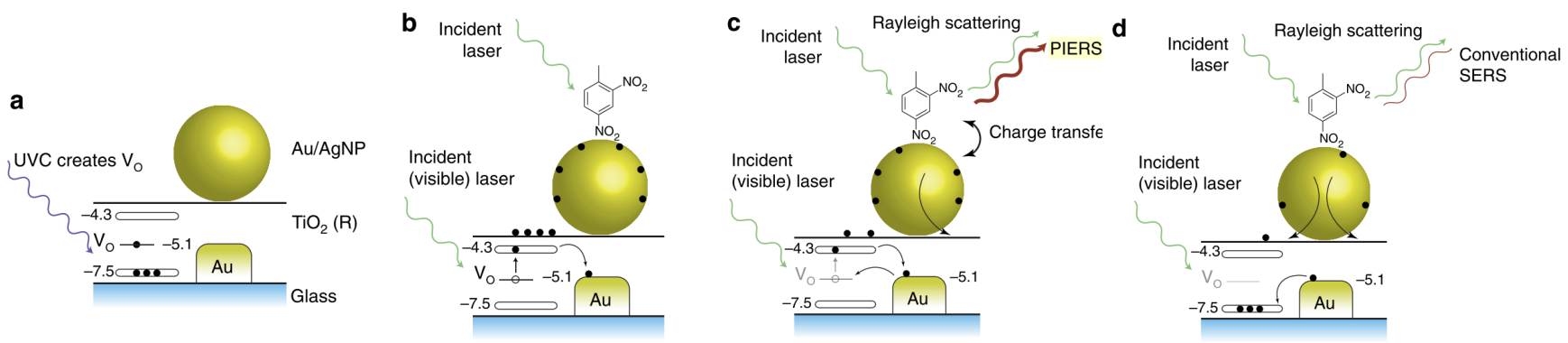

Figure 19: Proposed PIERS mechanism. UV light is used to increase the availability of electrons in the conduction band of the SERS substrate through the creation of vacancy defects. This results in elevated levels of electron migration from substrate to nanoparticles upon Raman laser illumination. (A) Creation of oxygen vacancies $\left(\mathrm{V}_{\mathrm{O}}\right)$ in the $\mathrm{TiO}_{2}$ below the conduction band using ultraviolet C light (UVC).(B) Sample deposition (DNT shown) followed by irradiation with $633 \mathrm{~nm}$ Raman laser. This leads to photoexcitation of $\mathrm{TiO}_{2}$ and increase in charge on the nanoparticles. (C) Charged nano particles lead to PIERS signal enhancement. $V_{O}$ are replenished upon exposure to air. (D) The PIERS effect gradually disappears as the $\mathrm{V}_{\mathrm{O}}$ are completely replenished over time. The substrate can then be cleaned and recharged through exposure to more UVC light absorption. ${ }^{342}$ Reproduced from ref. ${ }^{342}$ Copyright 2016 Nature.

A limitation of SERS is signal reproducibility, which is affected by the shape and size, as well as the separation, of the nanoparticles used in the substrate. Efforts to overcome these problems have resulted in some commercially available substrates which include; QSERS, RAMSERS, Klarite ${ }^{\mathrm{TM}}$ and SERStrate, which have recently been tested using commercial Raman systems for contraband detection. ${ }^{347-350}$

A limitation of SORS is the ability to probe thin layers which are micrometers thick. This is due to the wide Raman excitation beam and collection area used, generally at the $\mathrm{mm}$ scale or higher. ${ }^{351}$ The use of SORS for subsurface detection of analyte through thin turbid media was reported by Conti et al. Termed MicroSORS, the technique utilises a conventional Raman confocal microscope to perform two measurements; with the sample in its original and defocused positions. Spectral subtraction combined with a scaling factor to cancel out residual surface layer Raman bands results in a Raman signal for the sub-surface. Interrogation of multi-layers can be achieved with additional defocused positions and subtractions. ${ }^{352}$ The technique was used to interrogate painted layers on delicate artwork, but would also benefit defence and security. Micro-SORS could be used for non-invasive analysis of multi-layered samples which are very thin i.e. white powders within envelopes or parcels. Cletus et. al used nanosecond time-resolved SORS to achieve detection of explosives through opaque containers under ambient and fluorescent light. ${ }^{353} \mathrm{By}$ exploiting the time delay between laser excitation and detector activation, emitted photons due to fluorescence can be excluded, thus suppressing interference from ambient light. Using this approach, detection of DNT, hydrogen peroxide and nitromethane was achieved in different coloured HDPE containers. Another approach to reduce fluorescence interference is reported by Hopkins et. al, which involved the use of a $1064 \mathrm{~nm}$ laser excitation source in combination with an indium gallium arsenide (InGaAs) detector. $^{354}$ 
Table 7: SERS substrates for ETD - recent developments

\begin{tabular}{|c|c|c|c|c|c|c|}
\hline Substrate & Nanostructure & $\begin{array}{l}\text { Laser } \\
(\mathrm{nm})\end{array}$ & $\lambda$ & Material detected & LOD & Reference \\
\hline Borosilicate glass & Au nanocubes & 633 & & DNT, RDX & $\begin{array}{l}10^{-15} \mathrm{M}(\mathrm{DNT}), 10^{-9} \mathrm{M} \\
(\mathrm{RDX})\end{array}$ & 355 \\
\hline Filter paper & $\begin{array}{l}\text { Aggregated } \mathrm{Ag} / \mathrm{Au} \text { nano- } \\
\text { particles }\end{array}$ & 800 & & $\begin{array}{l}\text { TNP, DNT and } \\
\text { 3-nitro-1,2,4-triazol-5- } \\
\text { one (NTO) }\end{array}$ & $\begin{array}{l}11.5 \mathrm{ng}(\mathrm{TNP}), 1.82 \\
\text { ng (DNT) and } 13.1 \mathrm{ng} \\
(\mathrm{NTO})\end{array}$ & 356 \\
\hline Klarite & - & 785 & & TATP, TNT & - & 357 \\
\hline $\begin{array}{l}\text { Chemically modified } \\
\text { Klarite }^{\circledR} \text { containing MIPs }\end{array}$ & Au nanoparticles & 785 & & TNT & $3.0 \mu \mathrm{M}$ & 358 \\
\hline Au colloid & - & 633 & & TNT & Millimolar & 359 \\
\hline Polystyrene & $\mathrm{Au}$ nanoparticles & 785 & & TNT & $10^{-5} \mathrm{M}$ & 360 \\
\hline $\begin{array}{l}\text { Porous silicon photonic } \\
\text { crystals }\end{array}$ & Ag nanoparticles & 633 & & TNP & $10^{-8} \mathrm{M}$ & 361 \\
\hline Silicon wafer & $\begin{array}{l}\text { Ag nanoparticles decorated } \\
\text { with Si nanowires }\end{array}$ & 632 & & $\begin{array}{l}\text { Ammonium Perchlo- } \\
\text { rate }\end{array}$ & $10 \mu \mathrm{M}$ & 321 \\
\hline Silicon & $\begin{array}{l}\text { Bimetallic } \mathrm{Ag} / \mathrm{Au} \text { and } \\
\mathrm{Cu} / \mathrm{Au} \text { nanoparticles }\end{array}$ & 785 & & DTN, TNP & $\begin{array}{l}1 \mu \mathrm{M}(\mathrm{DNT}) \text { and } 5 \mu \mathrm{M} \\
(\mathrm{TNP})\end{array}$ & 362 \\
\hline Aluminium & Ag nanoflowers & 785 & & TNT & $5 \mu \mathrm{g}$ & 363 \\
\hline Reduced graphene oxide & Ag nanoparticles & 532 & & DNT & Nanomolar & 364 \\
\hline Silicon & $\mathrm{Ag} / \mathrm{Cu}$ nanoparticles & 632 & & $\begin{array}{l}\text { Ammonium nitrate, } \\
\text { TNP }\end{array}$ & $\begin{array}{l}5 \mu \mathrm{M} \text { (ammonium ni- } \\
\text { trate and TNP) }\end{array}$ & 365 \\
\hline $\begin{array}{l}\text { Graphene nanosheets with } \\
\text { Ag nanoparticles }\end{array}$ & - & 514 & & TNT & $5.0 \times 10^{-16} \mathrm{M}$ & 366 \\
\hline $\begin{array}{l}\mathrm{Au} \text { nanoparticles and } \\
\text { nanostructures }\end{array}$ & - & 785 & & TNP,DNT, NTO & Micromolar & 367 \\
\hline $\begin{array}{l}\text { Porous alumina mem- } \\
\text { branes }\end{array}$ & $\begin{array}{l}\text { Au nanorod and nanopar- } \\
\text { ticle mixed clusters }\end{array}$ & 785 & & HMTD & $3 \mathrm{ppm}$ & 368 \\
\hline Silicon & $\begin{array}{l}\text { Magnetic hybrid system } \\
\text { - } \mathrm{Fe}_{3} \mathrm{O}_{4} @ \mathrm{mTiO}_{2} / \mathrm{P}-\mathrm{ATP}- \\
\mathrm{TNT} / \mathrm{Au} @ \mathrm{Ag}\end{array}$ & 785 & & TNT & $1 \mathrm{pM}$ & 369 \\
\hline Microscope slide & $\begin{array}{l}\text { Cucurbit[7]uril and } \mathrm{Au} \\
\text { nanoparticles }\end{array}$ & 633 & & DNT & $1 \mu \mathrm{M}$ & 370 \\
\hline
\end{tabular}

\section{Conclusions and future per- spectives}

Table 8 and Figure 20 provide a comparison of each technology, with insight into their analytical performances. Note, a holistic approach has been taken with consideration from literature reviewed here in addition to subjective assessments. Animals remain a benchmark for emerging technologies with key attributes being high selectivity, sensitivity, concurrent detection of multiple analytes and fast screening times. The majority of in-field systems have sampling times within minutes and this has also been observed in many emerging technologies reviewed here. IMS remains a key technology in the field of ETD due to having good overall sensitivity, selectivity and analysis times in seconds.

However, current IMS systems lack molecular selectivity compared with spectroscopic approaches such as Raman and absorption/emission spectroscopy which can provide molecular fingerprinting and functional group

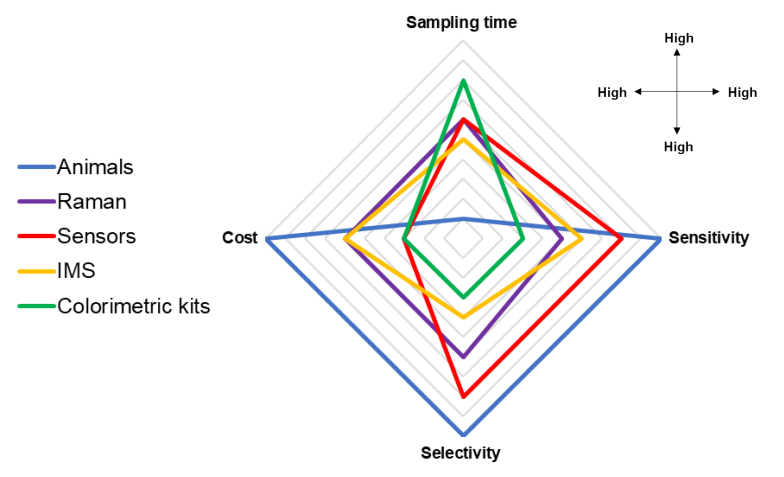

Figure 20: Visual comparison of ETD technologies based on sampling time, sensitivity, molecular selectivity and cost.

information. Ions generated from benign materials with similar mobilities to explosive ions can trigger false positive responses and such interferences include oils, creams, perfumes and medication. Efforts to improve the selectivity of IMS include; use of dopants, development of chemically modified swabs, understanding the ion chemistry of analytes and integration of IMS with mass spectrometry techniques. 
Table 8: Advantages and limitations of ETD technologies

\begin{tabular}{|c|c|c|}
\hline Techniques & Advantages & Limitations \\
\hline Animals & $\begin{array}{l}\text { concurrent sampling in real-time, wide range of threat } \\
\text { materials }\end{array}$ & $\begin{array}{l}\text { high training and maintenance costs, inconsistencies, } \\
\text { affected by the environment and surroundings, not al- } \\
\text { ways practical in civilian environments }\end{array}$ \\
\hline IMS & $\begin{array}{l}\text { easy to use, dual vapour and particulate detection in } \\
\text { some systems, can be integrated with mass spectrom- } \\
\text { etry, library }\end{array}$ & $\begin{array}{l}\text { expensive, radioactive ionisation source, affected by } \\
\text { humidity, temperature and sample composition, de- } \\
\text { structive, requires rigorous sampling to maximise an- } \\
\text { alyte collection }\end{array}$ \\
\hline Raman & $\begin{array}{l}\text { portability, non-destructive analysis, sampling } \\
\text { through packaging, stand-off detection capability, } \\
\text { sampling of solid, liquid and gasses }\end{array}$ & $\begin{array}{l}\text { interference from fluorescent or strongly absorbing ma- } \\
\text { terials, small scan area, cannot be used for metals or } \\
\text { alloys }\end{array}$ \\
\hline $\begin{array}{l}\text { Colorimetric } \\
\text { kits }\end{array}$ & $\begin{array}{l}\text { easy to use, portability, inexpensive, integration with } \\
\text { smart phone technology, small footprint and power re- } \\
\text { quirements }\end{array}$ & $\begin{array}{l}\text { stability/shelf life, may require multiple tests, destruc- } \\
\text { tive }\end{array}$ \\
\hline Sensors & portability, customisable, multi-modal capability & largely untested in operational environments \\
\hline
\end{tabular}

Traditional colorimetric reagents are limited by specificity, sensitivity and toxicity of some materials. Development of sensor arrays and use of ratiometric fluorescence approaches overcomes these problems as they probe the chemical properties of analytes, leading to greater selectivity and sensitivity. The use of multiple sensor elements to give a combined response further improves analyte differentiation and selectivity. This has been largely possible through the use of tunable nanomaterials such as MOFs, nanoparticles, quantum dots and conjugated polymers. SERS is a promising approach with high sensitivity and can be used with current desktop and portable Raman systems. However the technique has yet to be adopted in operational environments. As the number of SERS substrates continue to expand, the need to develop standardised tests for assessing detection capability and reproducibility is required. Work towards reproducible substrates at low cost for commercial use is also important for SERS to be a viable option for operational screening.

\section{Emerging fields and possible new directions for ETD}

Many nanomaterials have been successfully integrated into MEMS-based sensors and these advances in miniaturised technologies have produced systems with favourable qualities such as; multi-modal detection, portability, high selectivity and sensitivity. The wide tunability of many nanomaterials, combined with a variety of MEMS-based sensors such as; piezoresistive, calorimetric, acoustic wave resonators and thermal analyzers, means that multi-mode detection systems are likely to become the next generation of ETD detector. Furthermore, the recent development of a MEMS vacuum pump ${ }^{371}$ and 3D printed sensors introduces further applications for ETD. ${ }^{372}$

Traditional methods of vapour sampling include IMS and GC-MS. However, these systems are limited by their range, lack of real-time sampling and cost, making air sampling of large areas a challenge. $\mathrm{MO}_{\mathrm{x}}$ semiconductor gas sensors are promising alternatives due to their low cost, ease in which they can be set up and potential for real time analysis. In addition, numerous approaches now exist to improve selectivity. Enoses containing multiple gas sensors have also been developed showing both high sensitivity and selectivity. Gas sensing and MEMS technology already share many overlaps and with advances in both fields, we are likely to see more examples of multi-modal systems. Further advances will also likely see more sensors integrated with AI to improve detection. ${ }^{373}$

Another emerging field for ETD is hyperspectral imaging, which allows rich datasets to be collected across very narrow spectral bands. The resultant image, a 3D hyperspectral data cube, can be probed pixel-by-pixel to interrogate reflection, emission and absorption data. Concurrent spectral and spatial interrogation of surfaces can be achieved and the technique can be used with a range of illumination sources, including; UV, ${ }^{374,375} \mathrm{IR}^{376-378}$ and Raman, ${ }^{379-381}$ all demonstrated for the detection of explosives.

Hyphenated techniques involve connecting 
two or more instruments together to improve material characterisation. Successful integration of different technologies requires considerations such as; sample delivery, design of the interface and the sample phase for analysis by each technology. In ETD, the most notable examples of hyphenated technologies are IMS systems combined with mass spectrometry. However, hyphenated vibrational spectroscopy techniques have received less attention. Whilst, IR and Raman can provide high specificity through generation of molecular fingerprint profiles and functional group information, interpretation of mixtures can be difficult due to the complexity of the spectra. The combination of Raman with separation technologies could overcome these problems. Such a system could involve the use of a microextraction technique to isolate analytes of interest, ${ }^{382}$ combined with an integrated Raman-mass spectrometry system for analysis, ${ }^{383}$ all enabled through a microfluidic delivery system. Whilst a number of hyphenated Raman approaches have been reported, ${ }^{384,385}$ none have been applied to ETD and the area remains largely unexplored.

\section{Artificial Intelligence (AI) ap- proaches to ETD}

Machine learning is a branch of artificial intelligence which uses algorithms to extract patterns and features within data in order to make decisions. Data from sensor arrays is often complex and contains many features which are difficult to visualise or interpret through linear regression models. Chemometric approaches such as linear discriminant analysis (LDA) and principal component analysis (PCA) can reduce the dimensionality of data enabling feature selection and pattern recognition. ${ }^{386}$ LDA and PCA have been applied to a range of data types in the field of ETD, with many examples already covered in this review. ${ }^{66,70,161,171} \mathrm{~A}$ number of machine learning algorithms have been successfully applied to E-nose systems to classify sensor inputs, leading to improved chemical selectivity. Examples include; random forest, ${ }^{68,176}$ support vector machines ${ }^{91,387}$ and artificial neural networks. ${ }^{107}$ As detection sys- tems become more complex, the use of machine learning will likely become more prevalent to handle large datasets. Also, as the number of open source machine learning libraries (i.e. Caffe, TensorFlow ${ }^{\circledR}$ and PyTorch) increases, this will facilitate entry into using AI to analyse sensor data. However, a key challenge is integrating machine learning with multi-modal systems which combine different characterisation data to achieve selectivity. The use of machine learning can also benefit other ETD technologies such as IMS and Raman. In Raman-based approaches, complex mixtures produce spectra showing vibrational modes from each component. Spectral profiles in SERS is complicated further due to orientation effects of molecules with respect to SERS substrates. However, machine learning can be used to identify spectral features of analytes from Raman and SERS data and many examples can be found in fields outside of ETD. ${ }^{388}$

\section{Concluding remarks}

It is likely that nanomaterials will play an important role in the development of future ETD technologies. We have seen significant developments made in gas sensing such as graphene and quantum dots, with some systems able to detect multiple classes of explosives at low concentrations. SERS also continues to be an active area, through developments improving the properties of plasmonic and non-plasmonic nanoparticles. Whilst sensitivity and selectivity remain important goals for ETD systems, consideration of the operational environment is also important for design of future systems as deployment is a balancing act of many considerations. These include, cost, sampling throughput, sampling time, portability and ease of operation. Computational chemistry has not been discussed here but is one approach which could be used to develop rationally designed sensing materials. Other computational approaches beneficial for ETD would be modelling explosive adsorption on surfaces and vapour plumes in confined areas, to improve screening procedures and placement of sensors.

Acknowledgement This work was carried 
out under EPSRC grant no. EP/L015862/1 as part of the University College London Molecular Modelling and Materials Science Doctoral Training Centre and with support from the UK Defence Science and Technology Laboratory (DSTL).

\section{Vocabulary}

Chemical sensor, a device which responds to a particular analyte, transforming the chemical or physical interaction into a measurable signal; nanostructure, materials with at least one dimension in the nanoscale range $(<100$ $\mathrm{nm}$ ); field effect transistor (FET) sensor, a type of sensor which uses an electric field to control the flow of current, usually modified to detect specific analytes on the FET surface, observed through changes in the surface charge; redox reaction, reactions in which electrons are transferred from one type of substrate to another; Raman scattering, an optical process describing inelastic scattering of a photon by a sample, revealing vibrational transitions.

\section{References}

1. Guardian - Birmingham Attack. http://www.theguardian.com/uknews/2013/oct/21/pavlo-lapshynukrainian-student-terrorist, (visited on 14-08-2018).

2. Independent - London Attack. http://www.independent.co.uk/news/ uk/crime/silent-bomber-mohammedrehman-and-wife-sana-ahmed-khansentenced-to-life-in-prison-for-londonterror-a6790741.html, (visited on 14-082018).

3. BBC News - Manchester Attack. http://www.bbc.co.uk/news/uk-englandmanchester-40008389, (visited on 01-082018).

4. Dutta, P.; Chakravarty, S.; Sarma, N. S. Detection of Nitroaromatic Explosives Using $\pi$-Electron Rich Luminescent Poly- meric Nanocomposites. $R S C$ Adv. 2016, 6, 3680-3689.

5. Convention on the Marking of Plastic Explosives for the Purpose of Detection. 1 March 1991, ICAO Doc 9571.

6. Boschan, R.; Merrow, R. T.; van Dolah, R. W. The Chemistry of Nitrate Esters. Chem. Rev. 1955, 55, 485-510.

7. Ewing, R. G.; Waltman, M. J.; Atkinson, D. A.; Grate, J. W.; Hotchkiss, P. J. The Vapor Pressures of Explosives. $\operatorname{Tr} A C$ - Trends Anal. Chem. 2013, 42, 35-48.

8. Fainberg, A. Explosives Detection for Aviation Security. Science (80-. ). 1992, 255, 1531-1537.

9. Albert, K. J.; Walt, D. R. High-Speed Fluorescence Detection of Explosives-Like Vapors. Anal. Chem. 2000, 72, 1947-1955.

10. Caygill, J. S.; Davis, F.; Higson, S. P. J. Current Trends in Explosive Detection Techniques. Talanta 2012, 88, 14-29.

11. Brown, K. E.; Greenfield, M. T.; McGrane, S. D.; Moore, D. S. Advances in Explosives Analysis - Part I: Animal, Chemical, Ion, and Mechanical Methods ABC Highlights: Authored by Rising Stars and Top Experts. Anal. Bioanal. Chem. 2016, 408, 35-47.

12. Brown, K. E.; Greenfield, M. T.; McGrane, S. D.; Moore, D. S. Advances in Explosives Analysis - Part II: Photon and Neutron Methods. Anal. Bioanal. Chem. 2016, 408, 49-65.

13. Mokalled, L.; Al-husseini, M.; Kabalan, K. Y.; El-hajj, A. Sensor Review for Trace Detection of Explosives. Int. J. Sci. Eng. Res. 2014, 5, 337-350.

14. Buryakov, I. A.; Buryakov, T. I.; Matsayev, V. T. Electrical, Electrochemical, and Thermometric Sensors for the Detection of Explosives. J. Anal. Chem. 2016, 71, 234-242. 
15. Giannoukos, S.; Brkić, B.; Taylor, S.; Marshall, A.; Verbeck, G. F. Chemical Sniffing Instrumentation for Security Applications. Chem. Rev. 2016, 116, 8146-8172.

16. Murray, N. C.; Lacey, R.; Mason, P. Exploitation of X-Ray Technology for the Detection of Contraband-Aviation Security Applications. Eur. Conf. Secur. Detect. 1997, 13-18.

17. Buffler, A. Contraband Detection with Fast Neutrons. Radiat. Phys. Chem. 2004, $71,853-861$.

18. Östmark, H.; Wallin, S.; Ang, H. G. Vapor Pressure of Explosives: A Critical Review. Propellants, Explos. Pyrotech. 2012, 37, $12-23$.

19. Camara, E. H.; Breuil, P.; Briand, D.; de Rooij, N. F.; Pijolat, C. A Micro Gas Preconcentrator with Improved Performance for Pollution Monitoring and Explosives Detection. Anal. Chim. Acta 2011, 688, 175-182.

20. McEneff, G. L.; Murphy, B.; Webb, T.; Wood, D.; Irlam, R.; Mills, J.; Green, D.; Barron, L. P. Sorbent Film-Coated Passive Samplers for Explosives Vapour Detection Part A: Materials Optimisation and Integration with Analytical Technologies. Sci. Rep. 2018, 8, 1-13.

21. Lichtenstein, A.; Havivi, E.; Shacham, R.; Hahamy, E.; Leibovich, R.; Pevzner, A.; Krivitsky, V.; Davivi, G.; Presman, I.; Elnathan, R.; Engel, Y.; Flaxer, E.; Patolsky, F. Supersensitive Fingerprinting of Explosives by Chemically Modified Nanosensors Arrays. Nat. Commun. 2014, 5 .

22. Hughes, S.; Dasary, S. S.; Begum, S.; Williams, N.; Yu, H. Meisenheimer Complex between 2,4,6-Trinitrotoluene and 3Aminopropyltriethoxysilane and Its Use for a Paper-Based Sensor. Sens. BioSensing Res. 2015, 5, 37-41.
23. Zwijnenburg, M. A.; Berardo, E.; Peveler, W. J.; Jelfs, K. E. Amine Molecular Cages as Supramolecular Fluorescent Explosive Sensors: A Computational Perspective. J. Phys. Chem. B 2016, 120, 5063-5072.

24. Sablok, K.; Bhalla, V.; Sharma, P.; Kaushal, R.; Chaudhary, S.; Suri, C. R. Amine Functionalized Graphene Oxide/CNT Nanocomposite for Ultrasensitive Eelectrochemical Detection of Trinitrotoluene. J. Hazard. Mater. 2013, 248 249, 322-328.

25. Dasary, S. S.; Senapati, D.; Singh, A. K.; Anjaneyulu, Y.; Yu, H.; Ray, P. C. Highly Sensitive and Selective Dynamic LightScattering Assay for TNT Detection Using p-ATP Attached Gold Nanoparticle. ACS Appl. Mater. Interfaces 2010, 2, 34553460 .

26. Eslami, M. R.; Alizadeh, N. Ultrasensitive and Selective QCM Sensor for Detection of Trace Amounts of Nitroexplosive Vapors in Ambient Air Based on PolypyrroleBromophenol Blue Nanostructure. Sensors Actuators, B Chem. 2019, 278, 5563.

27. Dubnikova, F.; Kosloff, R.; Zeiri, Y.; Karpas, Z. Novel Approach to the Detection of Triacetone Triperoxide (TATP): Its Structure and Its Complexes with Ions. $J$. Phys. Chem. A 2002, 106, 4951-4956.

28. Ray, R. S.; Sarma, B.; Mohanty, S.; Misra, M. Theoretical and Experimental Study of Sensing Triacetone Triperoxide (TATP) Explosive through Nanostructured TiO2 Substrate. Talanta 2014, 118, 304-311.

29. Dubnikova, F.; Kosloff, R.; Oxley, J. C.; Smith, J. L.; Zeiri, Y. Role of Metal Ions in the Destruction of TATP: Theoretical Considerations. J. Phys. Chem. A 2011, 115, 10565-10575. 
30. Banerjee, S.; Mohapatra, S. K.; Misra, M.; Mishra, I. B. The Detection of Improvised Nonmilitary Peroxide Based Explosives Using a Titania Nanotube Array Sensor. Nanotechnology 2009, 20.

31. Amani, M.; Chu, Y.; Waterman, K. L.; Hurley, C. M.; Platek, M. J.; Gregory, O. J. Detection of Triacetone Triperoxide (TATP) Using a Thermodynamic Based Gas Sensor. Sensors Actuators, B Chem. 2012, 162, 7-13.

32. Rossi, A. S.; Ricci, P.; Gregory, O. J. Trace Detection of Explosives Using Metal Oxide Catalysts. IEEE Sens. J. 2019, 19, 4773-4780.

33. Wen, P.; Amin, M.; Herzog, W. D.; Kunz, R. R. Key Challenges and Prospects for Optical Standoff Trace Detection of Explosives. TrAC - Trends Anal. Chem. 2018, 100, 136-144.

34. Venugopal Rao, S.; Abdul Kalam, S.; Bharathi, M. S. S. Photonics for Explosives Detection. Digit. Encycl. Appl. Phys. 2019, 1-31.

35. Romolo, F. S.; Connell, S.; Ferrari, C.; Suarez, G.; Sauvain, J. J.; Hopf, N. B. Locating Bomb Factories by Detecting Hydrogen Peroxide. Talanta 2016, 160, 1520 .

36. Explosive Material Production (Hidden) Agile Search and Intelligence System. https://cordis.europa.eu/project/rcn/ 100353/factsheet/en, (visited on 14-012019).

37. BOmb factory Detection by Networks of Advanced Sensors. https://cordis.europa. $\mathrm{eu} / \mathrm{project} / \mathrm{rcn} / 98486 / \mathrm{reporting} / \mathrm{en}$, (visited on 14-01-2019).

38. Localisation of Threat Substances In Urban Society. https://cordis.europa.eu/ project/rcn/89390/factsheet/en, (visited on 14-01-2019).
39. Ferrari, C.; Ulrici, A.; Romolo, F. Expert System for Bomb Factory Detection by Networks of Advance Sensors. Challenges 2017, 8, 1 .

40. CBRNE Detection in Containers. https://cordis.europa.eu/project/rcn/ 218212/factsheet/en, (visited on 14-012019).

41. Chirico, R.; Almaviva, S.; Colao, F.; Fiorani, L.; Nuvoli, M.; Schweikert, W.; Schnürer, F.; Cassioli, L.; Grossi, S.; Murra, D.; Menicucci, I.; Angelini, F.; Palucci, A. Proximal Detection of Traces of Energetic Materials with an Eye-Safe UV Raman Prototype Developed for Civil Applications. Sensors (Switzerland) 2015, $16,1-18$.

42. Habib, M. K. Controlled Biological and Biomimetic Systems for Landmine Detection. Biosens. Bioelectron. 2007, 23, 1-18.

43. Jamieson, L. T. J.; Baxter, G. S.; Murray, P. J. Identifying Suitable Detection Dogs. Appl. Anim. Behav. Sci. 2017, 195, $1-7$.

44. Hayes, J. E.; McGreevy, P. D.; Forbes, S. L.; Laing, G.; Stuetz, R. M. Critical Review of Dog Detection and the Influences of Physiology, Training, and Analytical Methodologies. Talanta 2018, 185, 499-512.

45. Zubedat, S.; Aga-Mizrachi, S.; CymerblitSabba, A.; Shwartz, J.; Leon, J. F.; Rozen, S.; Varkovitzky, I.; Eshed, Y.; Grinstein, D.; Avital, A. Human-Animal Interface: The Effects of Handler's Stress on the Performance of Canines in an Explosive Detection Task. Appl. Anim. Behav. Sci. 2014, 158, 69-75.

46. Gazit, I.; Terkel, J. Explosives Detection by Sniffer Dogs following Strenuous Physical Activity. Appl. Anim. Behav. Sci. 2003, 81, 149-161. 
47. Staymates, M. E.; MacCrehan, W. A.; Staymates, J. L.; Kunz, R. R.; Mendum, T.; Ong, T. H.; Geurtsen, G.; Gillen, G. J.; Craven, B. A. Biomimetic Sniffing Improves the Detection Performance of a 3D Printed Nose of a Dog and a Commercial Trace Vapor Detector. Sci. Rep. 2016, 6, 1-10.

48. Poling, A.; Weetjens, B.; Cox, C.; Beyene, N. W.; Bach, H.; Sully, A. Using Trained Pouched Rats to Detect Land Mines: Another Victory for Operant Conditioning. J. Appl. Behav. Anal. 2011, 44, 351-355.

49. Bromenshenk, J. J.; Henderson, C. B.; Seccomb, R. A.; Welch, P. M.; Debnam, S. E.; Firth, D. R. Bees as Biosensors: Chemosensory Ability, Honey Bee Monitoring Systems, and Emergent Sensor Technologies Derived from the Pollinator Syndrome. Biosensors 2015, 5, 678711.

50. Bogue, R. Detecting Explosives and Chemical Weapons: A Review of Recent Developments. Sens. Rev. 2015, 35, 237243.

51. Biological Method (BEES) for Explosives Detection. https://www.sps-bees4exp. com/project-bees-for-explosive-detection, (visited on 21-07-2020).

52. Gillanders, R. N. Bees for Explosive Detection. Proceedings of Mine Action 2018. Slano, Croatia, 9 April 2018; pp 42-44.

53. Gillanders, R. N.; Glackin, J. M.; Filipi, J.; Kezic, N.; Samuel, I. D.; Turnbull, G. A. Preconcentration Techniques for Trace Explosive Sensing. Sci. Total Environ. 2019, 658, 650-658.

54. Persaud, K.; Dodd, G. Analysis of Discrimination Mechanisms in the Mammalian Olfactory System Using a Model Nose. Nature 1982, 299, 352-355.

55. Hu, W.; Wan, L.; Jian, Y.; Ren, C.; Jin, K.; Su, X.; Bai, X.; Haick, H.;
Yao, M.; Wu, W. Electronic Noses: From Advanced Materials to Sensors Aided with Data Processing. Adv. Mater. Technol. 2019, 4, 1-38.

56. Capitán-Vallvey, L. F.; López-Ruiz, N.; Martínez-Olmos, A.; Erenas, M. M.; Palma, A. J. Recent Developments in Computer Vision-Based Analytical Chemistry: A Tutorial Review. Anal. Chim. Acta 2015, 899, 23-56.

57. Choodum, A.; Malathong, K.; NicDaeid, N.; Limsakul, W.; Wongniramaikul, W. A Cost Effective Hydrogel Test Kit for Pre and Post Blast Trinitrotoluene. Forensic Sci. Int. 2016, 266, 202208.

58. Choodum, A.; Kanatharana, P.; Wongniramaikul, W.; Nicdaeid, N. Poly Vinyl Alcohol Cryogel as a Selective Test Kit for Pre and Post Blast Trinitrotoluene. Sensors Actuators, B Chem. 2016, 222, 654662 .

59. Choodum, A.; Keson, J.; Kanatharana, P.; Limsakul, W.; Wongniramaikul, W. Selective Pre and Post Blast Trinitrotoluene Detection with a Novel Ethylenediamine Entrapped Thin Polymer Film and Digital Image Colorimetry. Sensors Actuators, B Chem. 2017, 252, 463-469.

60. Kangas, M. J.; Burks, R. M.; Atwater, J.; Lukowicz, R. M.; Williams, P.; Holmes, A. E. Colorimetric Sensor Arrays for the Detection and Identification of Chemical Weapons and Explosives. Crit. Rev. Anal. Chem. 2017, 47, 138-153.

61. Yetisen, A. K.; Martinez-Hurtado, J. L.; Garcia-Melendrez, A.; Da Cruz Vasconcellos, F.; Lowe, C. R. A Smartphone Algorithm with Inter-Phone Repeatability for the Analysis of Colorimetric Tests. Sensors Actuators, B Chem. 2014, 196, 156160.

62. Askim, J. R.; Mahmoudi, M.; Suslick, K. S. Optical Sensor Arrays for 
Chemical Sensing: The Optoelectronic Nose. Chem. Soc. Rev. 2013, 42, 8649.

63. Okuom, M. O.; Holmes, A. E. Developing a Color-Based Molecular Sensing Device: DETECHIP. Sensors \& Transducers 2014, 183, 30-33.

64. Askim, J. R.; Li, Z.; LaGasse, M. K.; Rankin, J. M.; Suslick, K. S. An Optoelectronic Nose for Identification of Explosives. Chem. Sci. 2016, 7, 199-206.

65. Munk, J. K.; Buus, O. T.; Larsen, J.; Dossi, E.; Tatlow, S.; Jakobsen, M. H. CRIM-TRACK: Sensor System for Detection of Criminal Chemical Substances. Proc. SPIE 2015, 9652, 965208-9652085.

66. Salles, M. O.; Meloni, G. N.; de Araujo, W. R.; Paixão, T. R. L. C. Explosive Colorimetric Discrimination Using a Smartphone, Paper Device and Chemometrical Approach. Anal. Methods 2014, 6, 2047-2052.

67. Li, Z.; Bassett, W. P.; Askim, J. R.; Suslick, K. S. Differentiation among Peroxide Explosives with an Optoelectronic Nose. Chem. Commun. 2015, 51, 15312-15315.

68. Mølgaard, L. L.; Buus, O. T.; Larsen, J.; Babamoradi, H.; Thygesen, I. L.; Laustsen, M.; Munk, J. K.; Dossi, E.; O'Keeffe, C.; Lässig, L.; Tatlow, S.; Sandström, L.; Jakobsen, M. H. Improved Detection of Chemical Substances from Colorimetric Sensor Data Using Probabilistic Machine Learning . Chem. Biol. Radiol. Nucl. Explos. Sens. XVIII 2017, 10183, 1018307.

69. Bolse, N.; Eckstein, R.; Schend, M.; Habermehl, A.; Eschenbaum, C.; Hernandez-Sosa, G.; Lemmer, U. A Digitally Printed Optoelectronic Nose for the Selective Trace Detection of Nitroaromatic Explosive Vapours Using Fluorescence Quenching. Flex. Print. Electron. 2017, 2, 024001.
70. Bolse, N.; Eckstein, R.; Habermehl, A.; Hernandez-Sosa, G.; Eschenbaum, C.; Lemmer, U. Reliability of Aerosol Jet Printed Fluorescence Quenching Sensor Arrays for the Identification and Quantification of Explosive Vapors. ACS Omega 2017, 2, 6500-6505.

71. Yu, Y.; Cao, Q.; Zhou, M.; Cui, H. A Novel Homogeneous Label-Free Aptasensor for 2,4, 6-Trinitrotoluene Detection Based on an Assembly Strategy of Electrochemiluminescent Graphene Oxide with Gold Nanoparticles and Aptamer. Biosens. Bioelectron. 2013, 43, 137-142.

72. BBI Detection - Explosive Antibodies. https://bbisolutions.com/en/products/ antibodies.html/, (visited on 24-01-2019).

73. Enhancement of Three Existing Technologies and Data Fusion Algorithms for the Test and Demonstration of Multi-sensor Landmine Detection Techniques. https://cordis.europa.eu/project/ id/IST-2000-25351, (visited on 21-072020).

74. Crabbe, S.; Eng, L.; Gardhagen, P.; Berg, A. Detection of Explosive as an Indicator of Landmines: BIOSENS Project Methodology and Field Tests in Southeast Europe. Detect. Remediat. Technol. Mines Minelike Targets X 2005, 5794, 762.

75. Biosensor Applications@ AB. http:// biosensor.se/drugs/, (visited on 24-012019).

76. Mansson, P. Analysis of Several Target Antigens in a Liquid Sample. Feb. 16, 2012; Patent number US 20120040473 A1.

77. Singh, P.; Onodera, T.; Mizuta, Y.; Matsumoto, K.; Miura, N.; Toko, K. Dendrimer Modified Biochip for Detection of 2,4, 6 Trinitrotoluene on SPR Immunosensor: Fabrication and Advantages. Sensors Actuators, B Chem. 2009, 137, 403-409.

78. Nagatomo, K.; Kawaguchi, T.; Miura, N.; Toko, K.; Matsumoto, K. Development 
of a Sensitive Surface Plasmon Resonance Immunosensor for Detection of 2,4Dinitrotoluene with a Novel Oligo (Ethylene Glycol)-Based Sensor Surface. Talanta 2009, 79, 1142-1148.

79. Onodera, T.; Toko, K. Towards an Electronic Dog Nose: Surface Plasmon Resonance Immunosensor for Security and Safety. Sensors (Switzerland) 2014, 14, 16586-16616.

80. Charles, P. T.; Adams, A. A.; Deschamps, J. R.; Veitch, S.; Hanson, A.; Kusterbeck, A. W. Detection of Explosives in a Dynamic Marine Environment Using a Moored TNT Immunosensor. Sensors (Switzerland) 2014, 14, 4074-4085.

81. Charles, P. T.; Wadhwa, V.; Kouyate, A.; Mesa-Donado, K. J.; Adams, A. A.; Deschamps, J. R.; Kusterbeck, A. W. A High Aspect Ratio Bifurcated 128Microchannel Microfluidic Device for Environmental Monitoring of Explosives. Sensors (Switzerland) 2018, 18.

82. Charles, P. T.; Davis, J.; Adams, A. A.; Anderson, G. P.; Liu, J. L.; Deschamps, J. R.; Kusterbeck, A. W. MultiChanneled Single Chain Variable Fragment ( $\mathrm{scFv}$ ) Based Microfluidic Device for Explosives Detection. Talanta 2015, 144 , 439-444.

83. Wang, J.; Muto, M.; Yatabe, R.; Onodera, T.; Tanaka, M.; Okochi, M.; Toko, K. Rational Design of PeptideFunctionalized Surface Plasmon Resonance Sensor for Specific Detection of TNT Explosive. Sensors (Switzerland) $2017,17$.

84. Gubanova, O.; Andrianova, M.; Saveliev, M.; Komarova, N.; Kuznetsov, E.; Kuznetsov, A. Fabrication and Package of ISFET Biosensor for Micro Volume Analysis with the Use of Direct Ink Writing Approach. Mater. Sci. Semicond. Process. 2016, 60, 71-78.
85. Üzer, A.; YalçÄśn, U.; Can, Z.; ErçaÄ§, E.; Apak, R. Indirect Determination of Pentaerythritol Tetranitrate (PETN) with a Gold Nanoparticles-Based Colorimetric Sensor. Talanta 2017, 175, 243-249.

86. Krivitsky, V.; Filanovsky, B.; Naddaka, V.; Patolsky, F. Direct and Selective Electrochemical Vapor Trace Detection of Organic Peroxide Explosives via Surface Decoration. Anal. Chem. 2019, 91, 53235330 .

87. Zhang, Y.; Ma, Y.; Wang, L. Simple Copper Nanoparticle/Polyfurfural Film Modified Electrode for the Determination of 2, 4, 6-Trinitrotoluene (TNT). Anal. Lett. 2020, 2719, 1-14.

88. Procek, M.; Stolarczyk, A.; Pustelny, T.; Maciak, E. A Study of a QCM Sensor Based on TiO2 Nanostructures for the Detection of NO2 and Explosives Vapours in Air. Sensors (Switzerland) 2015, 15, 9563-9581.

89. Lü, X.; Hao, P.; Xie, G.; Duan, J.; Gao, L.; Liu, B. A Sensor Array Realized by a Single Flexible TiO2/POMs Film to Contactless Detection of Triacetone Triperoxide. Sensors (Switzerland) 2019, 19.

90. Zhang, W. H.; Zhang, W. D.; Chen, L. Y. Highly Sensitive Detection of Explosive Triacetone Triperoxide by an In2O3 Sensor. Nanotechnology 2010, 21, 1-6.

91. Horsfall, L. A.; Pugh, D. C.; Blackman, C. S.; Parkin, I. P. An Array of WO 3 and CTO Heterojunction Semiconducting Metal Oxide Gas Sensors Used as a Tool for Explosive Detection. J. Mater. Chem. A 2017, 5, 2172-2179.

92. Qi, W.; He, H.; Fu, Y.; Zhao, M.; Qi, L.; $\mathrm{Hu}$, L.; Liu, C.; Li, R. Water-Dispersed Fluorescent Silicon Nanodots as Probes for Fluorometric Determination of Picric Acid via Energy Transfer. Microchim. Acta 2019, 186, 18. 
93. Srinivasan, V.; Asha Jhonsi, M.; Kathiresan, M.; Kathiravan, A. Nanostructured Graphene Oxide Dots: Synthesis, Characterization, Photoinduced Electron Transfer Studies, and Detection of Explosives/Biomolecules. ACS Omega 2018, 3, 9096-9104.

94. Wang, H.; Chen, C.; Liu, Y.; Wu, Y.; Yuan, Y.; Zhou, Q. A Highly Sensitive and Selective Chemosensor for 2,4, 6-Trinitrophenol Based on L-CysteineCoated Cadmium Sulfide Quantum Dots. Talanta 2019, 198, 242-248.

95. Li, Z.; Zhou, Y.; Yan, D.; Wei, M. Electrochemiluminescence Resonance Energy Transfer (ERET) towards Trinitrotoluene Sensor Based on Layer-by-Layer Assembly of Luminol-Layered Double Hydroxides and CdTe Quantum Dots. J. Mater. Chem. C 2017, 5, 3473-3479.

96. Alizadeh, T.; Atashi, F.; Ganjali, M. R. Molecularly Imprinted Polymer NanoSphere/Multi-Walled Carbon Nanotube Coated Glassy Carbon Electrode as an Ultra-Sensitive Voltammetric Sensor for Picomolar Level Determination of RDX. Talanta 2019, 194, 415-421.

97. Wang, J.; Du, S.; Onodera, T.; Yatabe, R.; Tanaka, M.; Okochi, M.; Toko, K. An SPR Sensor Chip Based on Peptide-Modified Single-Walled Carbon Nanotubes with Enhanced Sensitivity and Selectivity in the Detection of 2,4, 6-Trinitrotoluene Explosives. Sensors (Switzerland) 2018, 18, 4-9.

98. Dettlaff, A.; Jakóbczyk, P.; Ficek, M.; Wilk, B.; Szala, M.; Wojtas, J.; Ossowski, T.; Bogdanowicz, R. Electrochemical Determination of Nitroaromatic Explosives at Boron-Doped Diamond/Graphene Nanowall Electrodes: 2,4, 6-Trinitrotoluene and 2,4, 6-Trinitroanisole in Liquid Effluents. $J$. Hazard. Mater. 2020, 387, 121672.
99. Patil, S. J.; Duragkar, N.; Rao, V. R. An Ultra-Sensitive Piezoresistive Polymer Nano-Composite Microcantilever Sensor Electronic Nose Platform for Explosive Vapor Detection. Sensors Actuators, B Chem. 2014, 192, 444-451.

100. Sun, Q.; Wu, Z.; Duan, H.; Jia, D. Detection of Triacetone Triperoxide (TATP) Precursors with an Array of Sensors Based on MoS 2 /RGO Composites. Sensors (Switzerland) 2019, 19.

101. Li, Z.; Li, H.; Wu, Z.; Wang, M.; Luo, J.; Torun, H.; Hu, P.; Yang, C.; Grundmann, M.; Liu, X.; Fu, Y. Advances in Designs and Mechanisms of Semiconducting Metal Oxide Nanostructures for HighPrecision Gas Sensors Operated at Room Temperature. Mater. Horizons 2019, 6, 470-506.

102. Mirzaei, A.; Janghorban, K.; Hashemi, B.; Neri, G. Metal-Core@metal Oxide-Shell Nanomaterials for Gas-Sensing Applications: A Review. J. Nanoparticle Res. 2015, 17, 1-36.

103. Lin, C.; Xu, W.; Yao, Q.; Wang, X. Novel Nanomaterials for Biomedical Environmental and Energy Applications; Elsevier, Oxford, 2018; pp 275-297.

104. Ji, H.; Zeng, W.; Li, Y. Gas Sensing Mechanisms of Metal Oxide Semiconductors: A Focus Review. Nanoscale 2019, 11, 22664-22684.

105. Asher, W. E.; Colosimo, P.; Thorsos, E. I.; Yao, A. On Sensing Nitro-Group Containing Compounds Using Thin Planar Arrays of Titanium Dioxide Nanowires. IEEE Sens. J. 2018, 18, 6927-6936.

106. Cao, Y.; Zou, X.; Wang, X.; Qian, J.; Bai, N.; Li, G. D. Effective Detection of Trace Amount of Explosive NitroCompounds by $\mathrm{ZnO}$ Nanofibers with Hollow Structure. Sensors Actuators, B Chem. 2016, 232, 564-570. 
107. Omijeh, B.; Okemeka Machiavelli, A. Optimizing a Sensor to Detect Ammonium Nitrate Based IEDS in Vehicles Using Artificial Neural Networks. Am. J. Neural Networks Appl. 2019, 5, 1.

108. Ratchapakorn, N.; Ariyakul, Y. Development of a Low-Cost Explosive Vapor Detector Using Metal Oxide Gas Sensors. $I C$ SEC 2017 - 21st Int. Comput. Sci. Eng. Conf. 2017, Proceeding 2018, 6, 316-319.

109. James, S.; Chishti, B.; Ansari, S. A.; Alothman, O. Y.; Fouad, H.; Ansari, Z. A.; Ansari, S. G. Nanostructured Cuprous-Oxide-Based ScreenPrinted Electrode for Electrochemical Sensing of Picric Acid. J. Electron. Mater. 2018, 47, 7505-7513.

110. Tang, Y.; Zhang, Y.; Xie, G.; Zheng, Y.; $\mathrm{Yu}$, J.; Gao, L.; Liu, B. Construction of Rutile-TiO2 Nanoarray Homojuction for Non-Contact Sensing of TATP Under Natural Light. Coatings 2020, 10.

111. Bastatas, L. D.; Wagle, P.; Echeverria, E.; Austin, A. J.; McIlroy, D. N. The Effect of UV Illumination on the Room Temperature Detection of Vaporized Ammonium Nitrate by a ZnO Coated NanospringBased Sensor. Materials (Basel). 2019, 12.

112. Qu, J.; Ge, Y.; Zu, B.; Li, Y.; Dou, X. Transition-Metal-Doped $p$-Type ZnO Nanoparticle-Based Sensory Array for Instant Discrimination of Explosive Vapors. Small 2016, 12, 1369-1377.

113. Bochenkov, V. E.; Sergeev, G. B. Sensitivity, Selectivity, and Stability of GasSensitive Metal-Oxide Nanostructures. Met. oxide nanostructures their Appl. 2010, 3, 31-52.

114. Marchisio, A.; Tulliani, J.-M. Semiconducting Metal Oxides Nanocomposites for Enhanced Detection of Explosive Vapors. Ceramics 2018, 1, 98-119.
115. Warmer, J.; Wagner, P.; Schöning, M. J.; Kaul, P. Detection of Triacetone Triperoxide Using Temperature Cycled MetalOxide Semiconductor Gas Sensors. Phys. Status Solidi Appl. Mater. Sci. 2015, 212, 1289-1298.

116. Patolsky, F.; Shacham, R.; Lichtenstein, A.; Havivi, E.; Modiln, H. Systems and Methods for Identifying Explosives. 24 July 2014; Patent number WO 2014111944 A8.

117. Tracense - explosives detection. http: //www.tracense.com/?page $\{$ _ $\mathrm{id}=714$, (visited on 14-01-2019).

118. Yang, Z.; Dou, X.; Zhang, S.; Guo, L.; Zu, B.; Wu, Z.; Zeng, H. A HighPerformance Nitro-Explosives Schottky Sensor Boosted by Interface Modulation. Adv. Funct. Mater. 2015, 25, 4039-4048.

119. Guo, L.; Yang, Z.; Dou, X. Artificial Olfactory System for Trace Identification of Explosive Vapors Realized by Optoelectronic Schottky Sensing. Adv. Mater. 2017, 29, 1604528.

120. Caron, Z.; Mallin, D.; Champlin, M.; Gregory, O. A Pre-Concentrator for Explosive Vapor Detection. ECS Trans. 2015, 66, $59-64$.

121. Ricci, P. P.; Rossi, A. S.; Gregory, O. J. Orthogonal Sensors for the Trace Detection of Explosives. IEEE Sensors Lett. 2019, 3, 2-5.

122. Zhang, Y.; Xu, M.; Bunes, B. R.; Wu, N.; Gross, D. E.; Moore, J. S.; Zang, L. Oligomer-Coated Carbon Nanotube Chemiresistive Sensors for Selective Detection of Nitroaromatic Explosives. ACS Appl. Mater. Interfaces 2015, 7, 7471-7475.

123. Ruan, W.; Li, Y.; Tan, Z.; Liu, L.; Jiang, K.; Wang, Z. In Situ Synthesized Carbon Nanotube Networks on a Microcantilever for Sensitive Detection of 
Explosive Vapors. Sensors Actuators, B Chem. 2013, 176, 141-148.

124. Martín-Palma, R. J.; MartínezDuart, J. M. Nanotechnol. Microelectron. Photonics; Elsevier, Oxford, 2017; pp 243-263.

125. Taylor, K. Encyclopedia of Paleoclimatology and Ancient Environments; Springer, Dordrecht, 2009; pp 1174-1179.

126. Sanjuán, A. M.; Reglero Ruiz, J. A.; García, F. C.; García, J. M. Recent Developments in Sensing Devices Based on Polymeric Systems. React. Funct. Polym. 2018, 133, 103-125.

127. Shukla, S. K.; Kushwaha, C. S.; Singh, N. B. Recent Developments in Conducting Polymer Based Composites for Sensing Devices. Mater. Today Proc. 2017, 4, 5672-5681.

128. Surya, S. G.; Nagarkar, S. S.; Ghosh, S. K.; Sonar, P.; Ramgopal Rao, V. OFET Based Explosive Sensors Using Diketopyrrolopyrrole and Metal Organic Framework Composite Active Channel Material. Sensors Actuators, B Chem. 2016, 223, 114-122.

129. Loch, A. S.; Stoltzfus, D. M.; Burn, P. L.; Shaw, P. E. High-Sensitivity Poly(dendrimer)-Based Sensors for the Detection of Explosives and Taggant Vapors. Macromolecules 2020, 53, 1652-1664.

130. Blue, R.; Thomson, N.; Taylor, S. J.; Fletcher, A. J.; Skabara, P. J.; Uttamchandani, D. Miniature Nitro and Peroxide Vapor Sensors Using Nanoporous Thin Films. IEEE Sens. J. 2016, 16, 87678774 .

131. Yuan, W.; Shi, G. Graphene-Based Gas Sensors. J. Mater. Chem. A 2013, 1, 10078-10091.
132. Novotný, F.; Urbanová, V.; Plutnar, J.; Pumera, M. Preserving Fine Structure Details and Dramatically Enhancing Electron Transfer Rates in Graphene 3DPrinted Electrodes via Thermal Annealing: Toward Nitroaromatic Explosives Sensing. ACS Appl. Mater. Interfaces 2019, 11, 35371-35375.

133. Pérez, E. M.; Martín, N. $\pi-\pi$ Interactions in Carbon Nanostructures. Chem. Soc. Rev. 2015, 44, 6425-6433.

134. Samaeifar, F.; Abdollahi, H. Graphene Oxide for High Sensitivity Detection of 2,4-Dinitrotoluene by Developing of a Heat Absorption Monitoring Sensor. Sensors Actuators, B Chem. 2019, 29\%, 126726 .

135. Yew, Y. T.; Ambrosi, A.; Pumera, M. Nitroaromatic Explosives Detection Using Electrochemically Exfoliated Graphene. Sci. Rep. 2016, 6, 1-11.

136. Masoumi, S.; Hajghassem, H.; Erfanian, A.; Rad, A. M. Design and Manufacture of TNT Explosives Detector Sensors Based on GFET. Sens. Rev. 2018, 38, 181-193.

137. Guo, S.; Wen, D.; Zhai, Y.; Dong, S.; Wang, E. Platinum Nanoparticle Ensemble-on-Graphene Hybrid Nanosheet: One-Pot, Rapid Synthesis, and Used as New Electrode Material for Electrochemical Sensing. ACS Nano 2010, 4, 3959-3968.

138. Rohaizad, N.; Sofer, Z.; Pumera, M. Boron and Nitrogen Dopants in Graphene Have Opposite Effects on the Electrochemical Detection of Explosive Nitroaromatic Compounds. Electrochem. commun. 2020, 112, 106660.

139. Shi, L.; Hou, A.; Chen, L.; Wang, Z. Electrochemical Sensor Prepared from Molecularly Imprinted Polymer for Recognition of TNT. Polym. Compos. 2015, 36, 12801285. 
140. Avaz, S.; Roy, R. B.; Mokkapati, V. R.; Bozkurt, A.; Pandit, S.; Mijakovic, I.; Menceloglu, Y. Z. Graphene Based Nanosensor for Aqueous Phase Detection of Nitroaromatics. $R S C A d v$. 2017, \%, 25519-25527.

141. Star, A.; Han, T. R.; Gabriel, J. C. P.; Bradley, K.; Grüner, G. Interaction of Aromatic Compounds with Carbon Nanotubes: Correlation to the Hammett Parameter of the Substituent and Measured Carbon Nanotube FET Response. Nano Lett. 2003, 3, 1421-1423.

142. Woods, L. M.; BÇŐdescu, . C.; Reinecke, T. L. Adsorption of Simple Benzene Derivatives on Carbon Nanotubes. Phys. Rev. B - Condens. Matter Mater. Phys. 2007, 75, 1-9.

143. Kumar, D.; Jha, P.; Chouksey, A.; Tandon, R. P.; Chaudhury, P. K.; Rawat, J. S. Flexible Single Walled Nanotube Based Chemical Sensor for 2,4-Dinitrotoluene Sensing. J. Mater. Sci. Mater. Electron. 2018, 29, 6200-6205.

144. Stefano, J. S.; Lima, A. P.; Nascentes, C. C.; Krzyzaniak, S. R.; Mello, P. A.; Gonçalves, J. M.; Richter, E. M.; Nossol, E.; Munoz, R. A. Electrochemical Detection of 2,4, 6Trinitrotoluene on Carbon Nanotube Modified Electrode: Effect of Acid Functionalization. J. Solid State Electrochem. 2020, 24, 121-129.

145. Ran, X.; Qu, Q.; Qian, X.; Xie, W.; Li, S.; Li, L.; Yang, L. Water-Soluble pillar[6]arene Functionalized NitrogenDoped Carbon Quantum Dots with Excellent Supramolecular Recognition Capability and Superior Electrochemical Sensing Performance towards TNT. Sensors Actuators, B Chem. 2018, 25\%, 362-371.

146. Wang, M.; Fu, Q.; Zhang, K.; Wan, Y.; Wang, L.; Gao, M.; Xia, Z.; Gao, D. A Magnetic and Carbon Dot Based Molecularly Imprinted Composite for Fluoromet- ric Detection of 2,4, 6-Trinitrophenol. $\mathrm{Mi}$ crochim. Acta 2019, 186, 86.

147. Ju, B.; Wang, Y.; Zhang, Y. M.; Zhang, T.; Liu, Z.; Li, M.; Xiao-An Zhang, S. Photostable and Low-Toxic Yellow-Green Carbon Dots for Highly Selective Detection of Explosive 2,4,6Trinitrophenol Based on the Dual Electron Transfer Mechanism. ACS Appl. Mater. Interfaces 2018, 10, 13040-13047.

148. Pisanic, T. R.; Zhang, Y.; Wang, T. H. Quantum Dots in Diagnostics and Detection: Principles and Paradigms. Analyst 2014, 139, 2968-2981.

149. Zhou, W.; Coleman, J. J. Semiconductor Quantum Dots. Curr. Opin. Solid State Mater. Sci. 2016, 20, 352-360.

150. Alivisatos, A. P. Semiconductor Clusters, Nanocrystals, and Quantum Dots. Science (80-. ). 1996, 271, 933-937.

151. Ghasemi, F.; Hormozi-Nezhad, M. R. Determination and Identification of $\mathrm{Ni}$ troaromatic Explosives by a DoubleEmitter Sensor Array. Talanta 2019, 201, 230-236.

152. Abbasi, F.; Akbarinejad, A.; Alizadeh, N. CdS QDs/N-Methylpolypyrrole Hybrids as Fluorescent Probe for Ultrasensitive and Selective Detection of Picric Acid. Spectrochim. Acta - Part A Mol. Biomol. Spectrosc. 2019, 216, 230-235.

153. Nguyen, A.; Gonzalez, C. M.; Sinelnikov, R.; Newman, W.; Sun, S.; Lockwood, R.; Veinot, J. G.; Meldrum, A. Detection of Nitroaromatics in the Solid, Solution, and Vapor Phases Using Silicon Quantum Dot Sensors. Nanotechnology 2016, 27.

154. Cui, Y.; Jin, Y.; Chen, X.; Wu, J. TwoDimensional Electrochemiluminescence on Porous Silicon Platform for Explosive Detection and Discrimination. ACS Sensors 2018, 3, 1439-1444. 
155. Wang, Y.; Hu, A. Carbon Quantum Dots: Synthesis, Properties and Applications. $J$. Mater. Chem. C 2014, 2, 6921-6939.

156. Chou, K. F.; Dennis, A. M. Förster Resonance Energy Transfer between Quantum Dot Donors and Quantum Dot Acceptors. Sensors (Switzerland) 2015, 15, 1328813325 .

157. Wang, S.; Li, N.; Pan, W.; Tang, B. Advances in Functional Fluorescent and Luminescent Probes for Imaging Intracellular Small-Molecule Reactive Species. TrAC - Trends Anal. Chem. 2012, 39, 337.

158. Khan, Z. M.; Saifi, S.; Shumaila,; Aslam, Z.; Khan, S. A.; Zulfequar, M. A Facile One Step Hydrothermal Synthesis of Carbon Quantum Dots for Label -Free Fluorescence Sensing Approach to Detect Picric Acid in Aqueous Solution. J. Photochem. Photobiol. A Chem. 2020, 388.

159. Ganiga, M.; Cyriac, J. Detection of PETN and RDX Using a FRET-Based Fluorescence Sensor System. Anal. Methods 2015, 7, 5412-5418.

160. Gong, W.; Li, H.; Gong, X.; Zhang, Z.; $\mathrm{Lu}, \mathrm{Z}$. Fabrication of Amine Functionalized CdSe@SiO2 Nanoparticles as Fluorescence Nanosensor for Highly Selective and Sensitive Detection of Picric Acid. Spectrochim. Acta - Part A Mol. Biomol. Spectrosc. 2020, 233, 118221.

161. Peveler, W. J.; Roldan, A.; Hollingsworth, N.; Porter, M. J.; Parkin, I. P. Multichannel Detection and Differentiation of Explosives with a Quantum Dot Array. ACS Nano 2016, 10, 1139-1146.

162. Peveler, W. J.; Jaber, S. B.; Parkin, I. P. Nanoparticles in Explosives Detection The State-of-the-Art and Future Directions. Forensic Sci. Med. Pathol. 2017, 13, 490-494.
163. Komikawa, T.; Tanaka, M.; Tamang, A.; Evans, S. D.; Critchley, K.; Okochi, M. Peptide-Functionalized Quantum Dots for Rapid Label-Free Sensing of 2,4,6Trinitrotoluene. Bioconjug. Chem. 2020,

164. Qian, J.; Hua, M.; Wang, C.; Wang, K.; Liu, Q.; Hao, N.; Wang, K. Fabrication of L-Cysteine-Capped CdTe Quantum Dots Based Ratiometric Fluorescence Nanosensor for Onsite Visual Determination of Trace TNT Explosive. Anal. Chim. Acta 2016, 946, 80-87.

165. Hassanzadeh, J.; Khataee, A.; Mosaei Oskoei, Y.; Fattahi, H.; Bagheri, N. Selective Chemiluminescence Method for the Determination of Trinitrotoluene Based on Molecularly Imprinted Polymer-Capped $\mathrm{ZnO}$ Quantum Dots. New J. Chem. 2017, 41, 10659-10667.

166. Kadian, S.; Manik, G. A Highly Sensitive and Selective Detection of Picric Acid Using Fluorescent Sulfur-Doped Graphene Quantum Dots. Luminescence 2020, 110.

167. Kaur, M.; Mehta, S. K.; Kansal, S. K. A Fluorescent Probe Based on Nitrogen Doped Graphene Quantum Dots for Turn Off Sensing of Explosive and Detrimental Water Pollutant, TNP in Aqueous Medium. Spectrochim. Acta - Part A Mol. Biomol. Spectrosc. 2017, 180, 37-43.

168. Partnership, P. F. An Introduction to Mems; Prime Faraday Partnership, Loughborough, 2002; pp 1-10.

169. Long, Z.; Kou, L.; Sepaniak, M. J.; Hou, X. Recent Advances in Gas Phase Microcantileverbased Sensing. Rev. Anal. Chem. 2013, 32, 135-158.

170. Chae, I.; Khan, M. F.; Song, J.; Lee, J.; Lee, J.; Thundat, T. Standoff Infrared Spectroscopy on Energetic Materials Using Hydrogel Microcantilevers. Proc. IEEE Int. Conf. Micro Electro Mech. Syst. 2016, 2016-Febru, 6-8. 
171. Palaparthy, V. S.; Doddapujar, S. N.; Gupta, G.; Das, P.; Chandorkar, S. A.; Mukherji, S.; Baghini, M. S.; Rao, V. R. E-Nose: Multichannel Analog Signal Conditioning Circuit with Pattern Recognition for Explosive Sensing. IEEE Sens. J. 2020, 20, 1373-1382.

172. Holthoff, E. L.; Li, L.; Hiller, T.; Turner, K. L. A Molecularly Imprinted Polymer (MIP)-Coated Microbeam MEMS Sensor for Chemical Detection. 2015, 94550W.

173. Udara, S.; Hadimani, H. C.; Revankar, P. K. Sensitivity and Selectivity Enhancement of MEMS/NEMS Cantilever by Coating of Polyvinylpyrrolidone. Mater. Today Proc. 2019, 18, 16101619 .

174. Mamo, S. K.; Gonzalez-Rodriguez, J. Development of a Molecularly Imprinted Polymer-Based Sensor for the Electrochemical Determination of Triacetone Triperoxide (TATP). Sensors (Switzerland) 2014, 14, 23269-23282.

175. Strle, D.; Štefane, B.; Trifkovič, M.; Van Miden, M.; Kvasić, I.; Zupanič, E.; Muševič, I. Chemical Selectivity and Sensitivity of a 16-Channel Electronic Nose for Trace Vapour Detection. Sensors 2017, $17,2845$.

176. Gradišek, A.; van Midden, M.; Koterle, M.; Prezelj, V.; Strle, D.; Štefane, B.; Brodnik, H.; Trifkovič, M.; Kvasić, I.; Zupanič, E.; Muševič, I. Improving the Chemical Selectivity of an Electronic Nose to TNT, DNT and RDX Using Machine Learning. Sensors (Switzerland) 2019, 19, 1-15.

177. Zandieh, O.; Kim, S. Sensitive and Selective Detection of Adsorbed Explosive Molecules Using Opto-Calorimetric Infrared Spectroscopy and MicroDifferential Thermal Analysis. Sensors Actuators, B Chem. 2016, 231, 393-398.
178. Tao, Y.; Kong, D.; Mei, T.; Zhang, T.; Lu, W.; Zhang, D. Development of an Explosive Detector with a MEMS Sensor Array. Int. J. Inf. Acquis. 2004, 1, 337-343.

179. Samaeifar, F.; Afifi, A.; Abdollahi, H. Trace 2,4-Dinitrotoluene Detection Using Suspended Membrane Micro-Hotplate Based on Heat Absorption Monitoring. Sensors Actuators, A Phys. 2018, 270, 25-33.

180. European Civil Aviation Conference. https://www.ecac-ceac.org/cep, https:// www.ecac-ceac.org/cep, (visited on 14-082018).

181. Keller, T.; Keller, A.; Tutsch-Bauer, E.; Monticelli, F. Application of Ion Mobility Spectrometry in Cases of Forensic Interest. Forensic Sci. Int. 2006, 161, 130-140.

182. Puton, J.; Namieśnik, J. Ion Mobility Spectrometry: Current Status and Application for Chemical Warfare Agents Detection. TrAC - Trends Anal. Chem. 2016, 85, 10-20.

183. Borsdorf, H.; Eiceman, G. A. Ion Mobility Spectrometry: Principles and Applications. Appl. Spectrosc. Rev. 2006, 41, $323-375$.

184. Haapala, M.; Pól, J.; Saarela, V.; Arvola, V.; Kotiaho, T.; Ketola, R. A.; Franssila, S.; Kauppila, T. J.; Kostiainen, R. Desorption Atmospheric Pressure Photoionization. Anal. Chem. 2007, 79, 7867-7872.

185. Khayamian, T.; Tabrizchi, M.; Jafari, M. T. Analysis of 2, 4, 6Trinitrotoluene, Pentaerythritol Tetranitrate and Cyclo-1, 3, 5-Trimethylene-2, 4, 6-Trinitramine Using Negative Corona Discharge Ion Mobility Spectrometry. Talanta 2002, 59, 327-333.

186. Tabrizchi, M.; ILbeigi, V. Detection of Explosives by Positive Corona Discharge Ion Mobility Spectrometry. J. Hazard. Mater. 2010, 176, 692-696. 
187. Yang, Z.; Pavlov, J.; Attygalle, A. B. Quantification and Remote Detection of Nitro Explosives by Helium Plasma Ionization Mass Spectrometry (HePI-MS) on a Modified Atmospheric Pressure Source Designed for Electrospray Ionization. $J$. Mass Spectrom. 2012, 47, 845-852.

188. Bruker DE-tector. https://www.bruker. $\mathrm{com} /$ products/cbrne-detection/ims/detector/overview.html, (visited on 24-012019).

189. Bruker RoadRunner. https:// www.bruker.com/products/cbrnedetection/ims/roadrunner/overview.html.

190. L3 B220 ${ }^{\mathrm{TM}}$ Desktop Trace Detector. http://www.sds.l3t.com/etd/B220-

desktop-ETD.htm, (visited on 24-012019).

191. Rapiscan Systems Itemiser 4DX. https://www.rapiscansystems.com/

en/products/itemiser-4dx, (visited on 24-01-2019).

192. Rapiscan Systems Itemiser DX. https://www.rapiscansystems.com/

en/products/itemiser- $\mathrm{dx}$, (visited on 24-01-2019).

193. Nuctech TR2000DB-A. http://www. nuctech.in/SitePages/ThDetailPage. aspx? $\mathrm{nk}=\mathrm{PAS}\{\&\} \mathrm{k}=\mathrm{BBFCBG}, \quad$ (visited on 24-01-2019).

194. Smiths Detection IONSCAN 500DT. https://www.smithsdetection.com/ products/ionscan-500dt-2/, (visited on 24-01-2019).

195. Smiths Detection Ionscan 600. https://www.smithsdetection.com/ products/ionscan-600/, (visited on 24-01-2019).

196. Smiths Detection MMTD (MultiMode Threat Detector). http://www. cbrnetechindex.com/Print/4249/smithsdetection-inc/mmtd-multi-mode-threatdetector, (visited on 24-01-2019).
197. Thermo Fisher Scientific EGIS Defender. https://assets.thermofisher. com/TFS-Assets/LSG/SpecificationSheets/D17430 .pdf, (visited on 24-012019).

198. Robinson, E. L.; Sisco, E.; Staymates, M. E.; Lawrence, J. A. A New Wipe-Sampling Instrument for Measuring the Collection Efficiency of Trace Explosives Residues. Anal. Methods 2018, 10, 204-213.

199. Choi, S.-S.; Son, C. E. Analytical Method for the Estimation of Transfer and Detection Efficiencies of Solid State Explosives Using Ion Mobility Spectrometry and Smear Matrix. Anal. Methods 2017, 9, 2505-2510.

200. DeGreeff, L. E.; Liddell, H. P.; Pogue, W. R.; Merrill, M. H.; Johnson, K. J. Effect of Re-Use of Surface Sampling Traps on Surface Structure and Collection Efficency for Trace Explosive Residues. Forensic Sci. Int. 2019, 297, 254-264.

201. Chouyyok, W.; Bays, J. T.; Gerasimenko, A. A.; Cinson, A. D.; Ewing, R. G.; Atkinson, D. A.; Addleman, R. S. Improved Explosive Collection and Detection with Rationally Assembled Surface Sampling Materials. $R S C$ Adv. 2016, 6, 94476-94485.

202. Kelley, J. A.; Ostrinskaya, A.; Geurtsen, G.; Kunz, R. R. Reagent Approaches for Improved Detection of Chlorate and Perchlorate Salts via Thermal Desorption and Ionization. Rapid Commun. Mass Spectrom. 2016, 30, 191-198.

203. Kelley, Jude A., Kunz, Roderick R., Ostrinskaya, A. Reagents for Enhanced Detection of Low Volatility Analytes. 8 October 2015; US 20150285780 A1.

204. Laster, J. S.; Ezeamaku, C. D.; Beaudoin, S. P.; Boudouris, B. W. Impact of Surface Chemistry on the Adhesion of an 
Energetic Small Molecule to a Conducting Polymer Surface. Colloids Surfaces A Physicochem. Eng. Asp. 2018, 551, 74-80.

205. Jiang, D.; Peng, L.; Wen, M.; Zhou, Q.; Chen, C.; Wang, X.; Chen, W.; Li, H. Dopant-Assisted Positive Photoionization Ion Mobility Spectrometry Coupled with Time-Resolved Thermal Desorption for On-Site Detection of Triacetone Triperoxide and Hexamethylene Trioxide Diamine in Complex Matrices. Anal. Chem. 2016, 88, 4391-4399.

206. Tsai, C. W.; Midey, A.; Wu, C.; Yost, R. A. Analysis of Ammonium Nitrate/Urea Nitrate with Crown Ethers and Sugars as Modifiers by Electrospray Ionization-Mass Spectrometry and Ion Mobility Spectrometry. Anal. Chem. 2016, 88, 9435-9442.

207. Smiths Detection - Multi-Mode Threat Detector (MMTD). https: //www.smithsdetection.com/index.php? option $=\mathrm{com}\left\{\_\right\} \mathrm{k} 2\{\&\}$ view $=\mathrm{item}\{\&\} \mathrm{id}=$ $118\{\&\}$ Itemid $=600\{\#\} . \mathrm{WjCaeUpl} 82 \mathrm{w}$, (visited on 13-12-2017).

208. Morpho - Hardened MobileTrace (HMT). https://www.morpho.com/sites/morpho/ files/morpho-hardened-mobiletrace-en022016\{_\}0.pdf, (visited on 13-12-2017).

209. Hauck, B. C.; Siems, W. F.; Harden, C. S.; McHugh, V. M.; Hill, H. H. Construction and Evaluation of a Hermetically Sealed Accurate Ion Mobility Instrument. Int. J. Ion Mobil. Spectrom. 2017, 1-10.

210. Kozole, J.; Stairs, J. R.; Cho, I.; Harper, J. D.; Lukow, S. R.; Lareau, R. T.; Debono, R.; Kuja, F. Interfacing an Ion Mobility Spectrometry Based Explosive Trace Detector to a Triple Quadrupole Mass Spectrometer. Anal. Chem. 2011, 83, 8596-8603.

211. Ewing, R. G.; Waltman, M. J.; Atkinson, D. A. Characterization of Triacetone
Triperoxide by Ion Mobility Spectrometry and Mass Spectrometry following Atmospheric Pressure Chemical Ionization. Anal. Chem. 2011, 83, 4838-4844.

212. Kozole, J.; Tomlinson-Phillips, J.; Stairs, J. R.; Harper, J. D.; Lukow, S. R.; Lareau, R. T.; Boudries, H.; Lai, H.; Brauer, C. S. Characterizing the Gas Phase Ion Chemistry of an Ion Trap Mobility Spectrometry Based Explosive Trace Detector Using a Tandem Mass Spectrometer. Talanta 2012, 99, 799-810.

213. Lee, J.; Park, S.; Cho, S. G.; Goh, E. M.; Lee, S.; Koh, S. S.; Kim, J. Analysis of Explosives Using Corona Discharge Ionization Combined with Ion Mobility Spectrometry-Mass Spectrometry. Talanta 2014, 120, 64-70.

214. Kozole, J.; Levine, L. A.; TomlinsonPhillips, J.; Stairs, J. R. Gas Phase Ion Chemistry of an Ion Mobility Spectrometry Based Explosive Trace Detector Elucidated by Tandem Mass Spectrometry. Talanta 2015, 140, 10-19.

215. Hilton, C. K.; Krueger, C. A.; Midey, A. J.; Osgood, M.; Wu, J.; Wu, C. Improved Analysis of Explosives Samples with Electrospray Ionization-High Resolution Ion Mobility Spectrometry (ESI-HRIMS). Int. J. Mass Spectrom. 2010, 298, 64-71.

216. Excellims ESI-IMS GA-2100. https://pdfs.semanticscholar.org/802b/ ac96dbe15fb2e5b0e2e18060c82011de7ef8. pdf, (visited on 08-05-2019).

217. Hagan, N.; Goldberg, I.; Graichen, A.; St. Jean, A.; Wu, C.; Lawrence, D.; Demirev, P. Ion Mobility Spectrometry - High Resolution LTQ-Orbitrap Mass Spectrometry for Analysis of Homemade Explosives. J. Am. Soc. Mass Spectrom. 2017, 28, 1531-1539.

218. Akmalov, A. E.; Chistyakov, A. A.; Kotkovskii, G. E. Laser-Stimulated Des- 
orption of Organic Molecules from Surfaces, as a Method of Increasing the Efficiency of Ion Mobility Spectrometry Analysis. Eur. J. Mass Spectrom. 2017, 23, 174-180.

219. Akmalov, A. E.; Chistyakov, A. A.; Kotkovskii, G. E.; Martynov, I. L.; Spitsin, E. M. Laser Ion Mobility Spectrometry in the Detection of Ultra-Low Quantities of Explosives. Eur. J. Mass Spectrom. 2017, 23, 140-145.

220. Akmalov, A. E.; Chistyakov, A. A.; Kotkovskii, G. E.; Teslya, A. Using Dopants to Increase the Sensitivity of a Laser Field Asymmetric Ion Mobility Spectrometer for Detection of Explosives. 2018; p 9.

221. Jafari Horestani, A. R.; Jafari, M. T.; Jazan, E.; Mossaddegh, M. Effect of Halide Ions on Secondary Electrospray Ionization-Ion Mobility Spectrometry for the Determination of TNT Extracted by Dispersive Liquid-Liquid Microextraction. Int. J. Mass Spectrom. 2018, 433, 19-24.

222. Shahraki, H.; Tabrizchi, M.; Farrokhpor, H. Detection of Explosives Using Negative Ion Mobility Spectrometry in Air Based on Dopant-Assisted Thermal Ionization. J. Hazard. Mater. 2018, 35\%, 1-9.

223. Chiluwal, U.; Lee, G.; Rajapakse, M. Y.; Willy, T.; Lukow, S.; Schmidt, H.; Eiceman, G. A. Tandem Ion Mobility Spectrometry at Ambient Pressure and Field Decomposition of Mobility Selected Ions of Explosives and Interferences. Analyst 2019,

224. Bunert, E.; Reinecke, T.; Kirk, A. T.; Bohnhorst, A.; Zimmermann, S. Ion Mobility Spectrometer with Orthogonal XRay Source for Increased Sensitivity. Talanta 2018, 185, 537-541.

225. Amo-González, M.; Pérez, S.; Delgado, R.; Arranz, G.; Carnicero, I. Tandem Ion Mobility Spectrometry for the Detection of
Traces of Explosives in Cargo at Concentrations of Parts per Quadrillion. Anal. Chem. 2019, 91, 14009-14018.

226. Namera, A.; Kawamura, M.; Nakamoto, A.; Saito, T.; Nagao, M. Comprehensive Review of the Detection Methods for Synthetic Cannabinoids and Cathinones. Forensic Toxicol. 2015, 33, 175-194.

227. Roda, A.; Michelini, E.; Zangheri, M.; Di Fusco, M.; Calabria, D.; Simoni, P. Smartphone-Based Biosensors: A Critical Review and Perspectives. TrAC - Trends Anal. Chem. 2016, 79, 317-325.

228. de Araujo, W. R.; Cardoso, T. M.; da Rocha, R. G.; Santana, M. H.; Muñoz, R. A.; Richter, E. M.; Paixão, T. R.; Coltro, W. K. Portable Analytical Platforms for Forensic Chemistry: A Review. Anal. Chim. Acta 2018, 1034, 1-21.

229. Meaney, M. S.; McGuffin, V. L. Luminescence-Based Methods for Sensing and Detection of Explosives. Anal. Bioanal. Chem. 2008, 391, 2557-2576.

230. Morphix TraceX. https://www.morphtec. com/tracex/, (visited on 23-01-2019).

231. ChemSee. https://www.chemsee.com/ commercial/explosive-detection/, (visited on 23-01-2019).

232. DetectaChem. https://www.detectachem. com/worldwide/seekere, (visited on 23-012019).

233. BBI Detection. http://www.bbidetection. com/distributor-hub/core-text-s2-threatdetk-letkv1draft/, (visited on 23-012019).

234. Mistral Security Inc. http:// www.mistralsecurityinc.com/OurProducts/Explosive-Detection-andIdentification-Field-Test-Kits/DropEx, (visited on 23-01-2019). 
235. Sun, X.; Wang, Y.; Lei, Y. Fluorescence Based Explosive Detection: From Mechanisms to Sensory Materials. Chem. Soc. Rev. 2015, 44, 8019-8061.

236. Zhou, X.; Liu, H.; Yang, L.; Liu, J. SERS and OWGS Detection of Dynamic Trapping Molecular TNT Based on a Functional Self-Assembly Au Monolayer Film. Analyst 2013, 138, 1858-1864.

237. Zhang, X.; Chen, S.; Jin, S.; Zhang, Y.; Chen, X.; Zhang, Z.; Shu, Q. Naphthalene Based Lab-on-a-Molecule for Fluorimetric and Colorimetric Sensing of F- and $\mathrm{CN}-$ and Nitroaromatic Explosives. Sensors Actuators, B Chem. 2017, 242, 994998.

238. Almog, J.; Klein, A.; Tamiri, T.; Shloosh, Y.; Abramovich-Bar, S. A Field Diagnostic Test for the Improvised Explosive Urea Nitrate. J. Forensic Sci. 2005, $50,582-6$.

239. Zhao, M.; Yu, H.; He, Y. A Dynamic Multichannel Colorimetric Sensor Array for Highly Effective Discrimination of Ten Explosives. Sensors Actuators, B Chem. 2019, 283, 329-333.

240. Mukherjee, S.; Ganguly, S.; Chakraborty, A.; Mandal, A.; Das, D. Green Synthesis of Self Assembled Nanospherical Dysprosium MOFs: Selective and Efficient Detection of Picric Acid in Aqueous and Gas Phase. ACS Sustain. Chem. Eng. 2019, 7, 819-830.

241. Itzhaky, H.; Keinan, E. Method and Kit for the Detection of Explosives. 1999, 1, 4-7.

242. Schulte-Ladbeck, R.; Kolla, P.; Karst, U. A Field Test for the Detection of PeroxideBased Explosives. Analyst 2002, 127, 1152-1154.

243. Fan, S.; Lai, J.; Burn, P. L.; Shaw, P. E. Solid-State Fluorescence-Based Sensing of TATP via Hydrogen Peroxide Detection. ACS Sensors 2019, 4, 134-142.
244. Liu, J.; Zhong, Y.; Lu, P.; Hong, Y.; Lam, J. W.; Faisal, M.; Yu, Y.; Wong, K. S.; Tang, B. Z. A Superamplification Effect in the Detection of Explosives by a Fluorescent Hyperbranched Poly(silylenephenylene) with Aggregation-Enhanced Emission Characteristics. Polym. Chem. 2010, 1, 426-429.

245. Wang, C.; Tian, L.; Zhu, W.; Wang, S.; Wang, P.; Liang, Y.; Zhang, W.; Zhao, H.; Li, G. Dye@bio-MOF-1 Composite as a Dual-Emitting Platform for Enhanced Detection of a Wide Range of Explosive Molecules. ACS Appl. Mater. Interfaces 2017, 9, 20076-20085.

246. Fu, H. R.; Yan, L. B.; Wu, N. T.; Ma, L. F.; Zang, S. Q. Dual-Emission MOF Dye Sensor for Ratiometric Fluorescence Recognition of RDX and Detection of a Broad Class of Nitro-Compounds . $J$. Mater. Chem. A 2018, 6, 9183-9191.

247. Jurcic, M.; Peveler, W. J.; Savory, C. N.; Bučar, D.-K.; Kenyon, A. J.; Scanlon, D. O.; Parkin, I. P. Sensing and Discrimination of Explosives at Variable Concentrations with a Large-Pore MOF as Part of a Luminescent Array. ACS Appl. Mater. Interfaces 2019, 11, 11618-11626.

248. Zhu, C.; Perman, J. A.; Gerald, R. E.; Ma, S.; Huang, J. Chemical Detection Using a Metal-Organic Framework Single Crystal Coupled to an Optical Fiber. ACS Appl. Mater. Interfaces 2019, 11, 43934398.

249. Zhao, L.; Gan, J.; Xia, T.; Jiang, L.; Zhang, J.; Cui, Y.; Qian, G.; Yang, Z. A Luminescent Metal-Organic Framework Integrated Hydrogel Optical Fibre as a Photoluminescence Sensing Platform for Fluorescence Detection. J. Mater. Chem. C 2019, 7, 897-904.

250. Chen, D. M.; Tian, J. Y.; Wang, Z. W.; Liu, C. S.; Chen, M.; Du, M. An Anionic $\mathrm{Na}(\mathrm{i})$-Organic Framework Platform: 
Separation of Organic Dyes and PostModification for Highly Sensitive Detection of Picric Acid. Chem. Commun. 2017, 53, 10668-10671.

251. Sharma, A.; Kim, D.; Park, J.-H.; Rakshit, S.; Seong, J.; Jeong, G. H.; Kwon, O.H.; Lah, M. S. Mechanistic Insight into the Sensing of Nitroaromatic Compounds by Metal-Organic Frameworks. Commun. Chem. 2019, 2, 39.

252. Wang, Q.; Liu, D. J.; Cui, L. L.; $\mathrm{Hu}$, X. L.; Wang, X. L.; Su, Z. M. A 3D Pillared-Layer Metal-Organic Framework with Fluorescence Property for Detection of Nitroaromatic Explosives. New J. Chem. 2019, 43, 963-969.

253. Yao, S. L.; Liu, S. J.; Cao, C.; Tian, X. M.; Bao, M. N.; Zheng, T. F. Temperatureand Solvent-Dependent Structures of Three Zinc(II) Metal-Organic Frameworks for Nitroaromatic Explosives Detection. J. Solid State Chem. 2019, 269, 195-202.

254. Zhan, Z.; Liang, X.; Zhang, X.; Jia, Y.; $\mathrm{Hu}$, M. A Water-Stable Europium-MOF as a Multifunctional Luminescent Sensor for Some Trivalent Metal Ions (Fe $3+$, Cr $3+, \mathrm{Al} 3+$ ), PO 43- Ions, and Nitroaromatic Explosives. Dalt. Trans. 2019, 48, 1786-1794.

255. Zhang, X. J.; Su, F. Z.; Chen, D. M.; Peng, Y.; Guo, W. Y.; Liu, C. S.; Du, M. A Water-Stable EU III -Based MOF as a Dual-Emission Luminescent Sensor for Discriminative Detection of Nitroaromatic Pollutants. Dalt. Trans. 2019, 48, 18431849.

256. Liu, W.; Huang, X.; Chen, C.; Xu, C.; Ma, J.; Yang, L.; Wang, W.; Dou, W.; Liu, W. Function-Oriented: The Construction of Lanthanide MOF Luminescent Sensors Containing Dual-Function Urea Hydrogen-Bond Sites for Efficient Detection of Picric Acid. Chem. - A Eur. J. 2019, 25, 1090-1097.
257. Qiao, X.; Han, Y.; Tian, D.; Yang, Z.; Li, J.; Zhao, S. MOF Matrix Doped with Rare Earth Ions to Realize Ratiometric Fluorescent Sensing of 2,4, 6Trinitrophenol: Synthesis, Characterization and Performance. Sensors Actuators, $B$ Chem. 2019, 286, 1-8.

258. Zhou, Q.; Swager, T. M. Fluorescent Chemosensors Based on Energy Migration in Conjugated Polymers: The Molecular Wire Approach to Increased Sensitivity. $J$. Am. Chem. Soc. 1995, 117, 12593-12602.

259. Yang, J. S.; Swager, T. M. Porous Shape Persistent Fluorescent Polymer Films: An Approach to TNT Sensory Materials. J. Am. Chem. Soc. 1998, 120, 5321-5322.

260. Thomas, S. W.; Joly, G. D.; Swager, T. M. Chemical Sensors Based on Amplifying Fluorescent Conjugated Polymers. Chem. Rev. 2007, 10\%, 1339-1386.

261. FLIR - Fido X2. https://www.flir.co. $\mathrm{uk} /$ products/fido-x2/, (visited on 29-042019).

262. Aker, C. A.; Cumming, C. J.; Fisher, M. E.; Fox, M. J.; La Grone, M.; Reust, D. K.; Rockley, M. G.; Towers, E. S. Vapor Sensing Instrument for Ultra Trace Chemical Detection. 6 May 2003; Patent number US006558626B1.

263. Ma, X. S.; Wang, D. H.; Cui, Y. Z.; Tao, F. R.; Wang, Y. T.; Li, T. D. A Novel Hydrophilic Conjugated Polymer Containing Hydroxyl Groups: Syntheses and Sensing Performance for NACs in Aqueous Solution. Sensors Actuators, B Chem. 2017, 251, 851-857.

264. Luo, J.; Xie, Z.; Xie, Z.; Lam, J. W.; Cheng, L.; Chen, H.; Qiu, C.; Kwok, H. S.; Zhan, X.; Liu, Y.; Zhu, D.; Tang, B. Z. Aggregation-Induced Emission of 1Methyl-1,2, 3,4, 5-Pentaphenylsilole. Chem. Commun. 2001, 18, 1740-1741.

265. Zhou, H.; Chua, M. H.; Tang, B. Z.; $\mathrm{Xu}, \quad$ J. Aggregation-Induced Emission 
(AIE)-Active Polymers for Explosive Detection. Polym. Chem. 2019, 10, 38223840 .

266. Wu, H.; Tao, F.; Cui, Y.; Guo, L. Two Triphenylamine-Based AIE Materials for the Detection of PA in Aqueous Medium. Mater. Chem. Phys. 2020, 240, 122141.

267. Zhu, Q.; Xiong, W.; Gong, Y.; Zheng, Y.; Che, Y.; Zhao, J. Discrimination of Five Classes of Explosives by a Fluorescence Array Sensor Composed of Two Tricarbazole-Nanostructures. Anal. Chem. 2017, 89, 11908-11912.

268. Xiong, W.; Zhu, Q.; Gong, Y.; Wang, C.; Che, Y.; Zhao, J. Interpenetrated Binary Supramolecular Nanofibers for Sensitive Fluorescence Detection of Six Classes of Explosives. Anal. Chem. 2018, 90, 42734276.

269. Ma, H.; Li, F.; Zhang, Y.; Li, X.; Li, T.; Shen, F.; Zhang, M. Supramolecular Self-Assembly Carbazolyl Radicals Nanospheres Triggered by Ultraviolet Light for Explosives Sensing. Talanta 2016, 160, 133-137.

270. Arshad, A.; Wang, H.; Bai, X.; Jiang, R.; $\mathrm{Xu}$, S.; Wang, L. Colorimetric Paper Sensor for Sensitive Detection of Explosive Nitroaromatics Based on Au@Ag Nanoparticles. Spectrochim. Acta - Part A Mol. Biomol. Spectrosc. 2019, 206, 16-22.

271. Idros, N.; Ho, M. Y.; Pivnenko, M.; Qasim, M. M.; Xu, H.; Gu, Z.; Chu, D. Colorimetric-Based Detection of TNT Explosives Using Functionalized Silica Nanoparticles. Procedia Technol. 2017, 27, 312-314.

272. Tawfik, S. M.; Sharipov, M.; Kakhkhorov, S.; Elmasry, M. R.; Lee, Y. I. Multiple Emitting Amphiphilic Conjugated Polythiophenes-Coated CdTe QDs for Picogram Detection of Trinitrophenol Explosive and Application Using Chitosan Film and Paper-Based Sensor Coupled with Smartphone. Adv. Sci. 2019, 6 .
273. Verbitskiy, E. V.; Baranova, A. A.; Lugovik, K. I.; Khokhlov, K. O.; Cheprakova, E. M.; Shafikov, M. Z.; Rusinov, G. L.; Chupakhin, O. N.; Charushin, V. N. New 4,5Di(hetero)arylpyrimidines as Sensing Elements for Detection of Nitroaromatic Explosives in Vapor Phase. Dye. Pigment. 2017, 137, 360-371.

274. Hu, J.; Wang, C.; Liu, R.; Su, Y.; Lv, Y. Poly(thymine)-CuNPs: Bimodal Methodology for Accurate and Selective Detection of TNT at Sub-PPT Levels. Anal. Chem. 2018, 90, 14469-14474.

275. Roushani, M.; Shahdost-fard, F.; Azadbakht, A. Using Au@nano-C60 Nanocomposite as an Enhanced Sensing Platform in Modeling a TNT Aptasensor. Anal. Biochem. 2017, 534, 78-85.

276. Aparna, R. S.; Anjali Devi, J. S.; Sachidanandan, P.; George, S. Polyethylene Imine Capped Copper Nanoclusters- Fluorescent and Colorimetric Onsite Sensor for the Trace Level Detection of TNT. Sensors Actuators, B Chem. 2018, 254, 811819.

277. Vinita,; Tiwari, M.; Prakash, R. Colorimetric Detection of Picric Acid Using Silver Nanoparticles Modified with 4-Amino-3-Hydrazino-5-Mercapto-1,2, 4Triazole. Appl. Surf. Sci. 2018, 449, 174180 .

278. Devi, S.; Kaur, R.; Paul, A. K.; Tyagi, S. MPA-Capped CdSe QD/Mercaptoethylamine-Capped AuNP Nanocomposite-Based Sensor for Instant Detection of Trinitrotoluene. Colloid Polym. Sci. 2018, 296, 427-440.

279. Can, Z.; Üzer, A.; Türkekul, K.; ErçâEĞ, E.; Apak, R. Determination of Triacetone Triperoxide with a N,NDimethyl-P-Phenylenediamine Sensor on Nafion Using Fe3O4 Magnetic Nanoparticles. Anal. Chem. 2015, 87, 9589-9594. 
280. Ghosh, D.; Dutta, U.; Haque, A.; Mordvinova, N. E.; Lebedev, O. I.; Pal, K.; Gayen, A.; Seikh, M. M.; Mahata, P. Ultra-High Sensitivity of Luminescent ZnCr2O4 Nanoparticles toward Nitroaromatic Explosives Sensing. Dalt. Trans. 2018, 47, 5011-5018.

281. Üzer, A.; Durmazel, S.; ErçaÄ§, E.; Apak, R. Determination of Hydrogen Peroxide and Triacetone Triperoxide (TATP) with a Silver Nanoparticles-Based TurnOn Colorimetric Sensor. Sensors Actuators, B Chem. 2017, 247, 98-107.

282. Du, J. L.; Zhang, X. Y.; Li, C. P.; Gao, J. P.; Hou, J. X.; Jing, X.; Mu, Y. J.; Li, L. J. A Bi-Functional Luminescent $\mathrm{Zn}(\mathrm{II})-\mathrm{MOF}$ for Detection of Nitroaromatic Explosives and $\mathrm{Fe} 3+$ ions. Sensors Actuators, B Chem. 2018, 257, 207-213.

283. Bagheri, N.; Khataee, A.; Hassanzadeh, J.; Habibi, B. Visual Detection of Peroxide-Based Explosives Using Novel Mimetic Ag Nanoparticle/ZnMOF Nanocomposite. J. Hazard. Mater. 2018, 360, 233-242.

284. He, N.; Gao, M.; Shen, D.; Li, H.; Han, Z.; Zhao, P. Rapid Visual Detection of Nitroaromatic Explosives Using a Luminescent Europium-Organic Framework Material. Forensic Sci. Int. 2019, 297, 1-7.

285. Zhang, X. D.; Zhao, Y.; Chen, K.; Guo, J. H.; Wang, P.; Wu, H.; Sun, W. Y. Cucurbit[6]uril-Based Supramolecular Assemblies Incorporating Metal Complexes with Multiaromatic Ligands as StructureDirecting Agent for Detection of Aromatic Amines and Nitroaromatic Compounds. Sensors Actuators, B Chem. 2019, 282, 844-853.

286. Chen, L.; Gao, Y.; Fu, Y.; Zhu, D.; He, Q.; Cao, H.; Cheng, J. Borate Ester Endcapped Fluorescent Hyperbranched Conjugated Polymer for Trace Peroxide Explosive Vapor Detection. $R S C A d v$. 2015, 5, 29624-29630.
287. Gao, Y.; Mu, D.; Guan, P.; Guo, P.; Song, H. A Simple Functionalized Silica Microsphere for Fast PETN Vapor Detection Based on Fluorescence Color Changes via a Catalyzed Oxidation Process. Analyst 2019, 144, 1361-1368.

288. Peng, X.; Liu, H.; Liu, A.; Xu, W.; Fu, Y.; He, Q.; Cao, H.; Cheng, J. Ultrasensitive and Direct Fluorescence Detection of RDX Explosive Vapor: Via Side-Chain Terminal Functionalization of a Polyfluorene Probe. Anal. Methods 2018, 10, 1695-1702.

289. Dong, W.; Ma, Z.; Chen, P.; Duan, Q. Carbazole and Tetraphenylethylene Based AIE-Active Conjugated Polymer for Highly Sensitive TNT Detection. Mater. Lett. 2019, 236, 480-482.

290. He, H.; Qi, W.; Fu, Y.; Zhao, M.; Qi, L.; Li, R. Glutaraldehyde Non-Conjugated Chitosan Polymer Fluorophores for Selective Determination of Picric Acid via Fluorescence Resonance Energy Transfer Strategy. Dye. Pigment. 2019, 165, 2530.

291. Panigrahi, A.; Sahu, B. P.; Mandani, S.; Nayak, D.; Giri, S.; Sarma, T. K. AIE Active Fluorescent Organic Nanoaggregates for Selective Detection of PhenolicNitroaromatic Explosives and Cell Imaging. J. Photochem. Photobiol. A Chem. 2019, 374, 194-205.

292. Xu, W.; Fu, Y.; Gao, Y.; Yao, J.; Fan, T.; Zhu, D.; He, Q.; Cao, H.; Cheng, J. A Simple but Highly Efficient Multi-Formyl Phenol-Amine System for Fluorescence Detection of Peroxide Explosive Vapour. Chem. Commun. 2015, 51, 10868-10870.

293. An, Y.; Xu, X.; Liu, K.; An, X.; Shang, C.; Wang, G.; Liu, T.; Li, H.; Peng, H.; Fang, Y. Fast, Sensitive, Selective and Reversible Fluorescence Monitoring of TATP in a Vapor Phase. Chem. Commun. 2019, 941-944. 
294. Wang, C.; Huang, H.; Bunes, B. R.; Wu, N.; Xu, M.; Yang, X.; Yu, L.; Zang, L. Trace Detection of RDX, HMX and PETN Explosives Using a Fluorescence Spot Sensor. Sci. Rep. 2016, 6, 1-9.

295. Jiang, K.; Luo, S. H.; Pang, C. M.; Wang, B. W.; Wu, H. Q.; Wang, Z. Y. A Functionalized Fluorochrome Based on Quinoline-Benzimidazole Conjugate: From Facile Design to Highly Sensitive and Selective Sensing for Picric Acid. Dye. Pigment. 2019, 162, 367-376.

296. Madhu, P.; Sivakumar, P. CurcuminBased Fluorescent Chemosensor for Selective and Efficient Detection of Picric Acid. J. Mol. Struct. 2019, 1185, 410-415.

297. Garreffi, B. P.; Guo, M.; Tokranova, N.; Cady, N. C.; Castracane, J.; Levitsky, I. A. Highly Sensitive and Selective Fluorescence Sensor Based on Nanoporous Silicon-Quinoline Composite for Trace Detection of Hydrogen Peroxide Vapors. Sensors Actuators, B Chem. 2018, 276, 466471.

298. Kose, M.; KÄśrpÄśk, H.; Kose, A. Fluorimetric Detections of Nitroaromatic Explosives by Polyaromatic Imine Conjugates. J. Mol. Struct. 2019, 1185, 369-378.

299. López-López, M.; García-Ruiz, C. Infrared and Raman Spectroscopy Techniques Applied to Identification of Explosives. TrAC - Trends Anal. Chem. 2014, $54,36-44$.

300. Chen, Z.; Xiao, C.; Xiao, W.; Qin, M.; Liu, X. A Review on Several Key Problems of Standoff Trace Explosives Detection by Optical-Related Technology. Int. Conf. Optoelectron. Microelectron. Technol. Appl. 2017; p $102440 \mathrm{H}$.

301. Zapata, F.; López-López, M.; GarcíaRuiz, C. Detection and Identification of Explosives by Surface Enhanced Raman Scattering. Appl. Spectrosc. Rev. 2016, 51, 207-242.
302. Hakonen, A.; Andersson, P. O.; Stenbæk Schmidt, M.; Rindzevicius, T.; Käll, M. Explosive and Chemical Threat Detection by Surface-Enhanced Raman Scattering: A Review. Anal. Chim. Acta 2015, 893, $1-13$.

303. Gillibert, R.; Huang, J. Q.; Zhang, Y.; Fu, W. L.; Lamy de la Chapelle, M. Explosive Detection by Surface Enhanced Raman Scattering. TrAC - Trends Anal. Chem. 2018, 105, 166-172.

304. Guicheteau, J.; Hopkins, R. Applications of Spatially Offset Raman Spectroscopy to Defense and Security. Proc. SPIE. 2016, 9824, $76-85$.

305. Liu, Q.; Zhang, X. Study and Application of New Raman Spectroscopy. Proc. SPIE. 2016, 10255, 1-8.

306. Stiles, P. L.; Dieringer, J. A.; Shah, N. C.; Duyne, R. P. V. Surface-Enhanced Raman Spectroscopy. Annu. Rev. Anal. Chem. 2008, 1, 601-626.

307. Le Ru, E. C.; Etchegoin, P. G. SingleMolecule Surface-Enhanced Raman Spectroscopy. Annu. Rev. Phys. Chem. 2012, 63, 65-87.

308. Smiths Detection ACE-ID. https://www. smithsdetection.com/products/ace-id/, (visited on 24-01-2019).

309. Nuchtech - RT1003. http://www. nuctechwarsaw.com/SitePages/ ThDetailPage.aspx? $\mathrm{nk}=\mathrm{PAS}\{\&\} \mathrm{k}=$ EIFBGB, (visited on 23-01-2019).

310. Thermo Fisher Scientific FirstDefenderấćc RMX. https://www. thermofisher.com/order/catalog/ product/FIRSTDEFENDERRMX, (visited on 24-01-2019).

311. Thermo Fisher Scientific Gemini Analyzer. https://www.thermofisher. com/order/catalog/product/GEMINI\# / GEMINI, (visited on 24-01-2019). 
312. Agilent Insight100M and Insight200M. https://www.agilent.com/ en/products/raman-spectroscopy/ramanspectroscopy-systems/aviation-security, (visited on 24-01-2019).

313. Agilent Resolve. https://www.agilent. com/en/products/raman-spectroscopy/ raman-spectroscopy-systems/handheldchemical-identification/resolve, (visited on 24-01-2019).

314. Real-Time Analyzers Portable SERS Analyser (PSA). http: //www.rta.biz/products/special-orderproducts/portable-sers-analyzer-psa/, (visited on 24-01-2019).

315. Hamamatsu - SERS Detection Module. https://www.hamamatsu.com/jp/ en/product/type/C13560/index.html, (visited on 19-04-2019).

316. Albrecht, M. G.; Creighton, J. A. Anomalously Intense Raman Spectra of Pyridine at a Silver Electrode. J. Am. Chem. Soc. 1977, 99, 5215-5217.

317. Haynes, C. L.; Van Duyne, R. P. Plasmon-Sampled Surface-Enhanced Raman Excitation Spectroscopy. J. Phys. Chem. B 2003, 10\%, 7426-7433.

318. McFarland, A. D.; Young, M. A.; Dieringer, J. A.; Duyne, R. P. V. Wavelength-Scanned Surface-Enhanced Raman Excitation Spectroscopy. J. Phys. Chem. C 2005, 109, 11279-11285.

319. Samransuksamer, B.; Horprathum, M.; Jutarosaga, T.; Kopwitthaya, A.; Limwichean, S.; Nuntawong, N.; Chananonnawathorn, C.; Patthanasettakul, V.; Muthitamongkol, P.; Treetong, A.; Klamchuen, A.; Leelapojanaporn, A.; Thanachayanont, C.; Eiamchai, P. Facile Method for Decorations of $\mathrm{Au}$ Nanoparticles on TiO2 Nanorod Arrays toward High-Performance Recyclable SERS Substrates. Sensors Actuators, B Chem. 2018, 277, 102-113.
320. Zhou, H.; Zhang, Z.; Jiang, C.; Guan, G.; Zhang, K.; Mei, Q.; Liu, R.; Wang, S. Trinitrotoluene Explosive Lights Up Ultrahigh Raman Scattering of Nonresonant Molecule on a Top-Closed Silver Nanotube Array. Anal. Chem. 2011, 83, 6913-6917.

321. Vendamani, V. S.; Nageswara Rao, S. V.; Venugopal Rao, S.; Kanjilal, D.; Pathak, A. P. Three-Dimensional Hybrid Silicon Nanostructures for Surface Enhanced Raman Spectroscopy Based Molecular Detection. J. Appl. Phys. 2018, 123.

322. Xu, J. Y.; Wang, J.; Kong, L. T.; Zheng, G. C.; Guo, Z.; Liu, J. H. SERS Detection of Explosive Agent by Macrocyclic Compound Functionalized Triangular Gold Nanoprisms. J. Raman Spectrosc. 2011, 42, 1728-1735.

323. Liyanage, T.; Rael, A.; Shaffer, S.; Zaidi, S.; Goodpaster, J. V.; Sardar, R. Fabrication of a Self-Assembled and Flexible SERS Nanosensor for Explosive Detection at Parts-per-Quadrillion Levels from Fingerprints. Analyst 2018, 143, 20122022.

324. Liu, X.; Zhao, L.; Shen, H.; Xu, H.; Lu, L. Ordered Gold Nanoparticle Arrays as Surface-Enhanced Raman Spectroscopy Substrates for Label-Free Detection of Nitroexplosives. Talanta 2011, 83, 10231029 .

325. Lombardi, J. R.; Birke, R. L.; Lu, T.; $\mathrm{Xu}$, J. Charge-Transfer Theory of Surface Enhanced Raman Spectroscopy: Herzberg-Teller Contributions. J. Chem. Phys. 1986, 84, 4174-4180.

326. Campion, A.; Ivanecky, J. E.; Child, C. M.; Foster, M. On the Mechanism of Chemical Enhancement in Surface-Enhanced Raman Scattering. J. Am. Chem. Soc. 1995, 117, 11807-11808.

327. Otto, A. The 'Chemical' (Electronic) Contribution to Surface-Enhanced Raman 
Scattering. J. Raman Spectrosc. 2005, 36, 497-509.

328. Idros, N.; Ho, M. Y.; Pivnenko, M.; Qasim, M. M.; Xu, H.; Gu, Z.; $\mathrm{Chu}$, D. Colorimetric-Based Detection of TNT Explosives Using Functionalized Silica Nanoparticles. Sensors (Switzerland) 2015, 15, 12891-12905.

329. Ular, N.; Üzer, A.; Durmazel, $\quad$ S.; $\quad$ ErçaÇ $\breve{g}, \quad$ E.; Apak, R. DiaminocyclohexaneFunctionalized/Thioglycolic AcidModified Gold Nanoparticle-Based Colorimetric Sensing of Trinitrotoluene and Tetryl. ACS Sensors 2018, 3, 2335-2342.

330. Yang, L.; Ma, L.; Chen, G.; Liu, J.; Tian, Z. Q. Ultrasensitive SERS Detection of TNT by Imprinting Molecular Recognition Using a New Type of Stable Substrate. Chem. - A Eur. J. 2010, 16, 12683-12693.

331. Piorek, B. D.; Lee, S. J.; Moskovits, M.; Meinhart, C. D. Free-Surface Microfluidics/Surface-Enhanced Raman Spectroscopy for Real-Time Trace Vapor Detection of Explosives. Anal. Chem. 2012, 84, 9700-9705.

332. Gupta, P.; Luan, J.; Wang, Z.; Cao, S.; Bae, S. H.; Naik, R. R.; Singamaneni, S. On-Demand Electromagnetic Hotspot Generation in Surface-Enhanced Raman Scattering Substrates via "AddOn" Plasmonic Patch. ACS Appl. Mater. Interfaces 2019, 11, 37939-37946.

333. Shi, Y. e.; Wang, W.; Zhan, J. A Positively Charged Silver Nanowire Membrane for Rapid On-Site Swabbing Extraction and Detection of Trace Inorganic Explosives Using a Portable Raman Spectrometer. Nano Res. 2016, 9, 2487-2497.

334. Liu, J.; Si, T.; Zhang, Z. Mussel-Inspired Immobilization of Silver Nanoparticles toward Sponge for Rapid Swabbing Extrac- tion and SERS Detection of Trace Inorganic Explosives. Talanta 2019, 204, 189 197.

335. Alessandri, I. Enhancing Raman Scattering without Plasmons: Unprecedented Sensitivity Achieved by TiO2 Shell-Based Resonators. J. Am. Chem. Soc. 2013, 135, 5541-5544.

336. Lombardi, J. R.; Birke, R. L. Theory of Surface-Enhanced Raman Scattering in Semiconductors. J. Phys. Chem. C 2014, $118,11120-11130$.

337. Shaik, U. P.; Hamad, S.; Mohiddon, M. A.; Soma, V. R.; Ghanashyam Krishna, M. Morphologically Manipulated $\mathrm{Ag} / \mathrm{ZnO}$ Nanostructures as Surface Enhanced Raman Scattering Probes for Explosives Detection. J. Appl. Phys. 2016, 119.

338. Garg, P.; Bharti,; Soni, R. K.; Raman, R. Graphene Oxide-Silver Nanocomposite SERS Substrate for Sensitive Detection of Nitro Explosives. J. Mater. Sci. Mater. Electron. 2019,

339. Kanchanapally, R.; Sinha, S. S.; Fan, Z.; Dubey, M.; Zakar, E.; Ray, P. C. Graphene Oxide-Gold Nanocage Hybrid Platform for Trace Level Identification of Nitro Explosives Using a Raman Fingerprint. $J$. Phys. Chem. C 2014, 118, 7070-7075.

340. De La Cruz-Montoya, E.; Jeréz, J. I.; Balaguera-Gelves, M.; Luna-Pineda, T.; Castro, M. E.; Hernández-Rivera, S. P. Enhanced Raman Spectroscopy of 2,4, 6-TNT in Anatase and Rutile Titania Nanocrystals. 2006, 62030X.

341. Dharmalingam, P.; Venkatakrishnan, K.; Tan, B. An Atomic-Defect Enhanced Raman Scattering (DERS)quantum Probe for Molecular Level Detection - Breaking the SERS Barrier. Appl. Mater. Today 2019, 16, 28-41. 
342. Ben-Jaber, S.; Peveler, W. J.; QuesadaCabrera, R.; Cortés, E.; SoteloVazquez, C.; Abdul-Karim, N.; Maier, S. A.; Parkin, I. P. PhotoInduced Enhanced Raman Spectroscopy for Universal Ultra-Trace Detection of Explosives, Pollutants and Biomolecules. Nat. Commun. 2016, 7, 1-6.

343. Glass, D.; Cortés, E.; Ben-Jaber, S.; Brick, T.; Peveler, W. J.; Blackman, C. S.; Howle, C. R.; Quesada-Cabrera, R.; Parkin, I. P.; Maier, S. A. Dynamics of Photo-Induced Surface Oxygen Vacancies in Metal-Oxide Semiconductors Studied Under Ambient Conditions. Adv. Sci. 2019, 6 .

344. Botti, S.; Cantarini, L.; Palucci, A. Surface-Enhanced Raman Spectroscopy for Trace-Level Detection of Explosives. $J$. Raman Spectrosc. 2010, 41, 866-869.

345. Botti, S.; Carpanese, M.; Cantarini, L.; Giubileo, G.; Lazic, V.; Jovicevic, S.; Palucci, A.; Puiu, A. Trace Detection of Explosive Compounds by Different LaserBased Techniques at the ENEA Laboratories. 2010, 76650 O.

346. Farrell, M. E.; Holthoff, E. L.; Pellegrino, P. M. Surface-Enhanced Raman Scattering Detection of Ammonium Nitrate Samples Fabricated Using Drop-onDemand Inkjet Technology. Appl. Spectrosc. 2014, 68, 287-296.

347. Hankus, M. E.; Stratis-Cullum, D. N.; Pellegrino, P. M. Characterization of Next-Generation Commercial SurfaceEnhanced Raman Scattering (SERS) Substrates. Chem. Biol. Radiol. Nucl. Explos. Sens. XII 2011, 8018, 80180P.

348. Gao, J.; Zhang, N.; Ji, D.; Song, H.; Liu, Y.; Zhou, L.; Sun, Z.; Jornet, J. M.; Thompson, A. C.; Collins, R. L.; Song, Y.; Jiang, S.; Gan, Q. Superabsorbing Metasurfaces with Hybrid Ag-Au Nanostructures for Surface-Enhanced Raman Spec- troscopy Sensing of Drugs and Chemicals. Small Methods 2018, $1800045,1800045$.

349. Liszewska, M.; Bartosewicz, B.; Budner, B.; Nasiłowska, B.; Szala, M.; Weyher, J. L.; Dzięcielewski, I.; Mierczyk, Z.; Jankiewicz, B. J. Evaluation of Selected SERS Substrates for Trace Detection of Explosive Materials Using Portable Raman Systems. Vib. Spectrosc. 2019, 100, 79-85.

350. Hakonen, A.; Wu, K.; Stenbæk Schmidt, M.; Andersson, P. O.; Boisen, A.; Rindzevicius, T. Detecting Forensic Substances Using Commercially Available SERS Substrates and Handheld Raman Spectrometers. Talanta 2018, 189, 649-652.

351. Matousek, P.; Clark, I. P.; Draper, E. R. C.; Morris, M. D.; Goodship, a. E.; Everall, N.; Towrie, M.; Finney, W. F.; Parker, a. W. Subsurface Probing in Diffusely Scattering Media Using Spatially Offset Raman Spectroscopy. Appl. Spectrosc. 2005, 59, 393-400.

352. Conti, C.; Colombo, C.; Realini, M.; Zerbi, G.; Matousek, P. Subsurface Raman analysis of Thin Painted Layers. Appl. Spectrosc. 2014, 68, 686-691.

353. Cletus, B.; Olds, W.; Izake, E. L.; Sundarajoo, S.; Fredericks, P. M.; Jaatinen, E. Combined Time- and Space-Resolved Raman Spectrometer for the Non-Invasive Depth Profiling of Chemical Hazards. Anal. Bioanal. Chem. 2012, 403, 255-263.

354. Hopkins, R. J.; Pelfrey, S. H.; Shand, N. C. Short-Wave Infrared Excited Spatially Offset Raman Spectroscopy (SORS) for Through-Barrier Detection. Analyst 2012, 137, 4408-4410.

355. Ben-Jaber, S.; Peveler, W. J.; QuesadaCabrera, R.; Sol, C. W.; Papakonstantinou, I.; Parkin, I. P. Sensitive and Specific Detection of Explosives in Solution 
and Vapour by Surface-Enhanced Raman Spectroscopy on Silver Nanocubes. Nanoscale 2017, 9, 16459-16466.

356. Moram, S. S. B.; Byram, C.; Shibu, S. N.; Chilukamarri, B. M.; Soma, V. R. $\mathrm{Ag} / \mathrm{Au}$ Nanoparticle-Loaded Paper-Based Versatile Surface-Enhanced Raman Spectroscopy Substrates for Multiple Explosives Detection. ACS Omega 2018, 3, 8190-8201.

357. Wackerbarth, H.; Salb, C.; Gundrum, L.; Niederkrüger, M.; Christou, K.; Beushausen, V.; Viöl, W. Detection of Explosives Based on Surface-Enhanced Raman Spectroscopy. Appl. Opt. 2010, 49, 4362 .

358. Holthoff, E. L.; Stratis-Cullum, D. N.; Hankus, M. E. A Nanosensor for TNT Detection Based on Molecularly Imprinted Polymers and Surface Enhanced Raman Scattering. Sensors 2011, 11, 2700-2714.

359. Muehlethaler, C.; Leona, M.; Lombardi, J. R. Towards a Validation of Surface-Enhanced Raman Scattering (SERS) for Use in Forensic Science: Repeatability and Reproducibility Experiments. Forensic Sci. Int. 2016, 268, 1-13.

360. Xu, Y.; Ye, Z.; Li, C.; McCabe, H.; Kelly, J.; Bell, S. E. Pressing Solids Directly Into Sheets of Plasmonic Nanojunctions Enables Solvent-Free SurfaceEnhanced Raman Spectroscopy. Appl. Mater. Today 2018, 13, 352-358.

361. Zhong, F.; Wu, Z.; Guo, J.; Jia, D. Porous Silicon Photonic Crystals Coated with Ag Nanoparticles as Efficient Substrates for Detecting Trace Explosives Using SERS. Nanomaterials 2018, 8, 872.

362. Sree Satya Bharati, M.; Byram, C.; Soma, V. R. Femtosecond Laser Fabricated Ag@Au and $\mathrm{Cu} @ A u$ Alloy Nanoparticles for Surface Enhanced Raman Spectroscopy Based Trace Explosives Detection. Front. Phys. 2018, 6, 1-13.
363. Gao, F.; Liu, W. F.; Meng, Z. H.; Su, P. F.; Li, Z. X.; Wang, M. H. A Rapid and Sensitive Quantitative Analysis Method for TNT Using Raman Spectroscopy. Propellants, Explos. Pyrotech. 2019, 44, 1-9.

364. Naqvi, T. K.; Srivastava, A. K.; Kulkarni, M. M.; Siddiqui, A. M.; Dwivedi, P. K. Silver Nanoparticles Decorated Reduced Graphene Oxide (rGO) SERS Sensor for Multiple Analytes. Appl. Surf. Sci. 2019, 478, 887-895.

365. Satya Bharati, M. S.; Chandu, B.; Rao, S. V. Explosives Sensing Using Ag$\mathrm{Cu}$ Alloy Nanoparticles Synthesized by Femtosecond Laser Ablation and Irradiation. RSC Adv. 2019, 9, 1517-1525.

366. Liu, M.; Chen, W. Graphene NanosheetsSupported Ag Nanoparticles for Ultrasensitive Detection of TNT by SurfaceEnhanced Raman Spectroscopy. Biosens. Bioelectron. 2013, 46, 68-73.

367. Byram, C.; Moram, S. S. B.; Soma, V. R. SERS Based Detection of Multiple Analytes from Dye/Explosive Mixtures Using Picosecond Laser Fabricated Gold Nanoparticles and Nanostructures. Analyst 2019, 144, 2327-2336.

368. Chang, S.; Ko, H.; Singamaneni, S.; Gunawidjaja, R.; Tsukruk, V. V. Nanoporous Membranes with Mixed Nanoclusters for Raman-Based Label-Free Monitoring of Peroxide Compounds. Anal. Chem. 2009, 81, 5740-5748.

369. Sun, M.; Chen, P.; Zhao, A.; Zuo, F. Ultrasensitive Detection of Trinitrotoluene by $\mathrm{Fe} 3 \mathrm{O} 4 @ \mathrm{mTiO} 2 / \mathrm{P}-\mathrm{ATP}-\mathrm{TNT} / \mathrm{Au} @ \mathrm{Ag}$ SERS Sensor via Synergetic Effect. Anal. Methods 2019, 11, 1923-1929.

370. Chio, W. I.; Peveler, W. J.; Assaf, K. I.; Moorthy, S.; Nau, W. M.; Parkin, I. P.; Olivo, M.; Lee, T. C. Selective Detection of Nitroexplosives Using Molecular 
Recognition within Self-Assembled Plasmonic Nanojunctions. J. Phys. Chem. C 2019, 123, 15769-15776.

371. Grzebyk, T. MEMS Vacuum Pumps. J. Microelectromechanical Syst. 2017, 26, 705-717.

372. Blachowicz, T.; Ehrmann, A. 3D Printed MEMS Technology - Recent Developments and Applications. Micromachines 2020, 11, 434 .

373. Chen, J.; Chen, Z.; Boussaid, F.; Zhang, D.; Pan, X.; Zhao, H.; Bermak, A.; Tsui, C. Y.; Wang, X.; Fan, Z. UltraLow-Power Smart Electronic Nose System Based on Three-Dimensional Tin Oxide Nanotube Arrays. ACS Nano 2018, 12, 6079-6088.

374. Hufziger, K. T.; Bykov, S. V.; Asher, S. A. Ultraviolet Raman Wide-Field Hyperspectral Imaging Spectrometer for Standoff Trace Explosive Detection. Appl. Spectrosc. 2017, 71, 173-185.

375. Dubroca, T.; Brown, G.; Hummel, R. E. Detection of Explosives by Differential Hyperspectral Imaging. Opt. Eng. 2014, 53, 021112.

376. Kuzovnikova, L. V.; Maksimenko, E. V.; Vorozhtsov, A. B.; Pavlenko, A. A.; Didenko, A. V.; Titov, S. S. Detection and Identification of the Traces of Explosives with Using of Active Spectral Imaging. Propellants, Explos. Pyrotech. 2019, 44, 181-187.

377. Wood, D. A.; Kelley, D.; Goyal, A.; Kotidis, P. Mid-Infrared Reflection Signatures for Trace Chemicals on Surfaces. 2018, 1062915, 40.

378. Nelson, M. P.; Shi, L.; Zbur, L.; Priore, R. J.; Treado, P. J. Real-Time Short-Wave Infrared Hyperspectral Conformal Imaging Sensor for the Detection of Threat Materials. Chem. Biol. Radiol. Nucl. Explos. Sens. XVII 2016, 9824, 982416.
379. Huehnerhoff, J.; Lozo, J. A.; Deutsch, E. R.; Hajian, A. R. High Resolution Handheld Raman and Reflectance Hyperspectral Imaging for Remote Sensing and Threat Detection. Next-Generation Spectrosc. Technol. XI 2018, 1065\%, 21.

380. Gooding, E. A.; Deutsch, E. R.; Huehnerhoff, J.; Hajian, A. R. The HighThroughput Virtual Slit Enables Compact, Inexpensive Raman Spectral Imagers. Biomed. Vib. Spectrosc. 2018 Adv. Res. Ind. 2018, 10490, 27.

381. Zachhuber, B.; Östmark, H.; Carlsson, T. Spatially Offset Hyperspectral Stand-Off Raman Imaging for Explosive Detection Inside Containers. Chem. Biol. Radiol. Nucl. Explos. Sens. $X V$ 2014, 9073, 90730J.

382. Zhang, M.; Zhang, X.; Shi, Y. e.; Liu, Z.; Zhan, J. Surface Enhanced Raman Spectroscopy Hyphenated with Surface Microextraction for In-Situ Detection of Polycyclic Aromatic Hydrocarbons on Food Contact Materials. Talanta 2016, 158, 322-329.

383. Meher, A. K.; Chen, Y. C. Combination of Raman Spectroscopy and Mass Spectrometry for Online Chemical Analysis. Anal. Chem. 2016, 88, 9151-9157.

384. Tinnemans, S. J.; Kox, M. H.; Nijhuis, T. A.; Visser, T.; Weckhuysen, B. M. Real Time Quantitative Raman Spectroscopy of Supported Metal Oxide Catalysts without the Need of an Internal Standard. Phys. Chem. Chem. Phys. 2005, 7, 211-216.

385. Khanal, N.; Masellis, C.; Kamrath, M. Z.; Clemmer, D. E.; Rizzo, T. R. Cryogenic IR Spectroscopy Combined with Ion Mobility Spectrometry for the Analysis of Human Milk Oligosaccharides. Analyst 2018, 143, 1846-1852.

386. Diehl, K. L.; Anslyn, E. V. Array Sensing Using Optical Methods for Detection of 
Chemical and Biological Hazards. Chem. Soc. Rev. 2013, 42, 8596-8611.

387. Zhao, P.; Wu, Y.; Feng, C.; Wang, L.; Ding, Y.; Hu, A. Conjugated Polymer Nanoparticles Based Fluorescent Electronic Nose for the Identification of Volatile Compounds. Anal. Chem. 2018, 90, 4815-4822.

388. Lussier, F.; Thibault, V.; Charron, B.; Wallace, G. Q.; Masson, J. F. Deep Learning and Artificial Intelligence Methods for Raman and Surface-Enhanced Raman Scattering. TrAC - Trends Anal. Chem. 2020, 124. 


\section{Graphical TOC Entry}

Some journals require a graphical entry for the Table of Contents. This should be laid out "print ready" so that the sizing of the text is correct.

Inside the tocentry environment, the font used is Helvetica 8 pt, as required by Journal of the American Chemical Society.

The surrounding frame is $9 \mathrm{~cm}$ by $3.5 \mathrm{~cm}$, which is the maximum permitted for Journal of the American Chemical Society graphical table of content entries. The box will not resize if the content is too big: instead it will overflow the edge of the box.

This box and the associated title will always be printed on a separate page at the end of the document. 